\title{
EXPLORANDO ALTERNATIVAS PARA CONSTRUÇÃO DE MODELOS NEURAIS DE INTERAÇÃO ESPACIAL
}

Dissertação apresentada à Escola de Engenharia de São Carlos da Universidade de São Paulo, como parte dos requisitos para a obtenção do título de Mestre em Engenharia Civil - Área de Concentração: Transportes.

Orientador: Prof. Assoc. Antônio Nélson Rodrigues da Silva

\section{São Carlos}


Ficha catalográfica preparada pela Seção de Tratamento da Informação do Serviço de Biblioteca - EESC/USP

Akamine, Alexandra

Explorando alternativas para construção de modelos neurais de interação espacial / Alexandra Akamine. -São Carlos, 2005 .

Dissertação (Mestrado) -- Escola de Engenharia de São Carlos-Universidade de São Paulo, 2005.

Área: Transportes.

Orientador: Prof. Assoc. Antônio Nélson Rodrigues da Silva.

1. Planejamento urbano. 2. Modelos de interação espacial. 3. Redes neurais artificiais. 4. Algoritmos genéticos. 5. Bootstrap. I. Título. 
Aos meus pais, Nélson e Sílvia, por tudo que sempre me proporcionaram. 
Ao Prof. Dr. Antônio Nélson Rodrigues da Silva, meu orientador, pela competência em seu trabalho e pela confiança em mim depositada.

À minha irmã Tatiana, pela amizade, paciência e por entender tão bem dos computadores.

À minha cúmplice Vanessa, pela ajuda e companhia de sempre, e a todos os amigos do Departamento de Transportes.

Ao Francisco, por existir na minha vida.

Aos professores e funcionários do Departamento de Transportes.

À FAPESP pelo apoio financeiro concedido para a realização deste trabalho.

À Secretaria Municipal de Educação de São Carlos, pelos dados fornecidos para esta pesquisa.

A todos aqueles que, direta ou indiretamente, colaboraram para este trabalho. 
AKAMINE, A. (2005). Explorando Alternativas para Construção de Modelos Neurais de Interação Espacial. Dissertação (Mestrado) - Escola de Engenharia de São Carlos, Universidade de São Paulo, São Carlos, 2005.

$\mathrm{O}$ rápido crescimento das cidades brasileiras, não acompanhado de um planejamento prévio de sua expansão (incluindo o uso e a ocupação do solo), vem acarretando transtornos à comunidade no que se refere aos deslocamentos, visto que estes se tornam cada vez maiores. Devido a isso, torna-se necessário um conhecimento das demarcações das áreas do município, dos tipos de serviços atualmente prestados à comunidade em cada área e dos usuários destes serviços, não só em termos quantitativos, mas principalmente no que diz respeito à sua distribuição no espaço. Mais ainda, o conhecimento da evolução da demanda no tempo e a sua localização espacial permitem a avaliação de inúmeros cenários de gestão da demanda e da oferta, possibilitando, por exemplo, prever em qual região haverá um crescimento maior da primeira. Outros aspectos que devem ser avaliados são a origem, o destino e o volume de deslocamentos que ocorrem em um determinado conjunto de zonas, $o$ que pode ser estimado através de modelos de interação espacial. Neste sentido, foram realizados estudos com o objetivo de avaliar o desempenho de modelos de interação espacial construídos com Redes Neurais Artificiais (RNAs). Observou-se nestes estudos, uma carência de técnicas para seleção da rede neural a ser utilizada na modelagem, ou seja, a rede com melhor desempenho e poder de predição. Tal como a maioria dos trabalhos que utilizam Redes Neurais Artificiais para este tipo de modelagem, os parâmetros de rede são escolhidos aleatoriamente e, ainda que se consiga resultados satisfatórios variando-se tais parâmetros, nem sempre a rede utilizada representa a solução ótima. O objetivo desta pesquisa é avaliar o uso de diferentes alternativas, tais como a técnica de otimização de Algoritmos Genéticos (AGs) na seleção de Redes Neurais Artificiais e o método de estimação por bootstrap na divisão dos dados, para a construção de modelos de interação espacial, e avaliar a distribuição espacial dos resíduos (erros) das previsões. O estudo foi desenvolvido em um Sistema de Informações Geográficas (SIG) e os dados empregados para este fim refletem a evolução espacial da demanda por serviços municipais de educação numa cidade média brasileira (São Carlos, SP) ao longo de dois anos. Os resultados deste trabalho mostraram que, embora a utilização dos modelos neurais seja apropriada para a estimativa de fluxos, a partir do método gravitacional é possível mensurar de forma precisa e aceitável o crescimento e a distribuição espacial da demanda futura por serviços de educação, permitindo-se identificar quais devem ser as melhores ações a serem tomadas pelo poder público no presente com o intuito de reduzir as distâncias de deslocamento dos alunos no futuro. Isto é particularmente importante para ações de planejamento, em virtude da simplicidade do modelo e de sua fácil e direta implementação.

Palavras-chave: Planejamento de Transportes; Modelos de Interação Espacial; Redes Neurais Artificiais; Algoritmos Genéticos; Bootstrap; SIG. 
AKAMINE, A. (2005). Exploring Alternatives for the Construction of Neural Spatial Interaction Models. Dissertation (Master) - School of Engineering of São Carlos, University of São Paulo, São Carlos, 2005.

The rapid growth of Brazilian cities, without a previous planning of their expansion (including land use and occupation), causes many inconveniences for the population related to their transportation, as they must cover longer distances. This asks for an understanding of the city areas limits, the services currently offered to the community in each area, and the users of these services, not only in quantitative terms, but also in terms of spatial distribution. Moreover, the knowledge of the demand evolution in time and its spatial location allows the evaluation of many planning scenarios for managing the demand and the supply, and it is possible, for example, to foresee the regions where the demand is going to be concentrated. Other aspects that must be evaluated are the origin, destination and number of trips that occur in a determined set of tracts, which can be predicted by the spatial interaction models. Therefore, some studies were made with the objective of evaluating the performance of Spatial Interaction Models based on Artificial Neural Networks (ANNs). It was observed in these studies, some difficulty in selecting the neural network configuration that best models the problem. As in the majority of research that uses Artificial Neural Networks for the construction of that kind of model, the network parameters are randomly chosen and, even if one can obtain satisfactory results by varying these parameters, the neural net used may not be producing the optimal solution. The objective of this work is to evaluate the use of different alternatives, such as the Genetic Algorithms (GAs) optimization technique and the bootstrapping estimation method, as supporting tools to select Artificial Neural Networks configurations applied to Spatial Interaction Models, and to evaluate the spatial distribution of the residual (errors) prediction results. The research was developed in a Geographic Information System (GIS) and the data used for this application reflects the changes in the spatial distribution of the demand for education services in a Brazilian medium-sized city (São Carlos, SP) throughout two years. The results obtained showed that although neural models are suitable for estimating transportation flows, gravity models are able to produce very good and precise estimates of the future spatial distribution of the demand for educational facilities. This is very important for the planning process aiming at the reduction of displacement costs of students in the future, given the simplicity of the gravity model structure and its straightforward implementation.

Keywords: Transportation Planning; Spatial Interaction Models; Artificial Neural Networks; Genetic Algorithms; Bootstrap; GIS. 


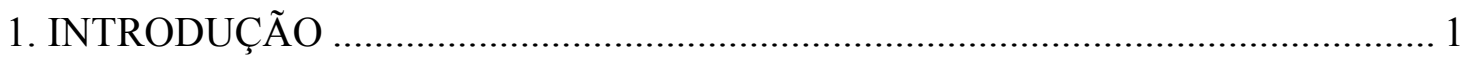

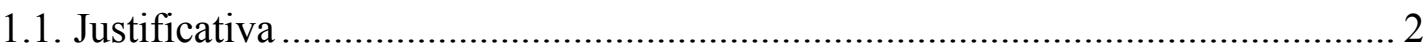

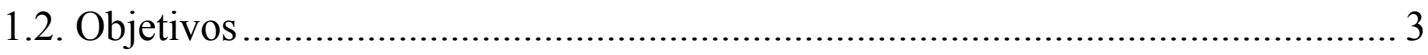

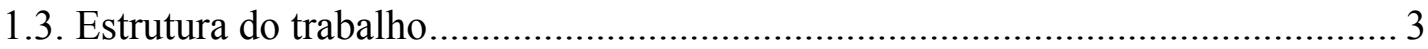

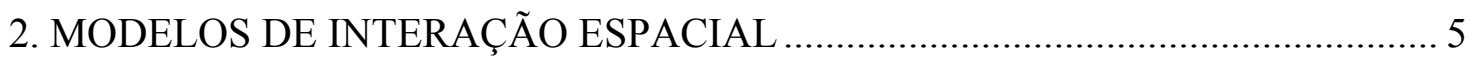

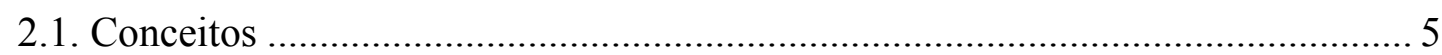

2.1.1. Modelos gravitacionais ................................................................................ 6

2.1.2. Avanços em Tecnologias de Computação ………………………………….... 7

2.1.3. Modelos Neurais de Interação Espacial ...................................................... 8

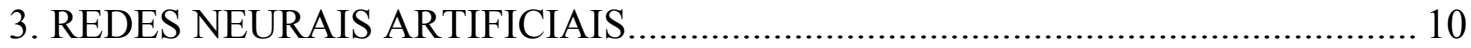

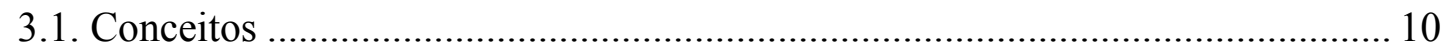

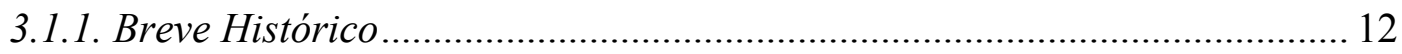

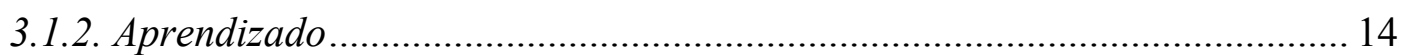

3.1.3. O Neurônio Artificial .............................................................................. 15

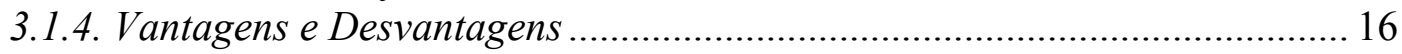

3.2. Desenvolvimento de Aplicações....................................................................... 18

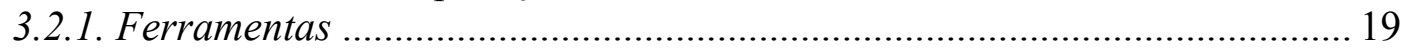

3.2.2. Medidas de Desempenho ......................................................................... 19

3.3. Redes Neurais Artificiais na Engenharia de Transportes .................................... 21

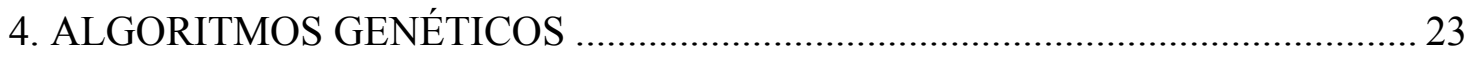

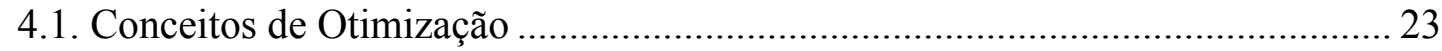

4.2. Características Gerais dos Algoritmos Genéticos................................................ 25

4.3. Desenvolvimento de Aplicações........................................................................ 28

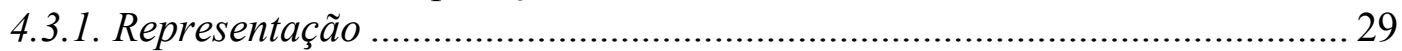

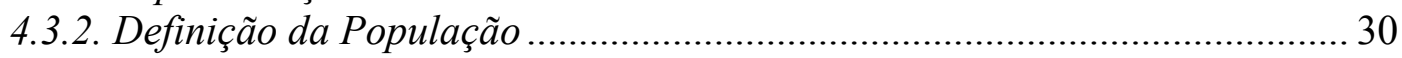

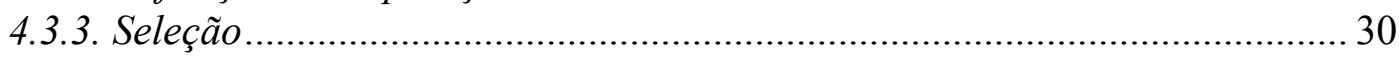

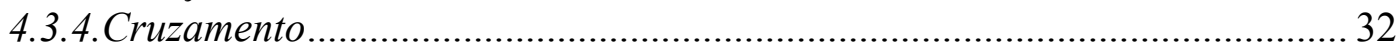

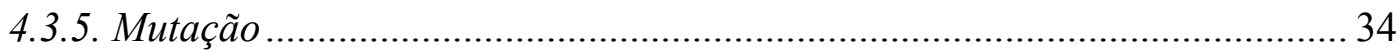

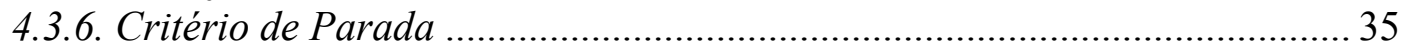

4.4. Algoritmos Genéticos na Engenharia de Transportes........................................... 35 


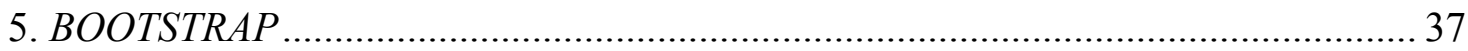

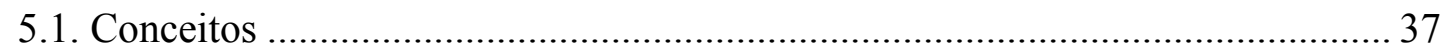

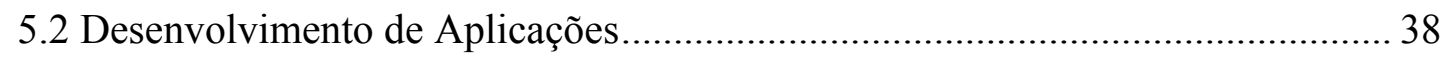

5.2.1. Descrição do Procedimento Bootstrap ....................................................... 38

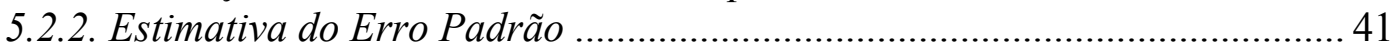

5.2.3. Estimativa de Intervalos de Confiança....................................................... 42

5.3. Aplicação do Bootstrap a Modelos Neurais de Interação Espacial .................... 43

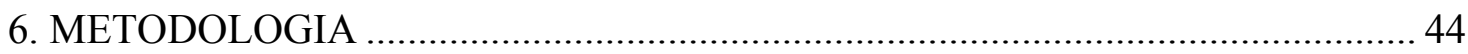

6.1. Análise dos Dados do Sistema de Educação ........................................................ 44

6.2. Construção dos Modelos de Interação Espacial ................................................... 45

6.3. Seleção dos Modelos Neurais de Interação Espacial através de Algoritmos

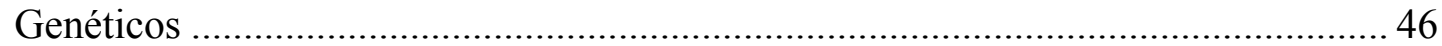

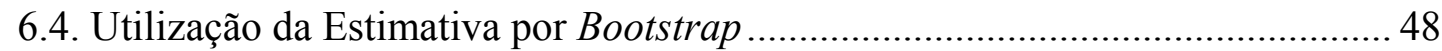

6.5. Análise Espacial dos Resíduos (erros) das Previsões ......................................... 48

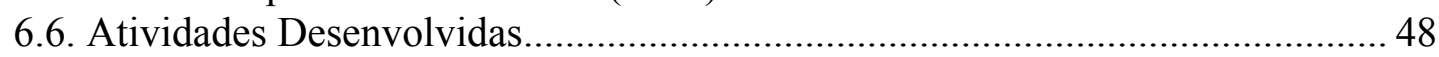

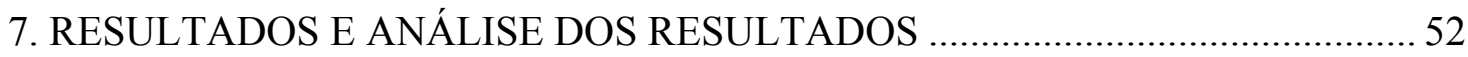

7.1. Modelos Neurais de Interação Espacial............................................................... 52

7.2. Seleção dos Modelos Neurais de Interação Espacial através de Algoritmos

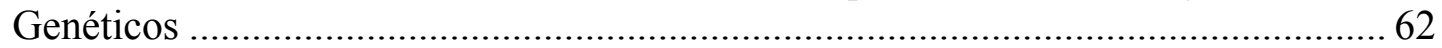

7.3. A Lógica Interna nos Modelos Neurais de Interação Espacial .......................... 70

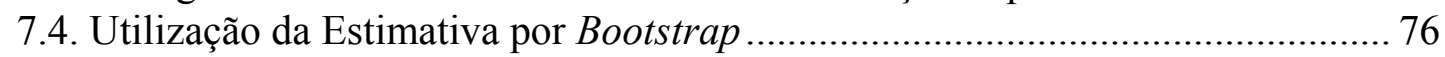

7.5. Análise Espacial dos Resíduos (erros) das Previsões ....................................... 78

8. CONCLUSÕES E SUGESTÕES PARA TRABALHOS FUTUROS ........................ 84 


\section{LISTA DE FIGURAS}

Figura 3.1 - Componentes do neurônio (GUYTON, 1977)...................................11

Figura 3.2 - Camadas de um Perceptron (SMITH, 1996) ........................................13

Figura 3.3 - Esquema de um neurônio artificial (BOCANEGRA, 2002)................15

Figura 3.4 - Representação da função sigmóide (BOCANEGRA, 2002) .................16

Figura 4.1 - Mínimo local e global (LACERDA; CARVALHO, 1999) ....................25

Figura 4.2 - Esquema geral de um AG (TORRES, 2003) .....................................29

Figura 4.3 - Cromossomo com representação binária ...............................................30

Figura 4.4 - Representação das probabilidades de seleção de cada indivíduo

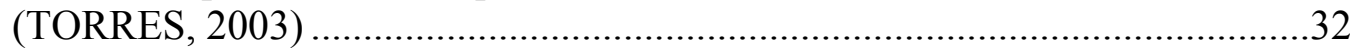

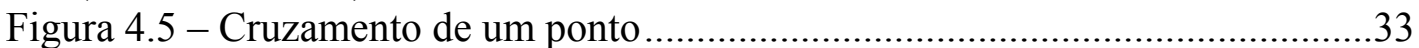

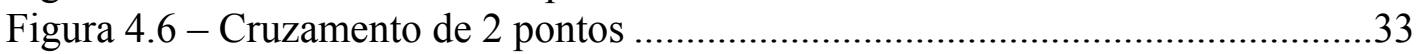

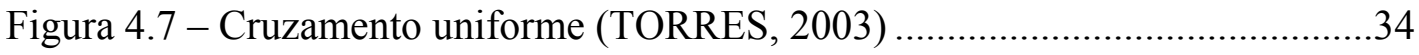

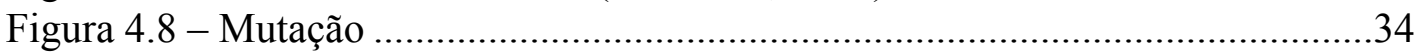

Figura 5.1 - Esquema do processo bootstrap (EFRON; TIBSHIRANI, 1993) ........40

Figura 6.1 - Representação binária dos parâmetros de uma rede neural ...................47

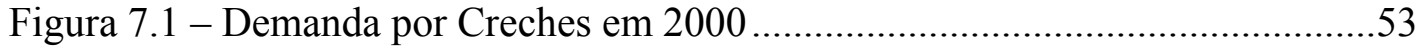

Figura 7.2 - Demanda por Creches em 2001 .........................................................53

Figura 7.3 - Demanda por EMEIs em 2000...........................................................54

Figura 7.4 - Demanda por EMEIs em 2001 ........................................................54

Figura 7.5 - Distribuição da demanda atendida nas Creches municipais em 2000,

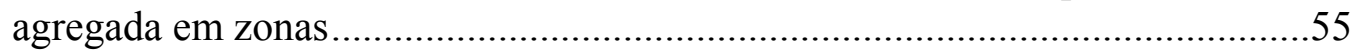

Figura 7.6 - Distribuição da demanda atendida nas Creches municipais em 2001,

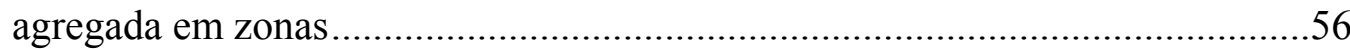

Figura 7.7 - Distribuição da demanda atendida nas EMEIs em 2000, agregada em zonas

Figura 7.8 - Distribuição da demanda atendida nas EMEIs em 2001, agregada em

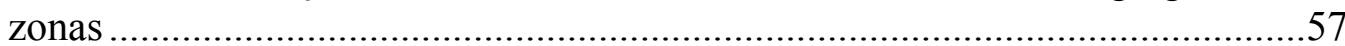

Figura 7.9 - Pontos de demanda (centróides) e oferta (Creches municipais) ...........57

Figura 7.10 - Pontos de demanda (centróides) e oferta (EMEIs) ..............................58

Figura 7.11 - Desempenho das RNAs testadas com dados das Creches..................60

Figura 7.12 - Desempenho das RNAs testadas com dados das EMEIs....................61

Figura 7.13 - Fluxos de viagens para Creches com distância de 0,5 quilômetro ......72

Figura 7.14 - Fluxos de viagens para Creches com distância de 1,0 quilômetro ......72

Figura 7.15 - Fluxos de viagens para Creches com distância de 1,5 quilômetro ......72

Figura 7.16 - Fluxos de viagens para Creches com distância de 2,0 quilômetros....72

Figura 7.17 - Fluxos de viagens para Creches com distância de 2,5 quilômetros....72

Figura 7.18 - Fluxos de viagens para Creches com distância de 3,0 quilômetros....72

Figura 7.19 - Fluxos de viagens para Creches com distância de 3,5 quilômetros....72

Figura 7.20 - Fluxos de viagens para Creches distância de 4,0 quilômetros ............72

Figura 7.21 - Fluxos de viagens para Creches com distância de 4,5 quilômetros....72

Figura 7.22 - Fluxos de viagens para Creches com distância de 5,0 quilômetros....72

Figura 7.23 - Fluxos de viagens para EMEIs com distância de 0,5 quilômetro........73 
Figura 7.24 - Fluxos de viagens para EMEIs com distância de 1,0 quilômetro.......73

Figura 7.25 - Fluxos de viagens para EMEIs com distância de 1,5 quilômetro........73

Figura 7.26 - Fluxos de viagens para EMEIs com distância de 2,0 quilômetros .....73

Figura 7.27 - Fluxos de viagens para EMEIs com distância de 2,5 quilômetros .....73

Figura 7.28 - Fluxos de viagens para EMEIs com distância de 3,0 quilômetros .....73

Figura 7.29 - Fluxos de viagens para EMEIs com distância de 3,5 quilômetros .....73

Figura 7.30 - Fluxos de viagens para EMEIs com distância de 4,0 quilômetros .....73

Figura 7.31 - Fluxos de viagens para EMEIs com distância de 4,5 quilômetros .....73

Figura 7.32 - Fluxos de viagens para EMEIs com distância de 5,0 quilômetros .....73

Figura 7.33 - Fluxos de viagens para Creches com distância de 0,5 quilômetro ......74

Figura 7.34 - Fluxos de viagens para Creches com distância de 2,5 quilômetros....74

Figura 7.35 - Fluxos de viagens para Creches com distância de 5,0 quilômetros ....74

Figura 7.36 - Fluxos de viagens para EMEIs com distância de 0,5 quilômetro........75

Figura 7.37 - Fluxos de viagens para EMEIs com distância de 2,5 quilômetros .....75

Figura 7.38 - Fluxos de viagens para EMEIs com distância de 5,0 quilômetros .....75

Figura 7.39 - Fluxos subestimados das Creches pelo modelo neural......................79

Figura 7.40 - Fluxos subestimados das Creches pelo Método Gravitacional ..........79

Figura 7.41 - Fluxos superestimados das Creches pelo modelo neural....................80

Figura 7.42 - Fluxos superestimados das Creches pelo Método Gravitacional .......80

Figura 7.43 - Fluxos subestimados das EMEIs pelo modelo neural .......................81

Figura 7.44 - Fluxos subestimados das EMEIs pelo Método Gravitacional ............81

Figura 7.45 - Fluxos superestimados das EMEIs pelo modelo neural ....................82

Figura 7.46 - Fluxos superestimados das EMEIs pelo Método Gravitacional .........82 


\section{LISTA DE TABELAS}

Tabela 5.1 - Exemplo de aplicação do bootstrap para estimativa do erro padrão ...41

Tabela 7.1 - Resumo quantitativo dos dados utilizados nos modelos de interação espacial

Tabela 7.2 - Exemplo dos dados utilizados nos modelos neurais de interação espacial

Tabela 7.3 - População inicial de cromossomos para seleção de modelos neurais de interação espacial

Tabela 7.4 - EN (\%) dos modelos neurais de interação espacial selecionados através de AGs, construídos com dados de Creches - continua.

Tabela 7.5 - EN (\%) dos modelos neurais de interação espacial selecionados através de AGs, construídos com dados de EMEIs - continua ....................................68

Tabela 7.6 - EN (\%) obtidos para a estimativa bootstrap com dados de Creches municipais.

Tabela 7.7 - EN (\%) obtidos para a estimativa bootstrap com dados das EMEIs ...77 


\section{LISTA DE ABREVIATURAS E SIGLAS}

AG Algoritmo Genético

ANN Artificial Neural Network

EESC Escola de Engenharia de São Carlos

EMEI Escola Municipal de Educação Infantil

EN Erro Normalizado

ERM Erro Relativo Médio

GA Genetic Algorithm

GIS Geographic Information System

IBGE Instituto Brasileiro de Geografia e Estatística

L Taxa de Aprendizagem (Learning Rate)

M Momentum

MLP Multilayer Perceptron

MSE Erro Quadrático Médio (Mean Squared Error)

$\mathrm{N} \quad$ Número de nós na camada intermediária

$\mathrm{O} / \mathrm{D} \quad$ Origem/ Destino

$\mathrm{p}_{\mathrm{c}} \quad$ Probabilidade de cruzamento

$\mathrm{p}_{\mathrm{i}} \quad$ Probabilidade de seleção

$\mathrm{p}_{\mathrm{m}} \quad$ Probabilidade de mutação

RMSE Raiz do Erro Quadrático Médio (Root Mean Squared Error)

RNA Rede Neural Artificial

SA Simulated Annealing

SAAE Serviço Autônomo de Água e Esgoto

SIG Sistema de Informações Geográficas

SIG-T Sistema de Informações Geográficas para Transportes

SP São Paulo

USP Universidade de São Paulo

UTM Projeção Universal Transversal de Mercator 


\section{INTRODUÇÃO}

Uma área de importância fundamental na Engenharia de Transportes é o campo dos Modelos de Interação Espacial (BLACK, 1995). Nesta área, procura-se conhecer os fatores que afetam os fluxos de viagens, bem como desenvolver métodos que permitam aos planejadores e analistas regionais prever os deslocamentos futuros. Além desta aplicação direta na fase de Distribuição de Viagens, os Modelos de Interação Espacial são importantes para a avaliação de impactos decorrentes de alterações na oferta de diversas infra-estruturas urbanas, tais como a ampliação dos equipamentos de educação e saúde. Existem diferentes abordagens para esta modelagem, tais como os modelos de oportunidades intervenientes e os modelos gravitacionais, sendo os últimos amplamente empregados em planejamento de transportes. O uso de técnicas emergentes, como é o caso das Redes Neurais Artificiais, para este tipo de modelagem também passou a ser testado a partir da última década do século XX, como se pode verificar nos trabalhos de Openshaw (1993), Black (1995), Fischer, Reismann e Hlavackova-Schindler (1999), Mozolin, Thill e Usery (2000) e Fischer e Reismann (2002a, 2002b).

Segundo Fischer e Reismann (2002b) os modelos neurais, apesar de exigirem um tempo de processamento elevado, são superiores aos modelos de gravidade clássicos em termos de generalização de desempenho. Esta afirmação constituiu-se na hipótese inicial do estudo de Akamine e Silva (2004), com o objetivo de avaliar o desempenho de Modelos de Interação Espacial construídos com Redes Neurais Artificiais. Tal estudo, baseado em uma aplicação prática, possibilitou o conhecimento da evolução da demanda por serviços municipais de educação no tempo e a sua localização espacial, importante para a avaliação de inúmeros cenários de gestão da 
demanda e da oferta, na busca, por exemplo, da redução da distância percorrida pelos alunos até as escolas existentes, através da realocação da demanda à oferta, ou do melhor local para a abertura de novas unidades de ensino.

O que se observou no desenvolvimento do trabalho de Akamine e Silva (2004), no entanto, foi a carência de técnicas para seleção da rede neural a ser utilizada na modelagem, ou seja, a rede com melhor desempenho e poder de predição (também observado por Fischer e Leung, 1998). Tal como na maioria dos trabalhos constantes da pesquisa bibliográfica que utilizam Redes Neurais Artificiais para este tipo de modelagem (como os de Brega, 1996; Furtado, 1998; Brondino, 1999; Raia Jr., 2000; Costa, 2001 e Bocanegra, 2002, só para citar alguns daqueles desenvolvidos no próprio Departamento de Transportes da EESC-USP), os parâmetros de rede são escolhidos aleatoriamente e, ainda que se consiga resultados satisfatórios variando-se tais parâmetros, nem sempre a rede utilizada representa a solução ótima. Para superar este problema, Fischer e Reismann (2002b) sugerem o uso de procedimentos de busca global como Simulated Annealing (SA), Alopex e Algoritmos Genéticos. Outra possibilidade para melhorar o desempenho dos modelos é o uso do método de estimação por bootstrap, na fase de divisão dos dados para treinamento das redes.

Deste conjunto de opções, esta pesquisa pretende explorar, como alternativa para melhoria do desempenho dos modelos neurais de interação espacial, os Algoritmos Genéticos e o método de estimação por bootstrap.

\subsection{Justificativa}

Considerando que um dos mais sérios problemas enfrentados pelas prefeituras é a escassez de recursos para os setores de educação e saúde, faz-se necessária a melhor utilização possível dos recursos disponíveis, o que implica, entre outras coisas, numa distribuição racional dos postos de atendimento (escolas e postos de saúde) visando o atendimento do maior número de munícipes possível. Com a possibilidade de se prever em qual região haverá um crescimento maior da demanda, é possível planejar a localização dos equipamentos coletivos de uma cidade, antevendo o futuro nível de atendimento de uma nova escola, por exemplo. Dessa maneira, pode-se 
direcionar a implantação da infra-estrutura pontual, de forma a melhorar continuamente as condições de acessibilidade intra-urbana, principalmente aos serviços essenciais.

Os modelos neurais de interação espacial, objetos de estudo desta pesquisa, além de possibilitarem tal previsão de crescimento da demanda, representam um tema relativamente pouco estudado e difundido no país. Além disso, o emprego da técnica de otimização de Algoritmos Genéticos e o método de estimação por bootstrapping, para melhorar o desempenho de predição destes modelos, e a avaliação da distribuição espacial dos resíduos, constituem importantes contribuições para a temática da pesquisa.

\subsection{Objetivos}

Os objetivos desta pesquisa são: avaliar o uso de diferentes alternativas, tais como a técnica de otimização de Algoritmos Genéticos na seleção de Redes Neurais Artificiais e o método de estimação por bootstrapping na fase de divisão dos dados, para a construção de Modelos de Interação Espacial, e avaliar a distribuição espacial dos resíduos (erros) das previsões.

\subsection{Estrutura do trabalho}

O presente trabalho apresenta, primeiramente, os resultados de uma revisão bibliográfica referente a assuntos pertinentes ao projeto. Assim, o capítulo 2 trata dos Modelos de Interação Espacial, abordando seus conceitos básicos, modelos tradicionais e modelos neurais de interação espacial.

Os capítulos 3 e 4 tratam respectivamente, das Redes Neurais Artificiais e dos Algoritmos Genéticos. Em ambos os casos são apresentados os conceitos fundamentais e aplicações na Engenharia de Transportes. O capítulo 5 apresenta o método Bootstrap de análise estatística e suas aplicações.

No capítulo 6 é descrita a metodologia adotada nesta pesquisa, em que são apresentadas as etapas de construção e avaliação dos modelos neurais. Os resultados e análises obtidos são apresentados no capítulo 7 . O capítulo 8 contém as conclusões do 
presente trabalho, bem como sugestões para pesquisas futuras, seguindo-se a bibliografia consultada. 


\section{MODELOS DE INTERAÇÃO ESPACIAL}

A grande concentração da população em áreas urbanas - que passou de $36 \%$ da população que vivia nas cidades em 1950 para 81\% no ano 2000 (IBGE, 2000) - e a quantidade considerável de recursos indispensáveis para a implantação e manutenção de serviços de infra-estrutura básica, como é o caso de escolas, hospitais, postos de saúde, correios e serviços emergenciais, são algumas das razões que evidenciam a necessidade de se investir em planejamento para uma distribuição adequada destes serviços.

\subsection{Conceitos}

Os modelos de interação espacial descrevem o fluxo de pessoas, cargas ou informações de uma origem $i$ para um destino $j$. Em geral, a distribuição deste fluxo dá-se com base na potencialidade de cada origem gerar viagens, na atratividade dos diversos destinos e em uma medida de impedância aos deslocamentos entre cada par $(i$, j) de origem-destino. A impedância é caracterizada como sendo uma medida que avalia os efeitos contrários à realização ou ao prolongamento das viagens.

Uma expressão geral para um modelo de interação espacial é dada por:

$T_{i j}=f$ (variáveis socioeconômicas em $i$ e $j$; separação espacial entre $i$ e $j$ )

onde a variável dependente $T_{i j}$ representa o fluxo entre as zonas $i$ e $j$ no intervalo de tempo considerado (ALMEIDA, 1999). 
Os modelos gravitacionais são os mais utilizados na prática para a estimativa de fluxos futuros. Através deles o planejador pode analisar a situação atual do sistema em estudo e determinar procedimentos sistemáticos para a previsão do número de viagens, elaborar planos alternativos de uso do solo e sugerir estratégias viáveis para o sistema de transportes.

\subsubsection{Modelos gravitacionais}

Os modelos gravitacionais de previsão de fluxos de viagens partem da suposição de que os padrões de distribuição de viagens seguem os princípios da Lei da Gravidade formulada por Newton em 1686, "A força da gravidade que age entre dois corpos é diretamente proporcional à massa dos dois corpos e inversamente proporcional ao quadrado da distância entre eles". No caso dos modelos de interação espacial, o fluxo de viagens entre duas zonas $i$ e $j$ que se pretende determinar corresponde à força da gravidade e a massa dos dois corpos é substituída, analogamente, por uma grandeza que representa o tamanho das zonas $i$ e $j$.

A formulação dos conceitos iniciais relativos a estes modelos é atribuída a Carey, que em 1858 utilizou-os para quantificar fluxos migratórios e analisar padrões de interação originados pelo comércio varejista entre as cidades (ALMEIDA, 1999). No entanto, foi durante a primeira metade do século XX que o modelo gravitacional se desenvolveu, até adquirir a forma que conhecemos hoje. Assim, algumas alterações foram introduzidas ao modelo, dentre as quais: a resistência ao deslocamento pode ser expressa por uma função do tempo ou do custo de transporte, ou de uma combinação do tempo e do custo, e não somente da distância; a potência utilizada na caracterização da impedância corresponde a um valor determinado através de calibração, e não mais ao quadrado; a grandeza que representa a massa pode ser a população da zona de origem $i$ ou grupo dessa população; a atração do destino $j$ pode ser caracterizada pelo número de empregos, número de vagas em escolas, etc, dependendo do sistema em estudo e, ao contrário do modelo de Newton, que possui uma única constante (de gravitação universal), no modelo de demanda costuma-se adotar uma constante de proporcionalidade para cada origem $i$ (KAWAMOTO, 1994). 
Os modelos gravitacionais são algumas das aproximações mais bem sucedidas utilizadas na estimativa de fluxos futuros e a precisão destes modelos geralmente encontra-se dentro de limites aceitáveis. No entanto, tais métodos exigem o conhecimento do número de viagens produzidas e atraídas em cada zona de tráfego e, em geral, dos números de viagens que ocorrem entre as zonas (matriz semente). Os fluxos estimados são calibrados a partir dos dados originais e é desejável que se tenha a matriz origem-destino completa, o que, em certos casos, inviabiliza a utilização dos modelos gravitacionais.

Além disso, segundo Black, Cheung e Suthanaya (2003), os modelos gravitacionais convencionais de previsão de fluxos de transporte, desenvolvidos na década de 1960, não foram projetados para lidar com problemas contemporâneos. Podese dizer que a principal abordagem, nos anos 1950 e 60, dos exercícios de planejamento de uso do solo e transportes baseados em computador era formular um plano de uso do solo futuro e projetar sistemas de transporte que suprissem a demanda planejada.

\subsubsection{Avanços em Tecnologias de Computação}

A reunião de grandes conjuntos de dados representando sistemas urbanos, incluindo complexas interações entre componentes como o uso do solo, transporte, tráfego e meio ambiente, foi facilitada através do uso de computadores. A análise de sistemas - processo para organizar as informações e auxiliar na tomada de decisões - estabeleceu-se a partir das décadas de 1950 e 60. Na literatura de planejamento, em geral, e na de planejamento e uso do solo e transporte, em particular, muitas das primeiras tarefas estavam focadas na observação e descrição do comportamento de sistemas complexos, e na construção de modelos para explicar tais observações (BLACK; CHEUNG; SUTHANAYA, 2003).

Segundo Black, Cheung e Suthanaya (2003), na década de 1970, devido à codificação manual de dados em cartões perfurados e ao poder computacional limitado, o processamento de grandes trabalhos era demorado. E, enquanto a teoria de modelação urbana, incluindo as etapas de validação e escolha do melhor modelo, estava bem avançada em termos de especificação de estruturas de modelos alternativos, a validação 
de modelos na prática de planejamento de transportes era executada apenas superficialmente.

De acordo com Fischer e Reismann (2002a), avanços na velocidade do processo computacional, a disponibilidade de aplicativos e ferramentas de computador e de dados de SIG em formato digital, permitiram uma mudança na metodologia de análise espacial - denominada análise espacial inteligente - e, de acordo com Black, Cheung e Suthanaya (2003), uma análise rigorosa da qualidade dos modelos de transporte e de suas predições. Além disso, a habilidade de manipular e desagregar grandes bases de dados nos computadores pessoais viabilizou estudos para avaliação da estrutura dos modelos, o que permitiu o desenvolvimento de estruturas mais apuradas de previsão.

Muito do recente interesse em análise espacial inteligente é devido à crescente percepção das limitações das ferramentas convencionais de análise espacial na exploração de padrões em dados de SIG, e da possibilidade de superação destas limitações pelo uso de tecnologias de inteligência computacional, tais como a computação evolutiva e modelagens por redes neurais (FISCHER; REISMANN, 2002a).

Como a proposta básica de uma rede neural é a identificação de padrões que relacionam dados de entrada a dados de saída e a posterior simulação desses padrões para novos dados de entrada, o uso de Redes Neurais Artificiais (RNAs) na estimativa de fluxos parece apropriado. Além disso, modelos neurais impõem menos restrições na forma de relacionamento funcional entre entradas e saídas do que as técnicas convencionais (MOZOLIN; THILL; USERY, 2000).

\subsubsection{Modelos Neurais de Interação Espacial}

Modelos Neurais de Interação Espacial são assim denominados por serem baseados em modelos computacionais inspirados na neurociência (FISCHER; REISMANN, 2002a).

Vários estudos a respeito do uso de RNAs na construção de modelos de interação espacial foram realizados na última década. Contudo, uma discussão avançada dos conceitos gerais envolvidos na aplicação desses modelos ainda faz-se necessária. 
Dentre os elementos que deveriam ser de interesse nas aplicações estão questões relacionadas às estimativas e ao desempenho (FISCHER; REISMANN, 2002b).

Uma comparação com os modelos de gravidade clássicos ilustrou a superioridade dos modelos neurais testados por Fischer e Reismann (2002b) em termos de generalização de desempenho. Estes modelos requerem, no entanto, um tempo de processamento muito elevado e, portanto, os próprios autores atestaram que os modelos de gravidade devem ser utilizados se o objetivo for minimizar o tempo de execução, ainda que em troca de perda na acurácia de generalização.

Mozolin, Thill e Usery (2000) afirmavam que, apesar de terem produzido resultados inferiores quando comparados a um modelo gravitacional específico, os modelos neurais de interação espacial são capazes de modelar não somente os fluxos de viagens, como todo o contexto do sistema de transportes em que estão inseridos.

Em um trabalho um pouco menos recente, Black (1995), além de apresentar resultados promissores e o bom desempenho das redes neurais para este tipo de modelagem, afirmava que uma das suas grandes vantagens seria o fato de que os modelos tendem a realizar melhores estimativas se treinados com volumes crescentes de dados, o que pode ser verificado com a utilização da técnica de bootstrap, sugerida por Fischer e Reismann (2002b).

Akamine e Silva (2004) utilizaram modelos neurais de interação espacial em uma aplicação prática, obtendo bons resultados, embora constatando a dificuldade de selecionar os modelos de melhor desempenho, o que veio a constituir a motivação principal para o presente projeto de pesquisa. O referencial teórico a respeito das Redes Neurais Artificiais é apresentado no próximo capítulo. 


\section{REDES NEURAIS ARTIFICIAIS}

$\mathrm{O}$ cérebro humano pode ser definido como um computador, composto por uma estrutura de grande complexidade, não-linear e paralela, que tem a capacidade de organizar os neurônios para a execução de determinados tipos de tarefas (HAYKIN, 1994). É justamente este paralelismo apresentado pelo cérebro do homem que garante a ele a capacidade de armazenar e representar o conhecimento adquirido e torná-lo acessível (BEALE; JACKSON, 1990).

\subsection{Conceitos}

Pode-se dizer que o desenvolvimento de sistemas de inteligência artificial teve início a partir do momento em que se tentou simular as atividades do cérebro humano através de máquinas. Os computadores convencionais mostram-se capazes de executar seqüencialmente tarefas que estejam programadas em sua memória. São, por exemplo, muito mais rápidos e precisos do que o cérebro humano no cálculo de operações matemáticas. Porém são pouco eficientes na execução de funções aparentemente simples para o ser humano como, por exemplo, o reconhecimento de padrões visuais.

Os neurocomputadores, por outro lado, buscam modelar a estrutura do cérebro do homem, bem como a forma pela qual ele é capaz de processar informações. Para atingir este objetivo, é preciso uma estrutura computacional diferente, que, tal como o cérebro do homem, possua uma grande quantidade de unidades de processamento, altamente conectadas, operando de forma paralela (BRONDINO, 1999). 
Estima-se que um cérebro possua mais de 100 bilhões de neurônios e mais de uma centena de tipos diferentes destes. Os neurônios funcionam em grupos, denominados redes, sendo que cada rede pode ser formada por milhares de neurônios interconectados. Portanto, o cérebro pode ser visto como uma coleção de Redes Neurais. Tanto o pensamento quanto o comportamento inteligente são controlados pelo sistema nervoso central e pelo cérebro (TRIPPI; TURBAN, 1992).

Cada neurônio é formado de dendritos, corpo celular (soma) e axônio, como apresentado na Figura 3.1. Ele é uma estrutura simples que possui três funções básicas: entrada, processamento e saída de sinais. Os dendritos são conexões através das quais os sinais de entrada chegam aos neurônios. O núcleo contido no corpo celular é o processador do neurônio. Ele recebe os sinais através dos dendritos e os adiciona de alguma forma. Se o valor resultante estiver acima de um certo limite, o neurônio se excita e tende a propagar o estímulo. Caso contrário ele fica inibido. Os axônios servem como canal de saída do neurônio. Eles estão ligados aos dendritos de outros neurônios através das sinapses. As sinapses não são ligações físicas, mas sim químicas e temporárias, e se dão através de neurotransmissores.

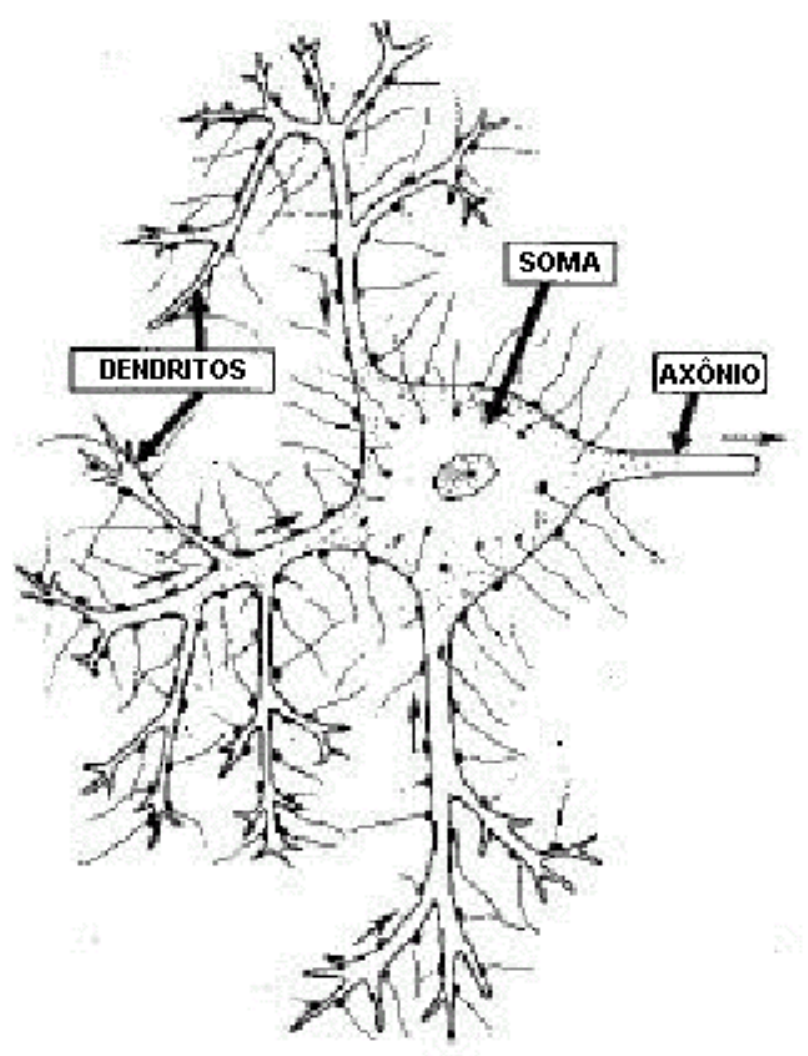

Figura 3.1 - Componentes do neurônio (GUYTON, 1977) 
As Redes Neurais Artificiais constituem um método de solução para problemas de inteligência artificial, através da construção de um sistema com circuitos que simulem o cérebro humano, aprendendo, errando e fazendo descobertas (PEREIRA et al., 2002). São sistemas paralelos distribuídos, compostos por unidades de processamento simples (nós) que calculam determinadas funções matemáticas (normalmente não-lineares). Essas unidades geralmente são conectadas por canais de comunicação que estão associados a determinado peso. As unidades fazem operações apenas sobre seus dados locais, que são entradas recebidas por suas conexões. O comportamento "inteligente" de uma Rede Neural Artificial vem das interações entre as unidades de processamento da rede (BRAGA; CARVALHO; LUDEMIR, 1998).

\subsubsection{Breve Histórico}

O primeiro modelo artificial de um neurônio biológico foi fruto do trabalho conjunto de um psiquiatra neuroanatomista e um matemático, respectivamente Warren McCulloch e Walter Pitts, em 1943. Tal modelo se concentrava muito mais em descrever um modelo artificial de um neurônio e apresentar suas capacidades computacionais do que em apresentar técnicas de aprendizado.

$\mathrm{O}$ aprendizado de redes biológicas e artificiais foi apresentado por Donald Hebb, em 1949. Hebb mostrou como a plasticidade da aprendizagem de redes neurais é conseguida através da variação dos pesos de entrada dos nós e propôs uma teoria para explicar o aprendizado em nós biológicos, baseada no reforço das ligações sinápticas entre nós excitados. A regra de Hebb, como é conhecida, foi interpretada do ponto de vista matemático, e é hoje utilizada em vários algoritmos de aprendizado (BRAGA; CARVALHO; LUDEMIR, 2000).

O modelo denominado Perceptron foi criado em 1958 por Frank Rosenblatt, Charles Wightman e outros. O interesse inicial para a criação do Perceptron era o reconhecimento de padrões. O Perceptron, em sua configuração mais simples (Figura 3.2), era composto por unidades de entrada, por um nível intermediário formado pelas unidades de associação e por um nível de saída formado pelas unidades de resposta (SILVA et al., 2001). O uso de redes neurais no desenvolvimento de sistemas 
de inteligência artificial, porém, foi deixado de lado por não ser eficiente na solução de determinados problemas, sendo retomado somente na década de 80 .

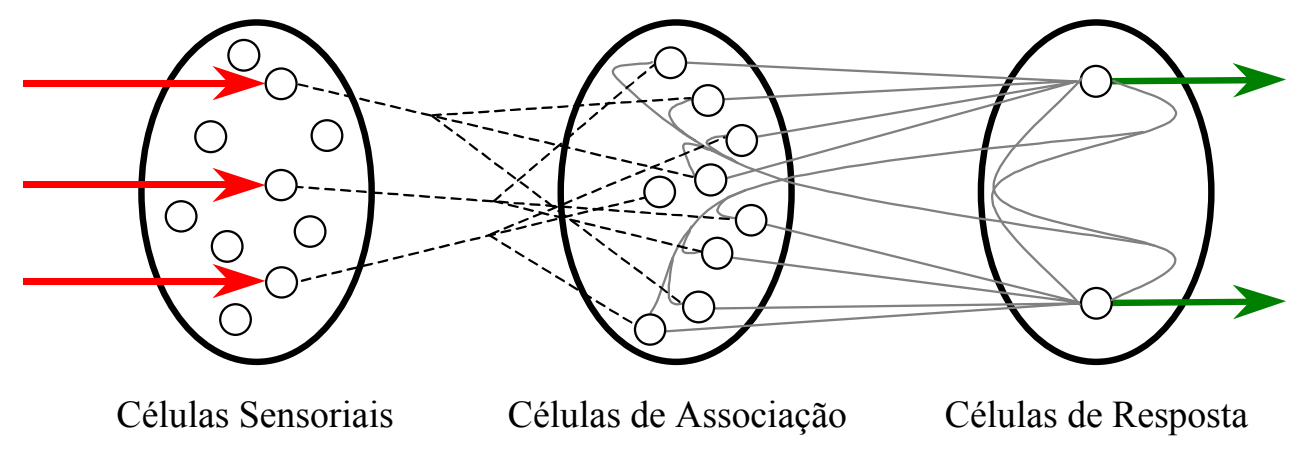

Figura 3.2 - Camadas de um Perceptron (SMITH, 1996)

Um passo importante para esta retomada foi dado por Hinton e Sejnowski (1986), ao introduzirem o método de backpropagation (retropropagação), que consiste de um algoritmo de aprendizado supervisionado, ou seja, necessita de pares de entrada e saída desejada para, por meio de um mecanismo de correção de erros, ajustar os pesos da rede. De acordo com Silva et al. (2001), o treinamento ocorre em duas fases, sendo que cada fase percorre a rede em um sentido. Essas duas fases são chamadas de fase forward (para frente) e fase backward (para trás). A fase forward é utilizada para definir a saída da rede para um dado padrão de entrada. A fase backward utiliza a saída desejada e a saída fornecida pela rede para atualizar os pesos de suas conexões.

O algoritmo backpropagation é um dos mais utilizados no treinamento de redes de camadas múltiplas, ou MLP (Multilayer Perceptron), que consiste de unidades de Perceptrons arranjadas em camadas. Nas redes MLP, portanto, existe mais de um neurônio entre alguma entrada e alguma saída. Ainda de acordo com Silva et al. (2001), as redes MLP apresentam um poder computacional muito maior do que aquele apresentado pelas redes sem camadas intermediárias. A solução de problemas nãolinearmente separáveis passa pelo uso de redes com uma ou mais camadas intermediárias. 


\subsubsection{Aprendizado}

Os paradigmas de aprendizado definem a maneira como a rede se relaciona com o ambiente e se dividem em três grupos principais: supervisionado, não supervisionado e híbrido.

Para o aprendizado supervisionado, apresenta-se à rede, na fase de treinamento, um conjunto de entradas acompanhadas de suas respectivas saídas, com o objetivo de minimizar o erro, que é uma função da diferença entre a saída desejada e aquela fornecida pela rede. O método backpropagation é um exemplo deste paradigma. No aprendizado não supervisionado a rede aprende sozinha, sem uma mensagem de erro, e é necessário que entradas parecidas sejam apresentadas à rede para que esta possa extrair características estatisticamente relevantes. $\mathrm{O}$ aprendizado híbrido, por sua vez, consiste de uma combinação dos aprendizados supervisionado e não supervisionado (BRONDINO, 1999).

No caso do algoritmo backpropagation, quando um padrão é apresentado à rede pela primeira vez, esta produz uma saída aleatória. A diferença entre esta saída e a desejada constitui o erro. A intenção do trabalho de treinamento é diminuir o valor deste erro, ajustando o valor dos pesos a cada nova iteração (RAIA JR., 2000). Tal ajuste depende de variáveis como a taxa de aprendizado e o momentum. Segundo Raia Jr. (2000), o valor da taxa de aprendizado determina o quão suavemente se dará a atualização dos pesos. O termo momentum pode aumentar a velocidade do aprendizado e tem por característica acelerar o processo de treinamento.

Ainda segundo Raia Jr. (2000), a atualização de pesos pode se dar de duas maneiras: por padrão ou por ciclo. Na primeira, os pesos são atualizados após a apresentação de cada padrão. Na segunda, os pesos são atualizados após a apresentação de todos os padrões. Se o conjunto de dados é grande e redundante (poucos padrões e muitas entradas, por exemplo), a primeira é melhor. Caso contrário, quando o conjunto apresenta muitos padrões a serem classificados, é melhor utilizar a atualização por ciclo.

$\mathrm{O}$ algoritmo backpropagation apresenta alguns problemas quanto ao aprendizado: em superfícies muito complexas, o treinamento é lento e existe o risco da rede cair num mínimo local. Além disso, pode ocorrer overfitting, fenômeno que surge depois de um certo tempo de treinamento, quando a rede memoriza os padrões que já foram apresentados e o processo de classificação piora sensivelmente. Possíveis 
soluções para esse problema são: alterar a taxa de aprendizado, adicionar nós na camada intermediária e variar o valor do momentum. (BRONDINO, 1999).

\subsubsection{O Neurônio Artificial}

A Figura 3.3 ilustra o esquema de um neurônio artificial, unidade fundamental de processamento de uma RNA, que recebe uma ou mais entradas, transformando-as em saídas (BOCANEGRA, 2002).

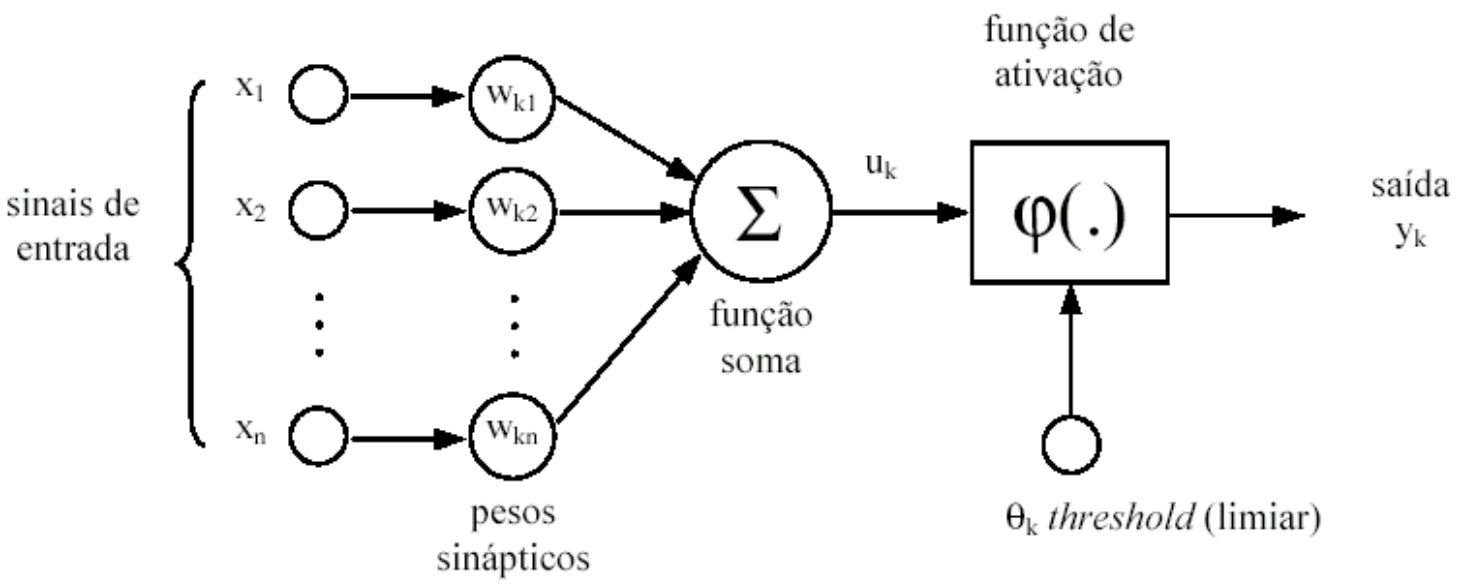

Figura 3.3 - Esquema de um neurônio artificial (BOCANEGRA, 2002)

O vetor $x=\left(x_{1}, \ldots, x_{n}\right)$ é o vetor de entrada e os pesos da rede (sinapses) estão associados ao vetor $w=\left(w_{k l}, \ldots, w_{k n}\right)$. O somatório adiciona as entradas ponderadas pelos seus respectivos pesos. Sendo $u_{k}$ o resultado desta operação, tem-se a Equação 3.1 (FISCHER; REISMANN, 2002b).

$$
u_{k}=\sum_{n=1}^{N} w_{k n} x_{n}
$$

O limiar (threshold), $\theta_{k}$, tem um papel determinante na saída do neurônio. Sua função é controlar a intensidade da função de ativação para se obter o desempenho desejado na rede. Se o valor de $u_{k}$ for menor que este limiar, então a saída do neurônio fica inibida. Caso contrário o neurônio fica ativo (BOCANEGRA, 2002).

A função de ativação $\varphi($.) funciona como um limitante à amplitude da saída do neurônio, ou seja, a entrada é normalizada dentro de um intervalo fechado, 
geralmente $[0,1]$ ou $[-1,1]$ (BOCANEGRA, 2002). A função sigmoidal logística (Equação 3.2) é a função de ativação mais utilizada. Uma grande quantidade de programas de RNAs utiliza este tipo de função, inclusive o software EasyNN-plus, utilizado no presente trabalho (bem como em Costa, 2001; Bocanegra, 2002 e Costa, 2003, por exemplo)

$$
\varphi(v)=\frac{1}{1+\exp (-a v)}
$$

onde $v$ é o nível de atividade interna do neurônio, isto é,

$$
v_{k}=\sum w_{k n} x_{j}-\theta_{k}
$$

e $a$ é o parâmetro de inclinação da função. Variando o parâmetro $a$, são obtidas funções sigmóides de diferentes inclinações, como ilustrado na Figura 3.4.

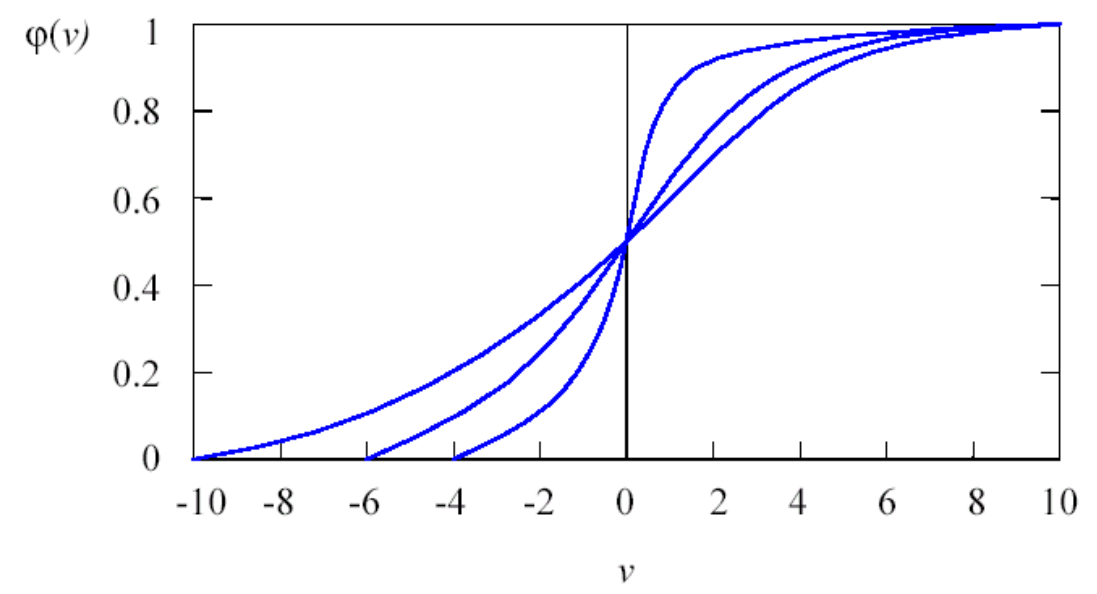

Figura 3.4 - Representação da função sigmóide (BOCANEGRA, 2002)

Finalmente tem-se a saída do neurônio, $y_{k}$, como na Equação 3.4.

$$
y_{k}=\varphi\left(u_{k}-\theta_{k}\right)
$$

\subsubsection{Vantagens e Desvantagens}

Algumas vantagens na utilização de Redes Neurais Artificiais: 
- As redes podem, em alguns casos, permitir análises superiores às conseguidas com técnicas estatísticas convencionais (SMITH, 1996);

- Não necessitam de conhecimentos de especialistas para tomar decisões, pois baseiam-se unicamente nos exemplos históricos que lhes são fornecidos;

- O tempo necessário para se implementar uma rede é menor que o utilizado para a construção de um sistema especialista equivalente;

- Como as unidades da rede operam em paralelo, a destruição ou “defeito" em um de seus nós não torna a rede inoperante;

- As redes conseguem separar o ruído (variações aleatórias, presentes nos dados reais, adicionadas aos valores originais) da informação relevante, tendo sido utilizadas inclusive como filtros de dados;

- Se as condições de trabalho variam pode-se fazer uso da capacidade das RNAs para adaptar-se a essas mudanças, voltando a treinar o sistema com novos exemplos (BRIO; MOLINA, 2001).

Desvantagens:

- As redes podem chegar a conclusões que contrariem as regras e teorias estabelecidas;

- O treinamento de uma rede, dependendo de sua aplicação, pode ser demorado;

- Uma vez treinada uma rede neural, pode ser difícil interpretar o seu funcionamento. Trata-se de um tipo de funcionamento denominado de 'caixa preta' (BRIO; MOLINA, 2001);

- Para uma rede aprender corretamente pode chegar a necessitar de milhares de dados históricos; nestes casos, a carência de dados passados relevantes em quantidade suficiente torna a rede inaplicável (Silva et al., 2001). 


\subsection{Desenvolvimento de Aplicações}

Segundo Silva et al. (2001), são passos para o desenvolvimento de projetos de Redes Neurais Artificiais:

1. Coleta de dados: os dados devem representar todos os casos que possam ocorrer na prática. Para que a rede apresente um bom treinamento, aconselha-se, antes de iniciá-lo, normalizar os dados, ou seja, deixar os valores dos conjuntos de dados, por exemplo, entre zero e um. Alguns programas de Redes Neurais já realizam este procedimento automaticamente.

2. Escolha da técnica a ser utilizada para separação dos dados: o principal objetivo de um modelo, segundo Carvalho (2001), é classificar novos exemplos com sucesso. O desempenho de um modelo é medido pela sua taxa de erro. Para o cálculo dessa taxa de erro existem várias técnicas, dentre as quais a mais comum é o Método Random Subsampling, que divide o conjunto de dados em: $50 \%$ dos dados no subconjunto de treinamento, $25 \%$ dos dados no subconjunto de validação e $25 \%$ dos dados no subconjunto de teste. O conjunto de treinamento é utilizado para o aprendizado da rede neural. O de validação é usado para a observação da eficácia da rede quanto à capacidade de generalização durante a fase de treinamento e o conjunto de teste, por fim, serve para a verificação do comportamento da rede sob situações reais de utilização.

3. Definição da configuração da rede: escolhe-se qual a topologia da rede que será utilizada para o modelo (número de camadas intermediárias, número de neurônios na camada intermediária, tipo de conexão) e qual o paradigma de aprendizado.

4. Importação dos dados no software escolhido. Neste trabalho foi utilizado o software EasyNN-plus. 


\subsubsection{Ferramentas}

Muitos dos passos necessários para produzir redes neurais são automatizados pelo EasyNN-plus. Este software tenta produzir a rede neural mais simples a partir dos dados de treinamento e é de fácil aplicação, sendo composto por ícones que facilitam o projeto das RNAs.

A estrutura de rede empregada pelo EasyNN-plus é a Multilayer Perceptron, com até 3 camadas intermediárias (hidden layers). Segundo o criador do programa, uma rede com uma camada intermediária geralmente produz resultados melhores do que redes com mais camadas. Apenas casualmente duas camadas intermediárias serão necessárias, porém uma rede neural com uma camada deverá sempre ser testada primeiro (WOLSTENHOLME, 2002). Os dados para criação dos arquivos para o processo de aprendizagem podem ser gerados com base em arquivos em formato de texto ou folhas de cálculo.

O algoritmo utilizado para seu aprendizado é o backpropagation. O EasyNN-plus utiliza a função sigmóide logística para construir os modelos analisados. Para cada conjunto de dados a ser rodado, o simulador EasyNN-plus estabelece valores para a taxa de aprendizagem e para o momentum, que podem ser alterados pelo usuário. Posteriormente, tendo os dados observados e os estimados, pode-se calcular o erro para o conjunto. O processo consiste em criar diferentes redes e escolher a que produz o menor erro (WOLSTENHOLME, 2002).

\subsubsection{Medidas de Desempenho}

Várias medidas estatísticas podem ser adotadas para avaliar o desempenho do modelo, dentre as quais estão:

- Comparação gráfica: neste tipo de avaliação de desempenho apenas são plotados lado a lado, em um mesmo gráfico, tanto os resultados observados como os previstos pelas RNAs e, em seguida, confrontados através de uma análise visual. Black, Cheung e Suthanaya (2003) utilizaram a comparação entre curvas de distribuição de freqüência de 
distâncias de viagens, para analisar o desempenho das estimativas em termos de distâncias de viagens.

- Gráfico de pontos (Scattergram): os dados são plotados como pontos em um gráfico, com o propósito de tornar explícito o quão próximo estão as previsões dos valores alvos correspondentes. Neste caso, no eixo x podese plotar o valor previsto e no eixo y o valor observado correspondente. De maneira ideal, os pontos devem formar uma linha de $45^{\circ}$ que passa pela origem dos eixos.

- Erro Quadrático Médio (Mean Squared Error, MSE): esta medida, fácil de se computar e que possui um apelo intuitivo muito forte, é uma medida de exatidão da previsão em termos de valores absolutos ou relativos. O cálculo é feito de acordo com a Equação 3.5.

$$
M S E=\frac{1}{n} \sum_{t=1}^{n}\left(\text { observado }_{t}-\text { estimado }_{t}\right)^{2}
$$

- Raiz do Erro Quadrático Médio (Root Mean Squared Error, RMSE): esta medida de desempenho, adotada por Black (1995), consiste no cálculo da raiz quadrada do MSE.

- Erro Relativo Médio: consiste da média das diferenças entre os valores estimados pelas redes neurais e os valores observados, expressas como porcentagem dos valores observados.

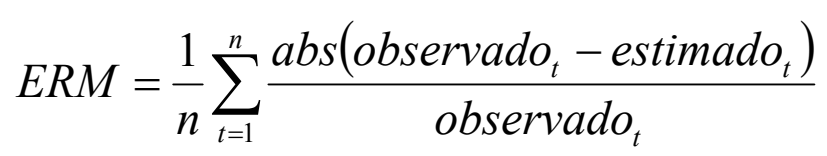

- Erro Normalizado: esta medida consiste da média dos erros de cada previsão, normalizada entre 0 e 1 através da divisão pelo maior erro possível de se obter. É calculada de acordo com a Equação 3.7. Multiplicando este valor por 100 obtém-se o resultado em porcentagem.

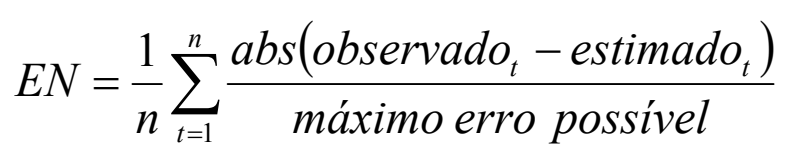

Segundo Black, Cheung e Suthanaya (2003), o uso de diferentes medidas estatísticas pode levar a diferentes conclusões sobre o desempenho do modelo. Embora uma combinação de duas ou mais medidas estatísticas possa ser usada para determinar o 
melhor modelo, estas medidas são apenas indicações do desempenho das transformações das interações, e não estão avaliando as predições reais de interação espacial. Há algumas implicações dessas conclusões nas políticas de desenvolvimento e investimento em infra-estrutura de transportes e, portanto, há necessidade de se investigar espacialmente fluxos sub e superestimados. Para tal, os autores sugerem que sejam plotados, com o auxílio de um SIG-T (Sistema de Informações Geográficas para Transportes), os resíduos das estimativas, através de linhas que representam os desvios dos fluxos entre origens e destinos, permitindo uma avaliação dos erros das previsões exatamente no local onde ocorrem.

\subsection{Redes Neurais Artificiais na Engenharia de Transportes}

Diversos trabalhos aplicando as técnicas de Redes Neurais Artificiais em transportes foram publicados, sobretudo a partir da década de 1990, quando o campo de estudos de transportes observou uma verdadeira explosão no uso de RNAs (DOUGHERTY, 1995).

De acordo com Dougherty (1995), na área de transportes, as redes neurais têm sido aplicadas em diversos temas, a saber: comportamento dos motoristas, manutenção de vias, detecção de veículos, análise do padrão de tráfego, operações de transporte de mercadorias, previsão de tráfego, política e economia de transportes, transporte aéreo, transporte marítimo, operações com metrô e controle de tráfego.

Dentre os trabalhos revisados em detalhes para a realização deste projeto de pesquisa pode-se citar o de Raia Jr. (2000), que estudou a acessibilidade e mobilidade na estimativa de um índice de potencial de viagens utilizando Redes Neurais Artificiais e Sistemas de Informações Geográficas. Além deste, Costa (2001) avaliou o consumo de energia com transportes em cidades do estado de São Paulo, Bocanegra (2002) pesquisou procedimentos para tornar mais efetivo o uso das Redes Neurais Artificiais em planejamento de transportes e Costa (2003) analisou o consumo de energia com transportes nas cidades portuguesas utilizando RNAs.

Especificamente na área de planejamento de transportes, os principais problemas relatados na literatura que utilizam a técnica de RNAs se referem às fases de geração de viagens, distribuição de viagens, escolha modal e alocação de viagens 
(PEREIRA et al., 2003). Nestas aplicações se identificam os trabalhos realizados por Openshaw (1993), Black (1995), Fischer, Reismann e Hlavackova-Schindler (1999), Chand (1991), Kikuchi, Nanda e Perincherry (1993), Raju, Sikdar e Dhingra (1994), Faghri e Hua (1992), Lyons et al. (1996), Ledoux (1997), Le e Young (1998a e 1998b), Jianzhong e Saito (1998), Dia e Rose (1998), Hoogendoorn e Bovy (2000), Dantas et al. (2001), Rodrigues (2000), Dia (2001), Dia, Harney e Boyle (2001) e Costa (2003). Ainda outros autores (Aguiar Jr., 2004; Antunes et al., 2001; Costa, Silva e Carvalho, 2001; Oliva, Cybis e Pretto, 2001; Queiroz, Jacques e Weigang, 2001; Raia Jr., Silva e Bocanegra, 2001; Wermersch e Kawamoto, 1999; Vidal, Faé e Salles, 2002; Farias, Dantas Neto e Pais, 2004; Madalozo, Dyminski e Ribeiro, 2004 e Oliveira e Cury, 2004) desenvolveram estudos relacionados ao emprego de Redes Neurais Artificiais em transportes, com qualidade e profundidade, que merecem destaque pelo fato de terem sido produzidos no Brasil.

Nesse contexto, pode-se perceber, ainda que através de uma avaliação somente quantitativa, que as RNAs têm se destacado como uma ferramenta de suporte para solução de problemas complexos de Engenharia de Transportes (PEREIRA et al., 2003).

O que tem sido observado no desenvolvimento de diversos modelos baseados em RNAs, no entanto, é a ausência de técnicas para seleção da rede neural a ser utilizada na modelagem (FISCHER; LEUNG, 1998). Geralmente, os parâmetros de rede são escolhidos pelo usuário e, ainda que se consiga resultados satisfatórios variando-se tais parâmetros, a rede selecionada por ter melhor desempenho não necessariamente representa a melhor solução para o problema que está sendo analisado.

Para superar este problema, Fischer e Reismann (2002b) sugerem o uso de procedimentos de busca global na seleção de melhores arquiteturas de rede. Nesta linha, o trabalho aqui apresentado tem por objetivo testar o emprego da técnica de otimização de Algoritmos Genéticos como alternativa para melhoria do desempenho dos modelos neurais de interação espacial. 


\section{ALGORITMOS GENÉTICOS}

Imagine o processo natural de evolução como um grande algoritmo, que seleciona as características que devem permanecer ao longo das gerações, tornando as espécies mais aptas à sobrevivência, e os organismos do mundo atual como resultados de muitas iterações neste grande algoritmo de otimização (HAUPT; HAUPT, 1998).

\subsection{Conceitos de Otimização}

Otimização é a busca da melhor solução para um dado problema. Segundo Novaes (1978), consiste da procura sistemática do melhor, que pode não ser o melhor absoluto, mas o melhor prático. Afirma ainda que conhecer o mecanismo de um certo problema, determinando as relações entre as variáveis, já constitui um avanço considerável.

Toda tarefa de busca e otimização possui vários componentes, entre eles: um espaço de busca, onde são consideradas todas as possibilidades de solução de um determinado problema, e uma função de avaliação (ou função de custo), uma maneira de avaliar os membros do espaço de busca. Existem inúmeros métodos de busca e funções de avaliação (LACERDA; CARVALHO, 1999).

Em geral, um problema de otimização está associado a um problema de minimização ou de maximização de uma ou mais funções, isto é, o objetivo principal da otimização é encontrar um conjunto tal de valores para as variáveis do problema que minimize uma função de custo ou que maximize uma função de lucro ou eficiência 
conhecida como função objetivo, satisfazendo algumas restrições. Minimizar uma função numérica $f(x)$ é equivalente a maximizar $g(x)$ se $g(x)=-f(x)$.

O problema de otimização pode ser formulado matematicamente como:

$$
\operatorname{Minimizar} f\left(x_{1}, x_{2}, \ldots, x_{n}\right)
$$

sujeito a:

$$
\begin{gathered}
g_{1}\left(x_{1}, x_{2}, \ldots, x_{n}\right) \geq b_{1} \\
g_{2}\left(x_{1}, x_{2}, \ldots, x_{n}\right) \geq b_{2} \\
\ldots \\
g_{j}\left(x_{1}, x_{2}, \ldots, x_{n}\right) \geq b_{j}
\end{gathered}
$$

Neste caso, o vetor $x$ é designado o vetor de incógnitas ou vetor de variáveis de projeto, $f(x)$ é a função objetivo e $g_{j}\left(x_{1}, x_{2}, \ldots, x_{n}\right) \geq b_{j}$ representa a $j$-ésima restrição dos valores das variáveis.

Quando os parâmetros da função objetivo podem assumir qualquer valor, são chamados irrestritos. Por exemplo:

$$
\text { Minimizar } f(x)
$$

sujeito a:

$$
x \in \mathfrak{R}^{n}
$$

Sob o ponto de vista de minimização as funções podem ser unimodais, quando apresentam um único ponto de mínimo, ou plurimodais (ou multimodais), quando apresentam dois ou mais pontos de mínimo. Em funções multimodais complicadas, muitas técnicas de otimização podem trazer dificuldade para identificar se um dado ponto de mínimo é local ou global (TORRES, 2003).

O gráfico da Figura 4.1 apresenta dois pontos de mínimo, $x_{0}$ e $x_{1}$. Um ponto de mínimo é chamado local quando satisfaz a condição de $\operatorname{Min} f(x)$ para um intervalo específico. Um mínimo é chamado global quando $f(x)$ é mínimo para todo $x$ do espaço de soluções. Em geral é difícil afirmar que um valor é um mínimo global devido à possibilidade de existência de vários mínimos locais e, assim, somente um 
deles será global. O que se pode afirmar é que o valor encontrado é mínimo numa vizinhança do espaço de busca (LEMONGE, 1999).

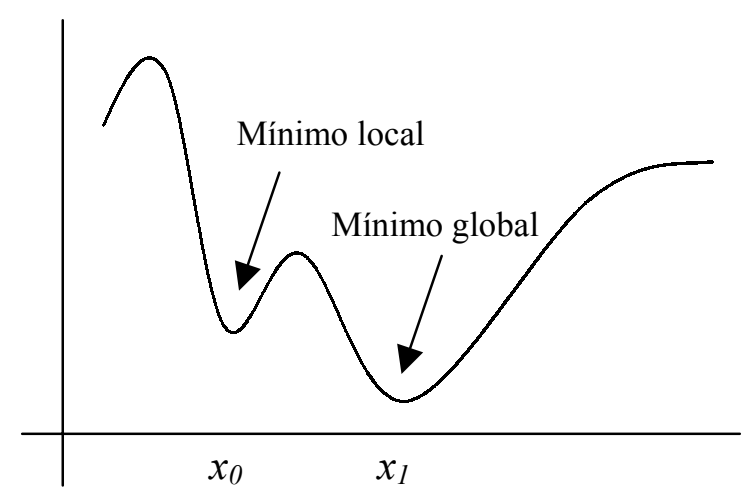

Figura 4.1 - Mínimo local e global (LACERDA; CARVALHO, 1999)

A função objetivo de um problema de otimização pode ser linear ou nãolinear e pode ter parâmetros contínuos ou discretos. A otimização de uma função com parâmetros contínuos (função contínua) tem um número infinito de possíveis soluções, enquanto a otimização de parâmetros discretos, em geral, tem um número finito de possíveis soluções, dado que o espaço de busca é finito (TORRES, 2003).

Existem diversos métodos de otimização, numéricos e algébricos, que procuram por um conjunto de valores no espaço de busca de um dado problema. Entretanto em problemas que apresentam não linearidade, ruído, descontinuidade ou espaços de busca extremamente grandes, esses métodos podem tornar-se computacionalmente proibitivos ou mesmo não serem aplicáveis. Para esse tipo de problemas que são intratáveis por métodos clássicos, os Algoritmos Genéticos (AGs) mostram-se como alternativa simples e eficiente (VALENTE; LOPES; ARRUDA, 2002).

\subsection{Características Gerais dos Algoritmos Genéticos}

Os AGs são métodos de otimização por busca inspirados nos mecanismos de genética e evolução dos seres vivos. Seguem os princípios da seleção natural e sobrevivência do mais apto, declarado em 1859 pelo naturalista e fisiologista inglês Charles Darwin em seu livro "A Origem das Espécies”. De acordo com Charles Darwin, 
"quanto melhor um indivíduo se adaptar ao seu meio ambiente, maior será sua chance de sobreviver e gerar descendentes".

Os primeiros estudos sobre AGs foram desenvolvidos por John Holland na década de 70, que acreditava que, incorporando esses princípios em um programa de computador, pudesse resolver, por simulação, problemas complexos, justamente como ocorria na natureza.

A idéia de sobrevivência do mais apto é exemplificada por Michalewicz (1996) numa população de coelhos, onde alguns são mais rápidos e inteligentes que outros. Estes têm menor probabilidade de serem capturados por algum predador e muitos deles acabam gerando descendentes.

Como se trata de questão de probabilidade, alguns coelhos mais vagarosos também irão sobreviver, mais devido à própria sorte do que à habilidade. Essa população sobrevivente de coelhos irá conceber uma nova geração. O resultado dessa geração é uma boa mistura de material genético dos coelhos, pois alguns foram gerados de coelhos mais lentos com coelhos mais velozes, ou apenas por coelhos mais velozes e assim por diante.

Por outro lado, algumas vezes a natureza impõe mutações no material genético. Os coelhos filhotes serão, em média, mais rápidos e inteligentes do que a população que os gerou, pois um maior número de coelhos com essa característica genética foi capaz de sobreviver aos ataques dos predadores. Importante lembrar que, da mesma maneira, também os predadores evoluirão de forma a tentar capturar a nova geração de coelhos.

Os Algoritmos Genéticos trabalham de forma semelhante à história de sobrevivência e evolução dos coelhos e utilizam o mesmo vocabulário empregado nos estudos da genética (TORRES, 2003). Dessa forma, os AGs iniciam com uma população que representa as possíveis soluções do problema e cada componente ou indivíduo dessa população é representado por um cromossomo. Cada cromossomo é composto por cadeias de genes e cada gene é composto por um ou mais alelos, que dão valor aos genes (BIELLI; CARAMIA; CAROTENUTO, 2002). O valor do alelo pode variar, sendo geralmente utilizada a representação binária e, nesse caso, a variação é 0 ou 1 (TORRES, 2003).

De acordo com Michalewicz (1996), cada indivíduo humano carrega consigo um certo número de cromossomos, no entanto o funcionamento dos AGs 
comumente aplicado na literatura considera apenas um cromossomo por indivíduo, ou seja, cromossomos haplóides (MICHALEWICZ, 1996).

De um modo geral os AGs têm as seguintes características que os diferenciam dos métodos tradicionais de busca e otimização (GOLDBERG, 1989):

- Trabalham com uma codificação do conjunto de parâmetros (cromossomos) e não com os próprios parâmetros;

- Trabalham com uma população de pontos e não com os próprios pontos;

- Utilizam uma função de adaptação direta de custo ou recompensa, e não derivadas ou outro conhecimento auxiliar;

- Utilizam regras de transição probabilísticas e não determinísticas.

Os AGs empregam uma estratégia de busca paralela e estruturada, mas aleatória, que é voltada em direção ao reforço da busca de pontos de alta aptidão, ou seja, pontos nos quais a função a ser minimizada (ou maximizada) tem valores relativamente baixos (ou altos). Apesar de aleatórias, as buscas não são caminhadas não direcionadas, ou seja, buscas totalmente sem rumo, pois exploram informações históricas para encontrar novos pontos de busca onde são esperados melhores desempenhos. Isto é feito através de processos iterativos, onde cada iteração é chamada de geração (TORRES, 2003).

Segundo Torres (2003), os Algoritmos Genéticos ocupam lugar de destaque entre os paradigmas da Computação Evolutiva por suas características funcionais. Junto com as Redes Neurais Artificiais, são os mais usados de toda a Computação Natural, devido a uma série de razões, dentre as quais:

- Apresentam resultados bastante aceitáveis com relação à precisão e recursos empregados (fáceis de implantar em computadores domésticos de porte médio) para uma ampla gama de problemas de difícil resolução por outros métodos;

- Em relação a outros paradigmas da Computação Evolutiva, são os que exigem para o seu funcionamento, menos conhecimento específico do 
problema em questão, o que os torna altamente versáteis e, além disso, agregam conhecimento específico com pouco esforço;

- São muito flexíveis, aceitam sem grandes dificuldades uma infinidade de alterações na sua implementação e permitem fácil hibridação, vantagem importante no caso de aprendizagem ou quando se pretende utilizar outros métodos para avaliar a aptidão, como por exemplo, análise multicritério ou algoritmos complementares.

\subsection{Desenvolvimento de Aplicações}

Inicialmente, é gerada uma população formada por um conjunto aleatório de indivíduos que podem ser vistos como possíveis soluções do problema, a população inicial. Durante o processo evolutivo, esta população é avaliada: para cada indivíduo é atribuída uma nota ou índice, refletindo sua habilidade de adaptação a determinado ambiente (SAMPAIO, 2004).

Uma porcentagem dos mais aptos é mantida, enquanto os outros são descartados (darwinismo) durante a etapa de seleção. Nos indivíduos selecionados, são aplicados os operadores de cruzamento e de mutação, gerando descendentes para as próximas iterações. Este processo, chamado de reprodução, é repetido até que uma solução satisfatória seja encontrada.

A Figura 4.2 apresenta o esquema geral do funcionamento de um AG. 


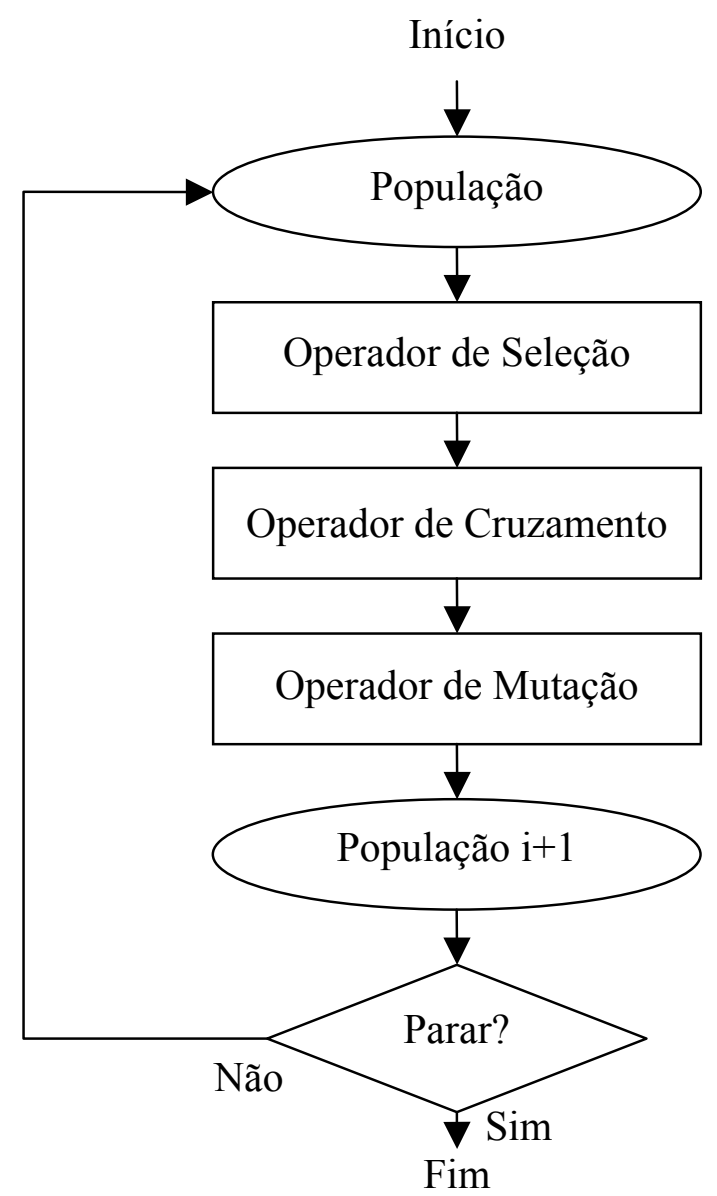

Figura 4.2 - Esquema geral de um AG (TORRES, 2003)

\subsubsection{Representação}

Uma das principais preocupações a ser avaliada quando se utiliza o AG como ferramenta de otimização é a escolha de uma codificação que represente as possíveis soluções (SAMPAIO, 2004). A representação binária é a tradicional, indicada para problemas com parâmetros discretos, sendo fácil de utilizar e manipular, além de simples de analisar teoricamente (GOLDBERG, 1989).

A representação binária consiste da codificação dos parâmetros de uma possível solução do problema em uma cadeia de bits com valores iguais a zero ou um (Figura 4.3). Esta cadeia é o cromossomo e o AG processa populações de cromossomos, efetuando substituições sucessivas de uma população por outra. 


\begin{tabular}{|l|l|l|l|l|l|l|l|l|l|l|l|}
\hline 1 & 0 & 1 & 0 & 0 & 1 & 0 & 1 & 1 & 0 & 0 & 1 \\
\hline
\end{tabular}

Figura 4.3 - Cromossomo com representação binária

A melhor estratégia de representação, binária ou real, tem sido tema de várias pesquisas e muitas delas têm demonstrado a maior utilização da representação real. Argumenta-se que a representação binária apresenta desvantagens quando aplicada a problemas multidimensionais que requerem alta precisão numérica. Nestes casos, a representação real possibilita gerar cromossomos menores e é mais fácil de ser compreendida do que a cadeia de bits (TORRES, 2003).

Por outro lado, a utilização dos operadores de cruzamento e mutação, descrita nos próximos itens, é mais eficiente na representação binária, visto que na real eles basicamente trocam valores dos genes e, portanto, não criam informações novas, isto é, novos números. Dessa forma, quando se opta pela representação real recomendase aplicar outros tipos de operadores (TORRES, 2003).

\subsubsection{Definição da População}

Após a codificação das soluções candidatas, pode-se definir a população inicial do algoritmo. Segundo Henderson e Fu (2004), o tamanho da população afeta diretamente a eficiência do algoritmo e não há regras para determinar o tamanho ótimo para uma aplicação ou problema específico. Uma regra geral, contudo, indica que o número de componentes da população deve ser no mínimo igual ao número de genes do cromossomo em uma representação binária.

\subsubsection{Seleção}

O primeiro passo para a aplicação do operador de seleção consiste da avaliação do nível de aptidão à sobrevivência do cromossomo, em relação aos demais indivíduos da população. Isto é feito atribuindo-se um valor numérico a cada 
cromossomo, que representa o seu grau de adaptação e é obtido através de sua medida de desempenho.

Os indivíduos são classificados de acordo com uma função aptidão (função objetivo), específica para cada tipo de problema. Essa classificação pode ser feita através da ordenação das soluções em ordem crescente ou decrescente de suas aptidões, se o problema é de minimização ou de maximização, respectivamente (SAMPAIO, 2004).

A etapa de seleção é feita probabilisticamente, em favor dos indivíduos mais aptos, e tem como objetivo selecionar os indivíduos que servirão de pais no processo de cruzamento (GOLDBERG, 1989; TORRES, 2003).

O método da roleta, ou método proporcional à aptidão, é um dos mais utilizados para a seleção. Segundo este método, deve ser criada uma roleta onde cada indivíduo da população é representado nessa roleta proporcionalmente ao seu índice de aptidão.

Dessa maneira, aos indivíduos com alta aptidão é dada uma porção maior da roleta, enquanto aos de aptidão mais baixa é dada uma porção relativamente menor. Finalmente, a roleta é girada um determinado número de vezes, de acordo com o tamanho da população, e de cada giro na roleta é sorteada uma cópia exata do candidato a compor a população intermediária, que irá passar pelos demais operadores de cruzamento e mutação (TORRES, 2003).

Dada uma população com $m$ indivíduos, a probabilidade de seleção $p_{i}$, de cada cromossomo $s_{i}$, com aptidão $f_{i}$, é dada por (LACERDA; CARVALHO, 1999):

$$
p_{i}=\frac{f_{i}}{\sum_{i=1}^{m} f_{i}}
$$

de onde se pode esboçar o gráfico da Figura 4.4, representativo da probabilidade, para uma população de quatro indivíduos $(m=4)$. 


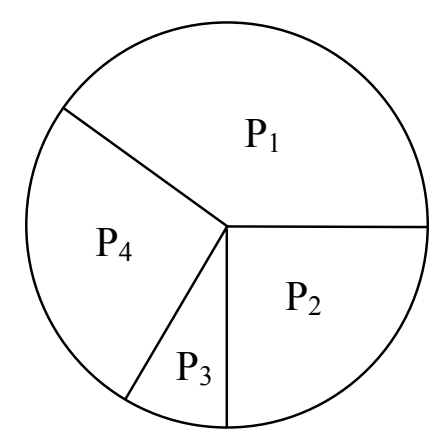

Figura 4.4 - Representação das probabilidades de seleção de cada indivíduo (TORRES, 2003)

Para evitar que um indivíduo de alta aptidão seja eliminado das próximas etapas do processo faz-se uso de uma estratégia conhecida por elitismo. Quando o elitismo é aplicado, o melhor indivíduo sobrevive até a próxima geração sem sofrer alterações. O elitismo é implementado no algoritmo logo antes da operação de seleção pelo método da roleta.

\subsubsection{Cruzamento}

O operador de cruzamento, assim como o de mutação, é utilizado para assegurar que a nova geração seja totalmente nova, apesar de possuir, de alguma forma, características de seus pais, ou seja, a população se diversifica mas mantém características de adaptação adquiridas pelas gerações anteriores (TORRES, 2003).

O cruzamento é aplicado a pares de cromossomos retirados aleatoriamente da população intermediária. De acordo com Henderson e Fu (2004), a maioria das operações de cruzamento são variações de três esquemas básicos de recombinação: cruzamento de um ponto de corte, cruzamento de múltiplos pontos de corte e cruzamento uniforme.

Um exemplo de como ocorre o cruzamento de um ponto de corte entre dois cromossomos pode ser visto na Figura 4.5. Os cromossomos pais são partidos em um ponto e dois novos cromossomos são gerados permutando-se as partes separadas pelo ponto de corte. A posição do corte é escolhida de forma aleatória e, portanto, pode incidir em qualquer posição. 


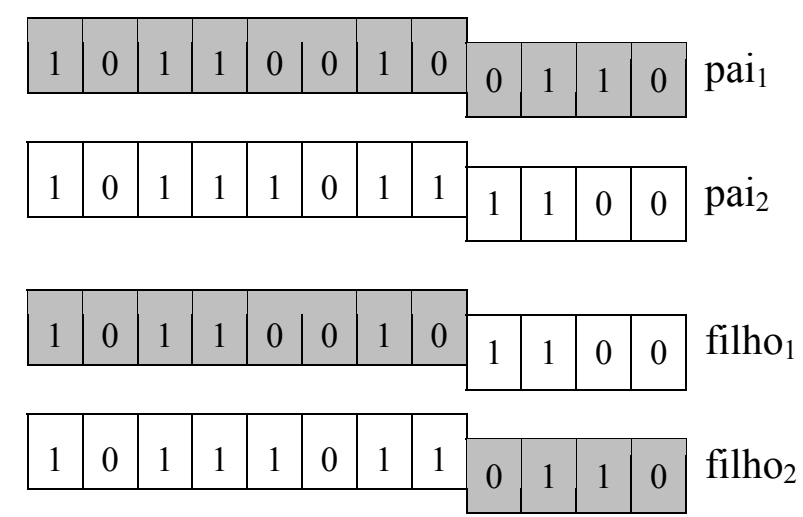

Figura 4.5 - Cruzamento de um ponto

A Figura 4.6 ilustra um exemplo de cruzamento de 2 pontos. Este tem sido o cruzamento de múltiplos pontos mais usado na literatura, pois o aumento excessivo de pontos de corte normalmente não leva a bons resultados, uma vez que destrói com facilidade os blocos de informações herdados das gerações anteriores (LACERDA; CARVALHO, 1999).

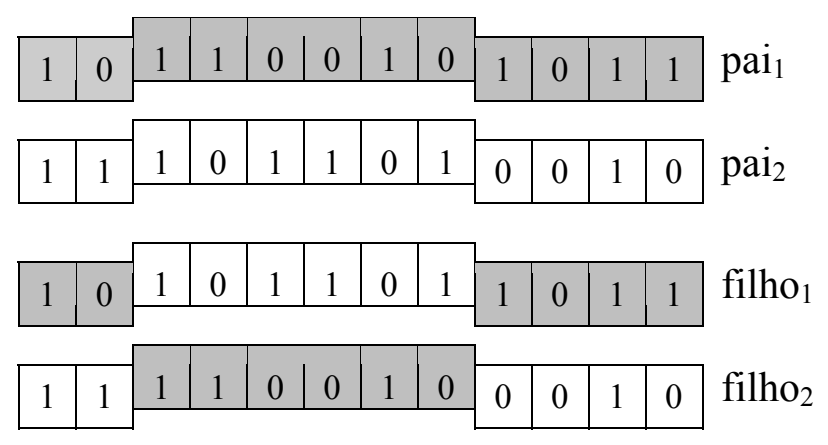

Figura 4.6 - Cruzamento de 2 pontos

Uma outra forma usual de cruzamento é o caso de cruzamento uniforme, em que para cada par de pais é gerada uma máscara de bits aleatórios. Para cada bit da máscara que tiver número 1 , o filho ${ }_{1}$ herdará o gene do pai $_{1}$. Se o bit tiver o número 0 , o filho $_{1}$ herdará o gene do $\mathrm{pai}_{2}$. O filho 2 é gerado com o processo invertido, isto é, para cada bit da máscara com o número 1 , herdará o gene do pai 2 . Caso contrário, herdará o gene do $\mathrm{pai}_{1}$, conforme ilustrado na Figura 4.7 (LACERDA E CARVALHO, 1999). 


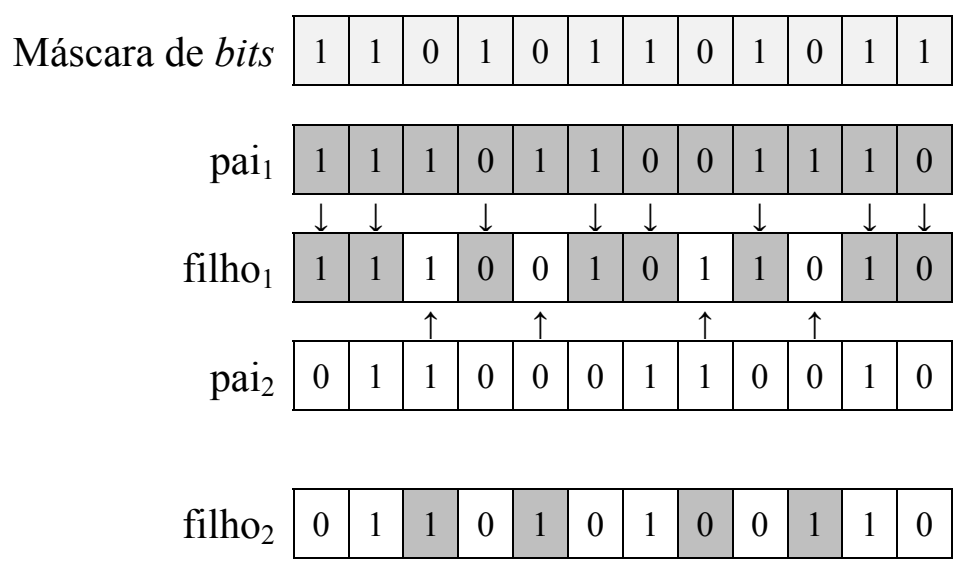

Figura 4.7 - Cruzamento uniforme (TORRES, 2003)

A decisão de quando deve ocorrer cruzamento em um par de cromossomos pais baseia-se em um parâmetro do AG denominado taxa de cruzamento ou probabilidade de cruzamento $\left(\mathrm{p}_{\mathrm{c}}\right)$. É comum a utilização de uma taxa de cruzamento alta $\left(\mathrm{p}_{\mathrm{c}} \geq 80 \%\right)$ devido à eficácia da operação (HENDERSON; FU, 2004).

\subsubsection{Mutação}

O operador de mutação é aplicado logo após o cruzamento. Mutações são pequenas mudanças no código genético resultantes da alteração aleatória de um ou mais genes no cromossomo. A Figura 4.8 ilustra o procedimento de mutação.

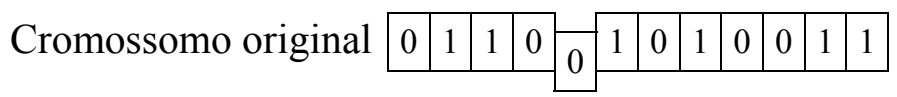

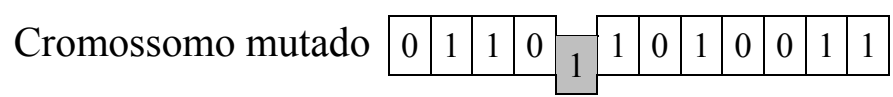

Figura 4.8 - Mutação

A operação de mutação é importante por garantir a possibilidade de exploração de todo o espaço de busca independentemente da população inicial, isto é, a mutação assegura que a probabilidade de se chegar a qualquer ponto de espaço de busca nunca será zero (BIELLI; CARAMIA; CAROTENUTO, 2002).

A decisão de quando o gene de um cromossomo deve sofrer mutação ou não se baseia em um parâmetro do AG denominado taxa de mutação ou probabilidade 
de mutação $\left(\mathrm{p}_{\mathrm{m}}\right)$ (HENDERSON; FU, 2004). Segundo Lacerda e Carvalho (1999), a mutação melhora a diversidade dos cromossomos na população, mas pode destruir informações contidas no cromossomo. Para evitar que isso ocorra deve ser utilizada uma taxa de mutação pequena, mas suficiente para assegurar a diversidade. Henderson e Fu (2004) sugerem a utilização do seguinte cálculo para determinar a chance de cada cromossomo sofrer mutação:

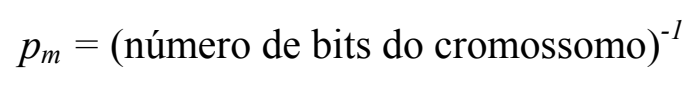

Um cromossomo cuja probabilidade de mutação é igual a 0,01 significa, por exemplo, que a chance de um gene aleatório deste cromossomo ter seu valor alterado é de $1 \%$.

\subsubsection{Critério de Parada}

Não há um critério exato que determina o fím da execução de um Algoritmo Genético. Pode-se adotar como critérios de parada as seguintes situações: a convergência, isto é, quando $95 \%$ a $99 \%$ dos cromossomos apresentam o mesmo desempenho (LACERDA; CARVALHO, 1999), o número máximo de gerações ou quando o algoritmo atinge um valor ótimo pré-definido.

\subsection{Algoritmos Genéticos na Engenharia de Transportes}

Segundo Henderson e Fu (2004), problemas de otimização são bastante freqüentes em processos de Engenharia de Transportes, tais como: planejamento, projeto, manutenção e operações de controle. Devido à natureza complexa dos sistemas de transporte, a maioria destes problemas é de difícil formulação e solução, caracterizados por funções objetivo complexas e grande número de variáveis. Exemplos típicos incluem projetos de transporte público, rotas e horários de veículos, coordenação semafórica e calibração de modelos de simulação. Desta forma, tais problemas não respondem satisfatoriamente a técnicas computacionais tradicionais de otimização, como programação linear ou não-linear e algoritmos de busca que freqüentemente 
requerem uma formulação explícita do problema com uma função objetiva convexa e diferenciável. Assim, processos heurísticos, como os AGs, têm atraído o interesse e grande parte da atenção da comunidade de pesquisa de transportes.

Vários estudos iniciados na última década investigam a aplicabilidade e eficiência dos Algoritmos Genéticos na Engenharia de Transportes. Para a realização desta pesquisa foram revisados detalhadamente os trabalhos de Torres (2003) e Sampaio (2004), que avaliaram a utilização dos AGs na determinação de redes ótimas de transporte público.

Os AGs têm sido muito utilizados na solução de problemas de Engenharia de Transportes computacionalmente intratáveis (Henderson e Fu, 2004), dentre os quais pode-se citar os trabalhos de Cheu et al. (1998); Lee, Young e Chandrasekar (2001); Kim e Rilett (2001); Ma e Abdulhai (2002) e Liu e Mahmassani (2000) para calibração de modelos. Srinivasan et al. (2000); Kim e Kim (2001) e Teodorovic et al. (2001) pesquisaram a utilização de AGs na calibração de modelos baseados em técnicas de inteligência artificial, tais como as Redes Neurais Artificiais e a teoria da lógica fuzzy. Roy e Abdulhai (2003) aplicaram AGs para otimizar parâmetros de modelos de transporte construídos a partir de RNAs e Fischer e Leung (1998) utilizaram AGs na seleção de RNAs para modelação de dados de interação espacial, caso em que se insere esta pesquisa. 


\section{BOOTSTRAP}

Uma passagem das “Aventuras do Barão Munchausen", de Rudolph Erich Raspe, relata a situação em que o Barão está afundando em um lago e, vendo que tudo estava perdido, tem a idéia de tentar emergir puxando os cadarços dos próprios sapatos. Daí o termo bootstrap (EFRON; TIBSHIRANI, 1993). O sentido estatístico do termo é passar a idéia de que, em situações difíceis, deve-se tentar as mais variadas soluções, utilizando o que está disponível.

\subsection{Conceitos}

$\mathrm{Na}$ estatística, as situações difíceis podem ser vistas como os problemas de soluções analíticas complexas, e as variadas soluções possíveis seriam a utilização de uma metodologia com grande quantidade de cálculos, para analisar um pequeno conjunto de dados disponíveis (LAVORANTI, 2003).

O bootstrap é uma metodologia para análise estatística computacionalmente intensiva, introduzida por Efron (1979), que teve grande desenvolvimento nos últimos anos, principalmente devido ao avanço computacional. É um método de simulação utilizado para inferências estatísticas, com base nos dados de uma única amostra existente.

A idéia chave do método é a retirada de réplicas da amostra original, para com elas estimar, por exemplo, o erro padrão de algum resultado estatístico. Segundo Efron e Tibshirani (1993), o bootstrap elimina a necessidade de derivações matemáticas complexas para análise estatística e também pode ser utilizado em casos em que não há 
um número suficiente de dados, principalmente devido a altos custos de mensuração ou outras restrições.

O bootstrap pode ser implementado tanto na estatística paramétrica quanto na não-paramétrica, dependendo apenas do conhecimento do problema. Se a forma da função de distribuição da amostra inicial $(F)$ é conhecida, trata-se do bootstrap paramétrico. Neste caso, o bootstrap depende das suposições do modelo paramétrico e pode fornecer estimativas mais precisas do que métodos tradicionais. O bootstrap nãoparamétrico é um modelo de suposições livres, cujas estimativas não são tão precisas, mas é vantajoso quando se desconhece a função de distribuição. Devido a essa característica, o método não-paramétrico é o mais usual (SALINAS, 1998).

\subsection{Desenvolvimento de Aplicações}

Operacionalmente, o procedimento bootstrap consiste na reamostragem de mesmo tamanho e com reposição dos dados da amostra original, e cálculo da estatística de interesse para cada reamostra bootstrap (pseudo-dados) (LAVORANTI, 2003).

No caso não-paramétrico, o método bootstrap reamostra os dados de acordo com uma distribuição empírica estimada, tendo em vista que não se conhece a distribuição subjacente aos dados. No caso paramétrico, quando se tem informação suficiente sobre a forma da distribuição dos dados, a amostra bootstrap é formada realizando-se a amostragem diretamente a partir desta distribuição. A distribuição da estatística de interesse aplicada aos valores da amostra bootstrap, condicional aos dados observados, é definida como a distribuição bootstrap dessa estatística (LAVORANTI, 2003).

\subsubsection{Descrição do Procedimento Bootstrap}

Deseja-se, por exemplo, estimar um parâmetro ou determinar o erro padrão ou intervalo de confiança deste parâmetro. 
Seja $x=\left(x_{1}, x_{2}, \ldots, x_{n}\right)$ uma amostra de variáveis aleatórias independentes de tamanho $n$ e função de distribuição de probabilidade $F$ desconhecida e $\hat{F}_{n}$ uma função de distribuição empírica de $x$, que associa a cada valor da amostra a probabilidade $1 / n$.

A idéia do bootstrap é sortear amostras aleatórias de tamanho $m$, a partir da função de distribuição empírica $\hat{F}_{n}$, com reposição. Usualmente, a amostra bootstrap é do mesmo tamanho da amostra original $(m=n)$.

Assim, de $x=\left(x_{1}, x_{2}, \ldots, x_{m}\right)$ toma-se $B$ amostras bootstrap de tamanho $m$,

$$
\begin{gathered}
x_{1}^{*}=\left(x_{2}, x_{4}, x_{m}, \ldots, x_{3}\right) \\
x_{2}^{*}=\left(x_{3}, x_{5}, x_{1}, \ldots, x_{9}\right) \\
\ldots \\
x_{B}^{*}=\left(x_{1}, x_{8}, x_{1}, \ldots, x_{5}\right)
\end{gathered}
$$

calcula-se o parâmetro desejado para cada uma das $B$ amostras bootstrap e, finalmente, determina-se o erro padrão ou intervalo de confiança pelo padrão amostral das $B$ réplicas.

O conjunto de dados bootstrap é formado pelas $B$ amostras $\left(x_{1}^{*}, x_{2}^{*}, \ldots\right.$, $\left.x_{B}{ }^{*}\right)$, sendo que em cada amostra $x_{b}{ }^{*}$ alguns valores $\left(x_{i}\right)$ podem não aparecer, ou aparecer mais de uma vez. De acordo com Efron (1987), o número $B$ de réplicas necessárias varia de acordo com o que se deseja estimar, para o caso de estimativa do erro padrão, por exemplo, esse valor pode variar de 25 a 100 réplicas.

\section{Exemplo:}

Amostra original: $x=(0,009 ; 0,631 ; 0,116 ; 0,728 ; 0,212 ; 0,144 ; 0,064$; $0,765 ; 0,021 ; 0,195)$

Parâmetro: $\mathrm{s}(x)=0,289$ (média amostral)

$$
B=25
$$




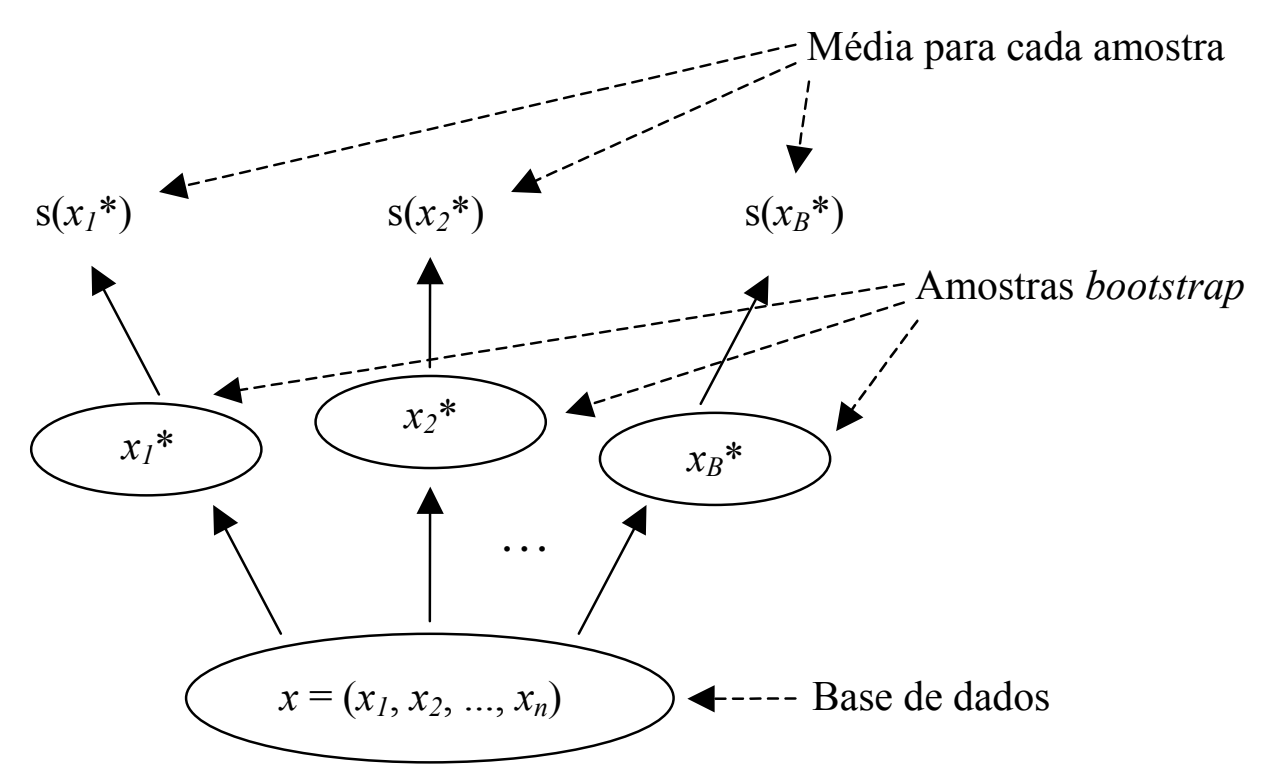

Figura 5.1 - Esquema do processo bootstrap (EFRON; TIBSHIRANI, 1993)

A partir da geração das $B$ amostras, apresentada esquematicamente na Figura 5.1, calcula-se a média $\left(\mathrm{s}\left(x_{b} *\right)\right)$ para cada amostra. A estimativa bootstrap do erro padrão da média é o desvio padrão das réplicas, calculada da seguinte forma e apresentada na Tabela 5.1:

$$
\begin{gathered}
\hat{e} p_{B}=\left\{\sum_{b=1}^{B} \frac{\left[s\left(x_{b}^{*}\right)-s(\cdot)\right]^{2}}{B-1}\right\}^{1 / 2} \\
s(\cdot)=\sum_{b=1}^{B} \frac{s\left(x_{b}^{*}\right)}{B}
\end{gathered}
$$




\begin{tabular}{|c|c|c|c|c|c|c|c|c|c|c|c|}
\hline Amostra & & & & & & & & & & & $s\left(x^{*}\right)$ \\
\hline$x_{1} *$ & 0,212 & 0,728 & 0,212 & 0,116 & 0,631 & 0,116 & 0,212 & 0,765 & 0,116 & 0,195 & $\mathbf{0 , 3 3 0}$ \\
\hline$x_{2}{ }^{*}$ & 0,765 & 0,116 & 0,144 & 0,144 & 0,728 & 0,195 & 0,144 & 0,765 & 0,064 & 0,212 & 0,328 \\
\hline$x_{3}{ }^{*}$ & 0,195 & 0,212 & 0,631 & 0,116 & 0,195 & 0,195 & 0,021 & 0,144 & 0,631 & 0,144 & 0,248 \\
\hline$x_{4}{ }^{*}$ & 0,064 & 0,144 & 0,631 & 0,116 & 0,064 & 0,116 & 0,021 & 0,195 & & & \\
\hline$x_{5}{ }^{*}$ & 144 & 0,064 & 0,116 & 0,728 & 0,631 & 0,765 & 0,009 & 0,728 & 0,195 & 0,009 & 0.339 \\
\hline$x_{6}{ }^{*}$ & 0,064 & 0,021 & 0,144 & 0,009 & 0,195 & 0,064 & 0,765 & 0,728 & 0,116 & 0,021 & 0,213 \\
\hline$x_{7}{ }^{*}$ & 0,631 & 0,765 & 0,144 & 0,212 & 0,631 & 0,009 & 0,116 & 0,212 & 0,631 & 0,195 & 0,355 \\
\hline$x_{8}{ }^{*}$ & 0,009 & 0,009 & 0,116 & 0,631 & 0,631 & 0,765 & 0,021 & 0,631 & 0,631 & 0,021 & $\mathbf{0 , 3 4 7}$ \\
\hline$x_{9} *$ & 0,064 & 0,728 & 0,021 & 0,212 & 0,195 & 0,144 & 0,021 & 0,116 & 0,212 & 0,195 & 0,191 \\
\hline$x_{10} *$ & 0,144 & 0,009 & 0,116 & 0,009 & 0,631 & 0,144 & 0,064 & 0,212 & 0,728 & 0,144 & 0,220 \\
\hline$x_{11}{ }^{*}$ & 0,021 & 0,212 & 0,009 & 0,212 & 0,116 & 0,021 & 0,064 & 0,195 & 0,064 & 0,021 & \\
\hline$x_{12} *$ & 0,765 & 0,195 & 0,212 & 0,195 & 0,728 & 0,195 & 0,1 & 0,728 & 0,009 & 0,009 & \\
\hline$x_{13} *$ & 0,195 & 0,212 & 0,631 & 0,212 & 0,195 & 0,144 & 0,116 & 0,021 & 0,728 & 0,728 & 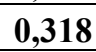 \\
\hline$x_{14} *$ & 0,009 & 0,631 & 0,116 & 0,728 & 0,631 & 0,765 & 0,728 & 0,765 & 0,212 & 0,195 & 0,478 \\
\hline$x_{15}{ }^{*}$ & 0,195 & 0,212 & 0,009 & 0,212 & 0,765 & 0,021 & 0,064 & 0,631 & 0,728 & 0,765 & 0,360 \\
\hline$x_{16} *$ & 0,009 & 0,144 & 0,212 & 0,116 & 0,631 & 0,144 & 0,009 & 0,631 & 0,116 & 0,212 & 0,223 \\
\hline$x_{17} *$ & 0,195 & 0,631 & 0,765 & 0,009 & 0,212 & 0,195 & 0,021 & 0,728 & 0,021 & 0,765 & 0,354 \\
\hline$x_{18} *$ & 0,116 & 0,728 & 0,144 & 0,021 & 0,631 & 0,728 & 0,009 & 0,631 & 0,631 & 0,631 & $\mathbf{0}$, \\
\hline$x_{19}{ }^{*}$ & 0,631 & 0,064 & 0,212 & 0,728 & & 0,728 & 0 & 0 , & 16 & 0 & \\
\hline$x_{20} *$ & 0,195 & 0,064 & 0,064 & 0,009 & 0,144 & 0,116 & 0,144 & 0,021 & 0,765 & 0,765 & 0,229 \\
\hline$x_{21} *$ & 0,144 & 0,064 & 0,116 & 0,021 & 0,631 & 0,212 & 0,765 & 0,195 & 0,009 & 0,765 & 0,292 \\
\hline$x_{22} *$ & 0,021 & 0,144 & 0,021 & 0,144 & 0,728 & 0,144 & 0,728 & 0,021 & 0,064 & 0,009 & 0,202 \\
\hline$x_{23} *$ & 0,728 & 0,631 & 0,195 & 0,195 & 0,009 & 0,009 & 0,116 & 0,631 & 0,009 & 0,631 & 0,316 \\
\hline$x_{24} *$ & 0,631 & 0,144 & 0,195 & 0,064 & 0,116 & 0,728 & 0,195 & 0,021 & 0,021 & 0,765 & 0,288 \\
\hline \multirow[t]{2}{*}{$x_{25} *$} & 0,144 & 0,009 & 0,116 & 0,144 & 0,064 & 0,064 & 0,212 & 0,144 & 0,116 & 0,009 & 0,102 \\
\hline & & & & & & & & & & & 0,098 \\
\hline
\end{tabular}

Tabela 5.1 - Exemplo de aplicação do bootstrap para estimativa do erro padrão

Embora inicialmente utilizada para o cálculo do erro padrão e do intervalo de confiança, a técnica bootstrap é uma ferramenta que pode ser usada para abordar uma ampla variedade de problemas estatísticos, como regressão logística e problemas de classificação, estimação de densidade, regressão não-linear, análise de séries temporais, etc, sendo aplicado em diferentes áreas como psicologia, física, geologia, biologia, genética, medicina, engenharia e química. A seguir, serão apresentadas as principais aplicações do procedimento bootstrap.

\subsubsection{Estimativa do Erro Padrão}

O erro padrão é uma maneira usual de indicar ou verificar a precisão estatística de um parâmetro de interesse, que pode ser a mediana, a média, etc. No 
procedimento apresentado anteriormente, verifica-se a aplicação do bootstrap para estimativa do erro padrão da média de uma amostra objeto de estudo.

\subsubsection{Estimativa de Intervalos de Confiança}

O método mais simples para estimar intervalos de confiança por bootstrap é o método percentil. Este método consiste em encontrar a distribuição $\hat{F}_{n}$ bootstrap e calcular os percentis da distribuição que correspondem aos limites inferiores $\left(L_{I}\right)$ e superiores $\left(L_{S}\right)$, respectivamente, do intervalo de confiança $(1-\alpha) \quad 100 \%$ (EFRON; TIBSHIRANI, 1993).

De acordo com Efron (1987), o número de réplicas para obtenção de um intervalo de confiança bootstrap é bem maior do que o usado para estimar o erro padrão de um estimador. Geralmente são utilizadas 1000 réplicas.

O exemplo seguinte, adaptado de Fred (2003), ilustra a estimativa do intervalo de confiança a $(1-\alpha) 100 \%$ para $\alpha=0,0005$, utilizando a ferramenta bootstrap.

Exemplo:

Amostra original: $x=\left(x_{1}, x_{2}, \ldots, x_{n}\right)$

Parâmetro: $\mathrm{s}(x)=$ média amostral

Passo 1: Selecionar 1000 amostras bootstrap:

$$
\begin{gathered}
x_{1}^{*}=\left(x_{2}, x_{4}, x_{m}, \ldots, x_{3}\right) \\
x_{2}^{*}=\left(x_{3}, x_{5}, x_{1}, \ldots, x_{9}\right) \\
\ldots \\
x_{1000^{*}}=\left(x_{1}, x_{8}, x_{1}, \ldots, x_{5}\right)
\end{gathered}
$$

Passo 2: Calcular s $\left(x_{b}^{*}\right)$ para cada amostra.

Passo 3: Ordenar as estimativas por ordem crescente:

$$
\mathrm{s}\left(x_{(1)} *\right)<\mathrm{s}\left(x_{(2)} *\right)<\mathrm{s}\left(x_{(3)} *\right)<\ldots<\mathrm{s}\left(x_{(1000)} *\right)
$$




$$
\mathrm{s}\left(x_{(k)} *\right) \text { é o k-ésimo menor valor de } \mathrm{s}\left(x_{1}^{*}\right), \ldots, \mathrm{s}\left(x_{1000^{*}}\right)
$$

Passo 4: O intervalo de confiança a $(1-\alpha) 100 \%$ é dado por:

$$
\begin{aligned}
& \left(\mathrm{s}\left(x_{(q)} *\right), \mathrm{s}\left(x_{(q 2)} *\right)\right) \\
& \mathrm{q}_{1}=B \alpha / 2 \\
& \mathrm{q}_{2}=B-\mathrm{q}_{1}+1
\end{aligned}
$$

Para $\alpha=0,0005$ e $B=1000$, tem-se $\mathrm{q}_{1}=25$ e $\mathrm{q}_{2}=976$.

O intervalo de confiança é, então, $\left.\left(\mathrm{s}\left(x_{(25)}\right)^{*}\right), \mathrm{s}\left(x_{(976)} *\right)\right)$.

O bootstrap também pode ser usado para testes de hipótese, que podem consistir, por exemplo, da comparação entre as médias de diferentes populações (PIRES; BRANCO, 1996).

\subsection{Aplicação do Bootstrap a Modelos Neurais de Interação Espacial}

Uma abordagem bastante comum para avaliar o desempenho da predição de modelos de redes neurais consiste em dividir o conjunto de dados de forma aleatória em três subconjuntos, por exemplo: o primeiro para treinamento da rede $(50 \%$ do total de dados), o segundo para validação ( $25 \%$ do total de dados) e o terceiro para teste ( $25 \%$ do total de dados). Tornou-se prática comum fixar estes conjuntos.

No entanto, experiências recentes têm demonstrado que esta abordagem é muito sensível à forma adotada para divisão dos dados. Fischer e Reismann (2002a) mostraram que a variabilidade dos resultados devida a diferentes divisões dos dados é significativamente maior do que a decorrente da aplicação de diferentes topologias de redes neurais.

Fischer e Reismann (2002b) utilizaram a estimativa por bootstrapping com reposição para superar este problema. Desta forma, os erros de predição e os erros nas estimativas de parâmetros são diretamente observados e estatísticas relativas à confiabilidade dos parâmetros podem ser facilmente computadas. 


\section{METODOLOGIA}

Este capítulo descreve o método proposto para o desenvolvimento desta pesquisa. Assim, são apresentadas as etapas de tratamento e formatação dos dados utilizados, construção dos modelos neurais de interação espacial, utilização dos Algoritmos Genéticos na seleção das Redes Neurais Artificiais e da estimação por bootstrap na fase de divisão dos dados.

\subsection{Análise dos Dados do Sistema de Educação}

Para a realização deste projeto de pesquisa foi proposto o emprego de dados que refletem a evolução espacial da demanda por serviços municipais de educação numa cidade média brasileira (São Carlos, SP) ao longo de dois anos.

Esta etapa do trabalho está fundamentada na metodologia para preparação da base de dados para o estudo de caso, apresentada em Lima et al. (2001) para a localização espacial dessa demanda com o auxílio de um Sistema de Informações Geográficas (SIG), através do cadastro municipal do SAAE (Serviço Autônomo de Água e Esgoto) contendo as coordenadas UTM (Projeção Universal Transversal de Mercator) de todos os endereços da cidade, e partindo da hipótese bastante plausível de que todo lote (residência) que apresentasse demanda por serviços de educação seria servido de água (segundo dados do próprio SAAE, a distribuição de água tratada atinge 99,5\% da população).

Segundo esta metodologia, o passo inicial do projeto consiste no levantamento do endereço residencial e da escola em que estuda cada um dos alunos das 
Creches e EMEIs (Escolas Municipais de Educação Infantil), junto à Secretaria Municipal de Educação de São Carlos. A seguir, esses dados devem ser tratados, pois mesmo quando são disponibilizados em planilhas eletrônicas, estas são em geral preenchidas a partir dos dados de matrícula dos alunos, sem grande padronização. Este é um problema comum nos bancos de dados municipais. Além disso, todos os dados devem passar por um processo de formatação praticamente caso a caso, para que os endereços dos alunos fiquem exatamente iguais aos do cadastro do SAAE e o SIG possa identificá-los e localizá-los espacialmente.

Depois de formatados, os dados referentes aos alunos matriculados no sistema municipal de educação devem ser lançados na base de dados do SIG. Na prática, isso significa que cada aluno tem seu endereço localizado num mapa (demanda), também no SIG, em que está representado o sistema viário da cidade. Do mesmo modo, cada uma das Creches e EMEIs são também localizadas espacialmente (oferta).

\subsection{Construção dos Modelos de Interação Espacial}

O primeiro passo após a localização dos dados de demanda e oferta é a identificação dos fluxos entre estes. Para isso é necessário agregar os primeiros em zonas, determinando, então, os fluxos entre estas e os pontos de oferta. Em seguida, calcula-se os valores de atração dos pontos de oferta, o total de viagens produzidas em cada zona e as distâncias entre as Creches e EMEIs e os centróides dos setores.

Todos os dados devem ser, então, normalizados de acordo com o seguinte procedimento:

- Para distâncias: $\quad$ distância $_{\text {norm. }}=\frac{\text { distância }}{\text { máx(distância })}$

- Para atração, produção e fluxo:

$$
Y_{i}=\left[\frac{\left(X_{i}-X_{\text {min }}\right) *\left(Y_{\text {max }}-Y_{\text {min }}\right)}{X_{\text {máx }}-X_{\text {min }}}\right]+Y_{\text {min }}
$$

Sendo: $Y_{i}=$ valor (de atração, produção ou fluxo) normalizado;

$X_{i}=$ valor a ser normalizado; 
$X_{\min }=$ menor valor do intervalo de origem de normalização;
$X_{\max }=$ maior valor do intervalo de origem de normalização;
$Y_{\min }=$ menor valor do intervalo de destino de normalização $(0,1)$
$Y_{\operatorname{máx}}=$ maior valor do intervalo de destino de normalização $(0,9)$.

Sugere-se adotar a normalização entre 0,1 e 0,9, por ser bastante utilizada em pesquisas dessa natureza. Após este pré-processamento, os dados devem ser lançados no software simulador de Redes Neurais Artificiais.

Para a construção dos modelos de redes neurais, com três nós de entrada (total de viagens produzidas, total de viagens atraídas e distâncias) e um de saída (fluxos), os conjuntos de dados do ano 2000 (conjunto de Creches e de EMEIs) devem ser divididos de forma aleatória em três subconjuntos: o primeiro para treinamento da rede ( $50 \%$ do total de dados), o segundo para validação ( $25 \%$ do total de dados) e o terceiro para teste $(25 \%$ do total de dados). Posteriormente, todos os dados são utilizados para estimar os fluxos futuros a partir de pontos conhecidos de origem e destino. Estes devem ser, então, comparados aos fluxos reais observados no ano de 2001, através do cálculo do Erro Normalizado, segundo a Equação 3.7. Todo este procedimento é repetido por três vezes, isto é, para os dados divididos aleatoriamente de três maneiras diferentes, em subconjuntos de treinamento (50\%), validação (25\%) e teste $(25 \%)$.

$\mathrm{Na}$ etapa de construção das redes neurais artificiais devem ser testadas várias redes com diferentes configurações, isto é, variando-se os valores de taxa de aprendizagem $(\mathrm{L})$, momentum $(\mathrm{M})$ e o número de nós da camada intermediária $(\mathrm{N})$.

\subsection{Seleção dos Modelos Neurais de Interação Espacial através de Algoritmos Genéticos}

O desenvolvimento do Algoritmo Genético é iniciado a partir da definição da população de cromossomos. Neste caso, cada cromossomo representa uma rede neural testada, ou seja, cada cromossomo contém, em notação binária, os possíveis valores de taxa de aprendizado (learning rate, L), momentum $(\mathrm{M})$ e número de nós na 
camada intermediária, como ilustrado na Figura 6.1 (AKAMINE; SILVA; LIMA, 2004).

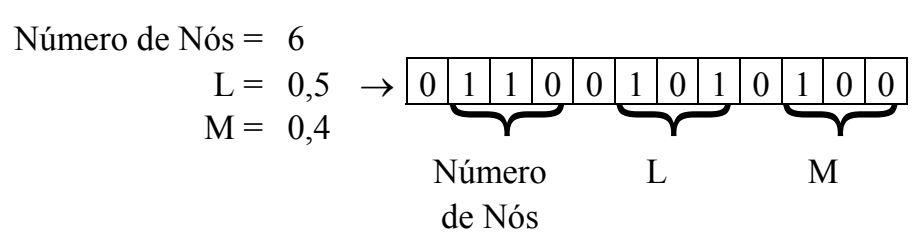

Figura 6.1 - Representação binária dos parâmetros de uma rede neural

Adotando-se o Erro Normalizado de cada modelo neural como sendo a função a ser minimizada, ordena-se a população de cromossomos segundo os valores de EN (Equação 3.7), de forma decrescente. Em seguida, deve-se construir uma coluna de aptidão, normalizando os valores da função objetivo no intervalo de 0 a 2 , de forma que ao maior valor é atribuída aptidão igual a 2 e, ao menor valor, aptidão igual a 0 .

Uma vez determinado o valor da aptidão de cada cromossomo, determina-se uma coluna de aptidão acumulada para iniciar o procedimento de seleção. Nesta fase, gera-se um número aleatório $r$ no intervalo [0, somatotal], em que somatotal é a soma de todas as aptidões. Por fim, o cromossomo selecionado é o primeiro (seguindo a tabela de cima para baixo) com aptidão acumulada maior que $r$ e sua cópia deve ser alocada na população intermediária. Os mesmos passos são, então, repetidos até o preenchimento da população intermediária com o número desejado de cromossomos.

Como é interessante que o melhor indivíduo passe de uma geração a outra sem alterações, faz-se uso do elitismo, segundo o qual o cromossomo de maior aptidão é imediatamente alocado na população seguinte, sem sofrer nenhum tipo de alteração.

Após a conclusão da etapa de seleção, devem ser aplicados os operadores de cruzamento e de mutação. O operador de cruzamento é aplicado aos cromossomos da população intermediária, separados aleatoriamente aos pares, gerando os cromossomos filhos. O processo de mutação consiste na inversão dos valores de alguns bits da população. 


\subsection{Utilização da Estimativa por Bootstrap}

A implementação desta abordagem inicia-se com a re-amostragem com reposição dos conjuntos de dados das Creches e EMEIs do ano de 2000. Devem ser gerados 50 conjuntos independentes e estes conjuntos são, então, divididos de acordo com a seguinte proporção: $50 \%$ dos dados utilizados para treinamento, $25 \%$ dos dados utilizados para validação e $25 \%$ dos dados utilizados para teste. A rede utilizada neste caso é a selecionada através dos Algoritmos Genéticos.

Cada rede treinada deve ser, então, utilizada para estimar fluxos futuros a partir de pontos conhecidos de origem e destino e estes são comparados aos fluxos reais observados no ano de 2001, através do cálculo do Erro Normalizado, segundo a Equação 3.7.

A variabilidade da estatística EN dos 50 conjuntos bootstrap de dados de Creches e EMEIs é representada pelo desvio padrão do resultado das estimativas das 50 representações.

\subsection{Análise Espacial dos Resíduos (erros) das Previsões}

Para a avaliação da distribuição espacial dos erros, devem ser elaborados mapas da cidade estudada apresentando, através da espessura das linhas que representam os fluxos, os Erros Normalizados, tal como sugerido por Black; Cheung e Suthanaya (2003). Estes valores devem ser calculados utilizando os resultados das melhores estimativas para o ano 2001 e os fluxos observados neste mesmo ano, e lançados no SIG através do método de alocação Tudo ou Nada. Neste método, todo fluxo de tráfego entre um par $\mathrm{O} / \mathrm{D}$ é alocado ao caminho mais curto que liga a origem e o destino.

\subsection{Atividades Desenvolvidas}

Nesta seção é apresentada uma síntese das atividades realizadas no estudo das alternativas para a construção dos modelos neurais de interação espacial, 
com o intuito de permitir uma maior compreensão dos procedimentos desenvolvidos, bem como auxiliar na elaboração de trabalhos futuros.

1. Revisão bibliográfica sobre assuntos pertinentes ao projeto, como modelos de interação espacial, redes neurais artificiais, algoritmos genéticos e bootstrap;

2. Obtenção do mapa, em formato digital, da cidade de São Carlos com sua rede viária, atualizado até 2000 ;

3. Obtenção do cadastro contendo as coordenadas UTM de todos os endereços da cidade de São Carlos servidos pelo Serviço Autônomo de Água e Esgoto (SAAE);

4. Obtenção do cadastro digital dos limites dos setores censitários da cidade de São Carlos utilizado pelo IBGE em 2000;

5. Obtenção, na Secretaria Municipal de Educação, do endereço e instituição de ensino dos alunos das Creches e EMEIs dos anos 2000 e 2001;

6. Formatação dos endereços dos alunos e das instituições de ensino;

7. Lançamento dos endereços dos alunos e das instituições de ensino no SIG TransCAD, a partir do cadastro do SAAE;

8. Obtenção dos mapas contendo a distribuição espacial individualizada dos alunos, diferenciados por cores de acordo com a escola que freqüentam, nos anos 2000 e 2001;

9. Obtenção dos mapas contendo a distribuição espacial dos alunos em setores censitários, nos anos 2000 e 2001;

10. Construção das matrizes de distâncias entre os centróides dos setores censitários e as Creches ou EMEIs, nos anos 2000 e 2001;

11.Obtenção do número total de alunos de cada instituição de ensino nos anos 2000 e 2001;

12.Obtenção do número total de alunos residentes em cada setor censitário nos anos 2000 e 2001;

13. Construção das matrizes de fluxos entre os setores censitários (pontos de origem) e as Creches ou EMEIs (pontos de destino) nos anos 2000 e 2001; 
14.Previsão do fluxo de viagens do ano 2001 a partir do Método Gravitacional, no SIG TransCAD;

15. Construção de tabelas contendo os valores normalizados dos fluxos e distâncias entre os pontos de origem e destino, além do total de viagens produzidas nos pontos de origem e do total de viagens atraídas nos pontos de destino, no ano 2000;

16. Construção de tabelas contendo os valores normalizados das distâncias entre os pontos de origem e destino, além do total de viagens produzidas nos pontos de origem e do total de viagens atraídas nos pontos de destino, no ano 2001;

17.Divisão aleatória dos dados do ano 2000, de 3 maneiras diferentes, em 3 subconjuntos (treinamento, validação e teste);

18.Previsão dos fluxos (normalizados) do ano 2001 a partir de diversas configurações de Redes Neurais Artificiais, no software EasyNN-plus;

19. Comparação dos fluxos estimados com os fluxos reais do ano 2001 pelo cálculo do Erro Normalizado;

20.Lançamento dos resultados obtidos pelas Redes Neurais Artificiais no software Neural Nets Genealogy;

21. Obtenção de novas configurações de redes a serem testadas;

22.Previsão dos fluxos do ano 2001 pelas novas redes e lançamento dos novos resultados obtidos no software Neural Nets Genealogy em um processo iterativo, até que se atinja o critério de parada estipulado;

23. Análise dos resultados obtidos pelos modelos neurais de interação espacial, através da construção de gráficos e comparações com os resultados obtidos pelo Método Gravitacional;

24.Re-amostragem dos dados do ano 2000 com reposição, de 25 a 100 vezes;

25.Estimativa dos fluxos do ano 2001 a partir dos novos conjuntos de dados do ano 2000;

26.Cálculo do Erro Normalizado e utilização da estimativa por bootstrap; 
27.Construção de mapas apresentando os erros das estimativas do Método Gravitacional e dos modelos neurais de interação espacial, através da espessura das linhas que representam os fluxos;

28. Análise espacial dos erros das previsões. 


\title{
7. RESULTADOS E ANÁLISE DOS RESULTADOS
}

\begin{abstract}
Neste capítulo são apresentados os resultados obtidos com o desenvolvimento dos procedimentos descritos no capítulo anterior, assim como as análises dos mesmos e a análise espacial dos resíduos (erros) das previsões. Também é mostrada com mais detalhes a aplicação das Redes Neurais Artificiais nos modelos de interação espacial, através da construção de gráficos que auxiliam o entendimento da lógica dos modelos neurais e que também podem ser utilizados como ferramentas de planejamento mais simples e diretas.
\end{abstract}

\subsection{Modelos Neurais de Interação Espacial}

No estudo de Lima et al. (2001), cerca de 16000 endereços foram localizados espacialmente com o auxílio de um SIG, caracterizando a distribuição espacial dos alunos de cada Creche e EMEI ao longo dos anos 2000 e 2001.

Os mapas gerados com o auxílio do SIG TransCAD, contendo a distribuição espacial individualizada dos alunos divididos pelo tipo de escola (Creches e EMEIs) são apresentados na seqüência, nas Figuras 7.1, 7.2, 7.3 e 7.4. 


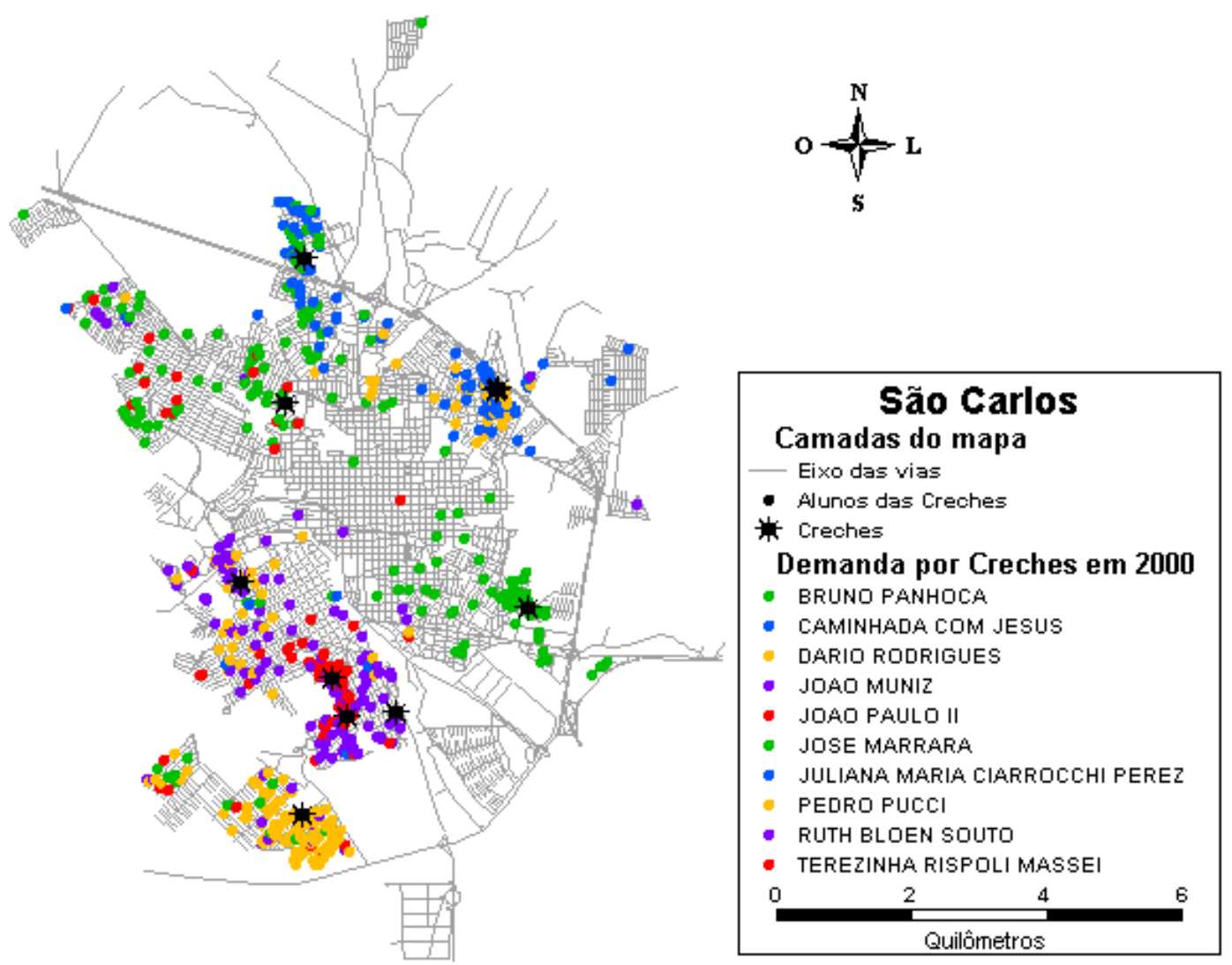

Figura 7.1 - Demanda por Creches em 2000

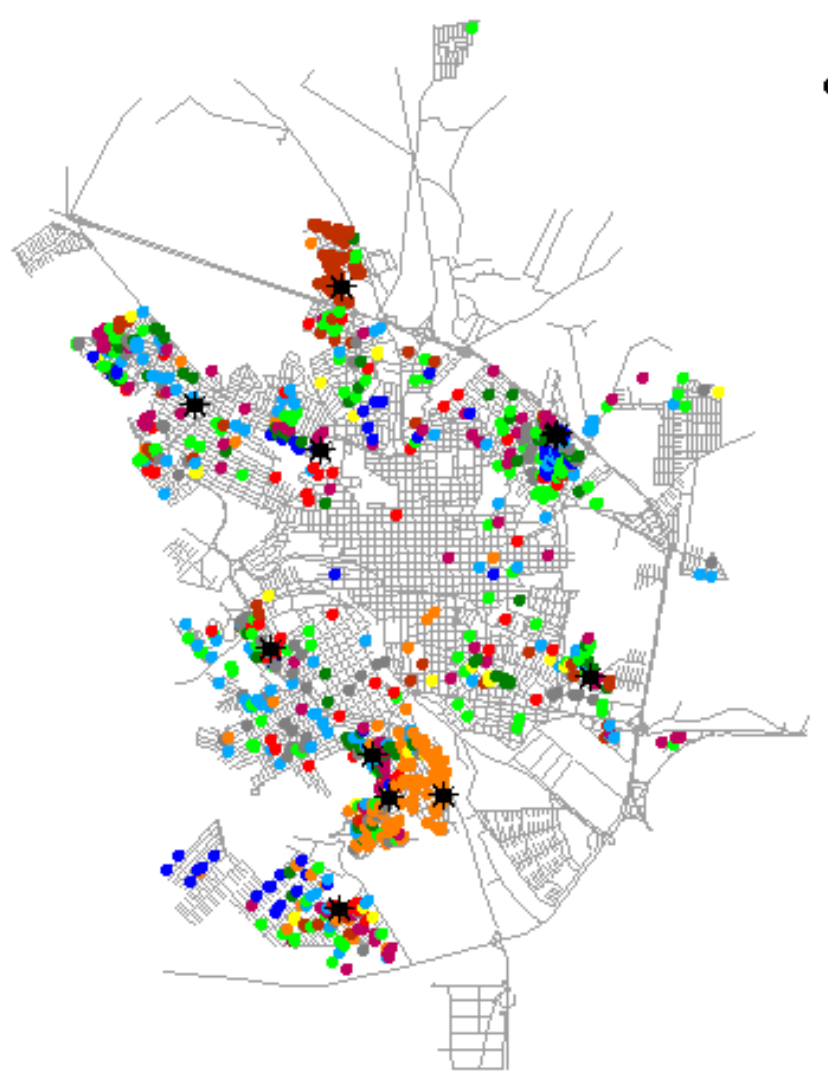<smiles>NC1CSC([Tl])O1</smiles>

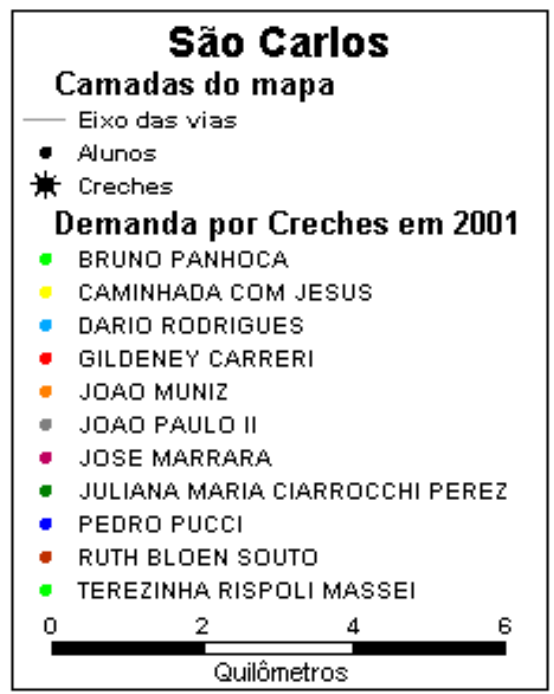

Figura 7.2 - Demanda por Creches em 2001 


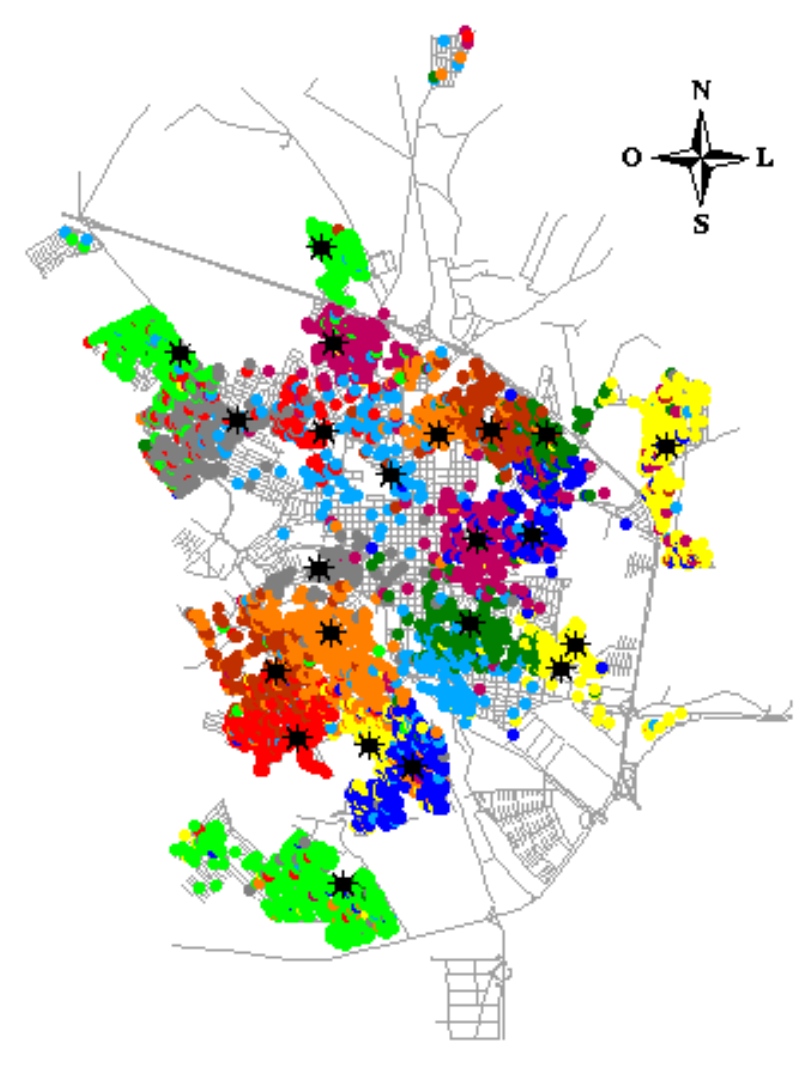

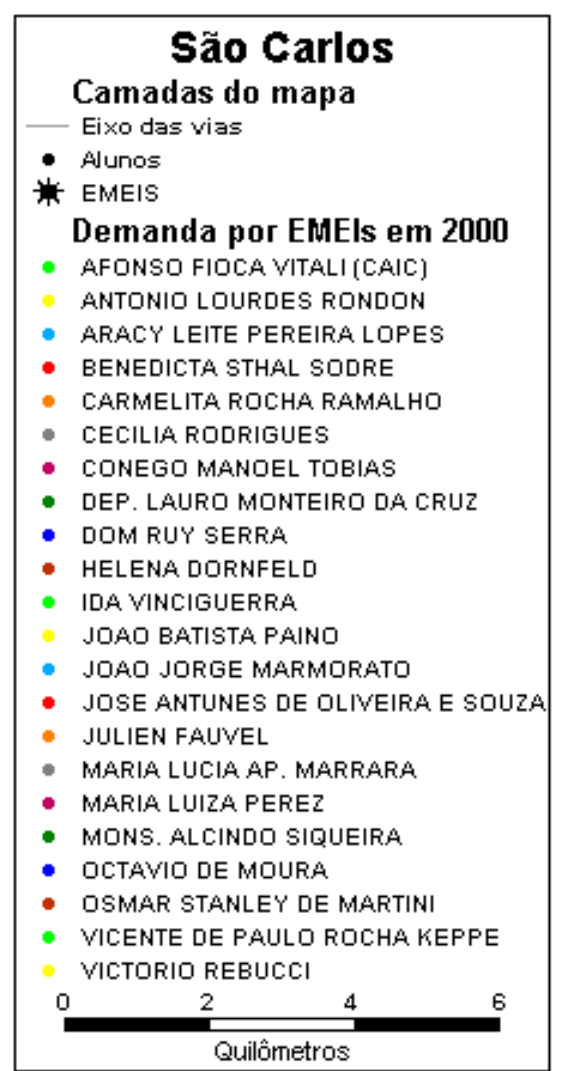

Figura 7.3 - Demanda por EMEIs em 2000

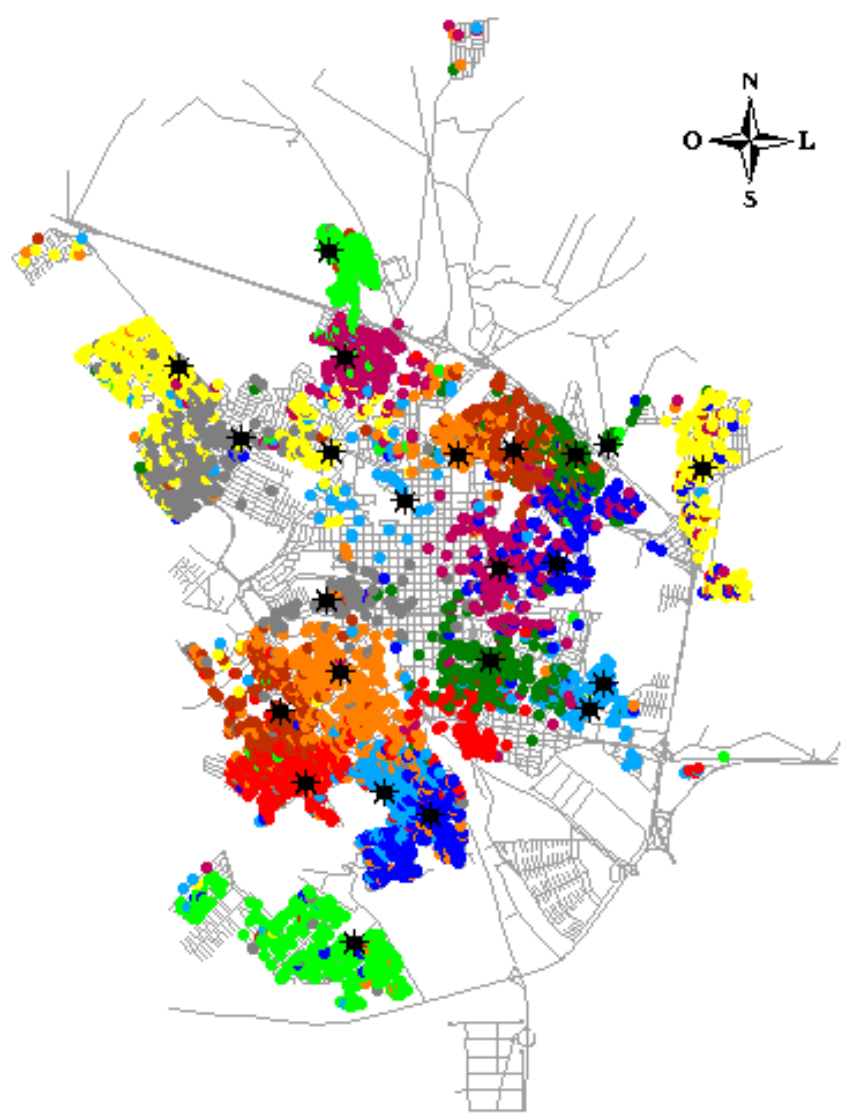

\begin{tabular}{|c|}
\hline 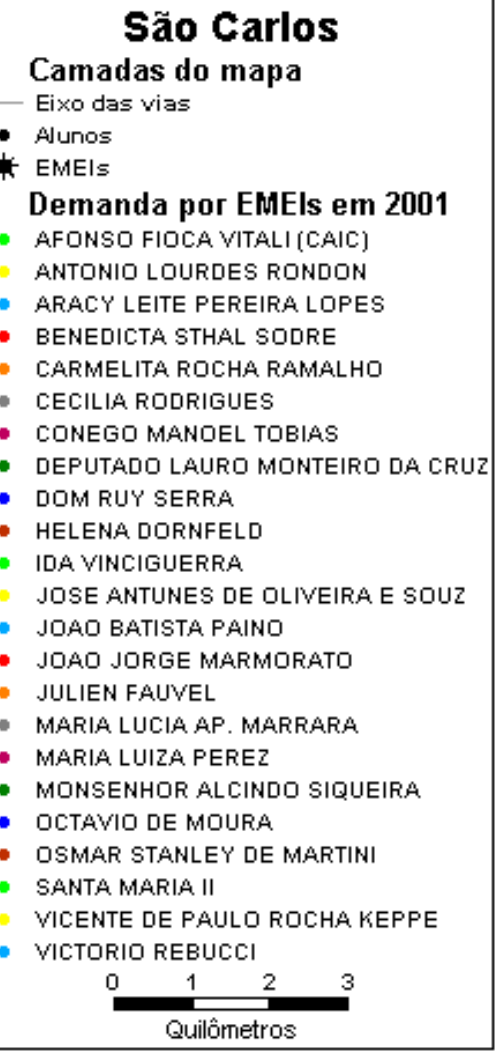 \\
\hline
\end{tabular}

Figura 7.4 - Demanda por EMEIs em 2001 
Após a localização no mapa, os dados de demanda foram agregados em zonas, determinando-se, então, os fluxos entre estas e os pontos de oferta. Tal procedimento foi feito com os dados das Creches municipais e das EMEIs nos anos de 2000 e 2001, utilizando a divisão da área da cidade de São Carlos em 245 setores censitários, adotada pelo IBGE no ano 2000.

Em seguida, calculou-se os valores de atração dos pontos de oferta, o total de viagens produzidas em cada zona, como ilustrado nas Figuras 7.5, 7.6, 7.7 e 7.8, e as distâncias entre as Creches e EMEIs e os centróides dos setores. A localização de tais pontos é mostrada nas Figuras 7.9 e 7.10. A Tabela 7.1 apresenta um resumo quantitativo dos dados desta etapa do projeto.

\begin{tabular}{ccccc}
\hline Unidades & Ano & Pontos de oferta & Pontos de demanda & Pares O/D (Origem/Destino) \\
\hline \multirow{2}{*}{ Creches } & 2000 & 10 & 245 & 2450 \\
\cline { 2 - 5 } & 2001 & 11 & 245 & 2695 \\
\hline \multirow{2}{*}{ EMEIs } & 2000 & 22 & 245 & 5390 \\
\cline { 2 - 5 } & 2001 & 23 & 245 & 5635 \\
\hline
\end{tabular}

Tabela 7.1 - Resumo quantitativo dos dados utilizados nos modelos de interação espacial

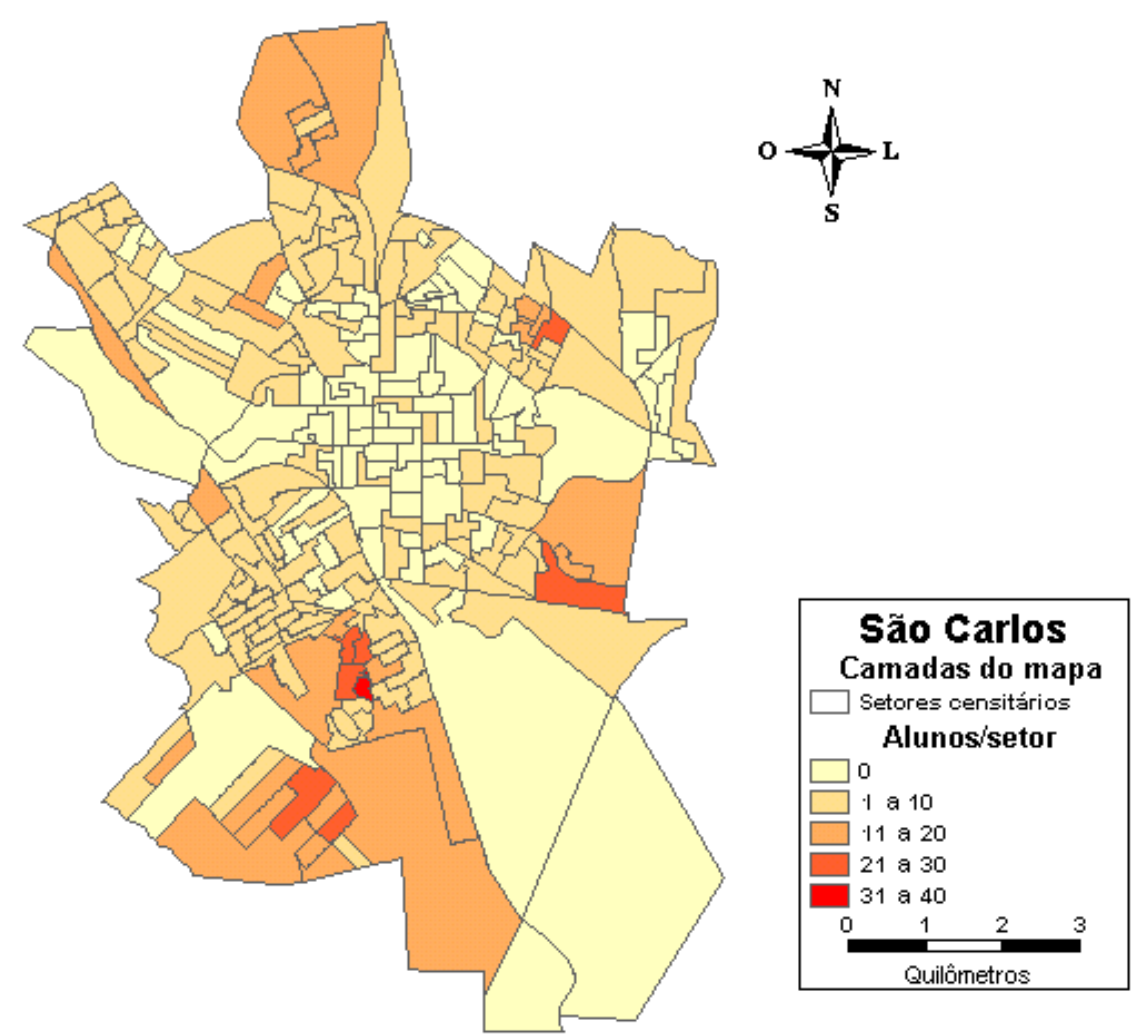

Figura 7.5 - Distribuição da demanda atendida nas Creches municipais em 2000, agregada em zonas 


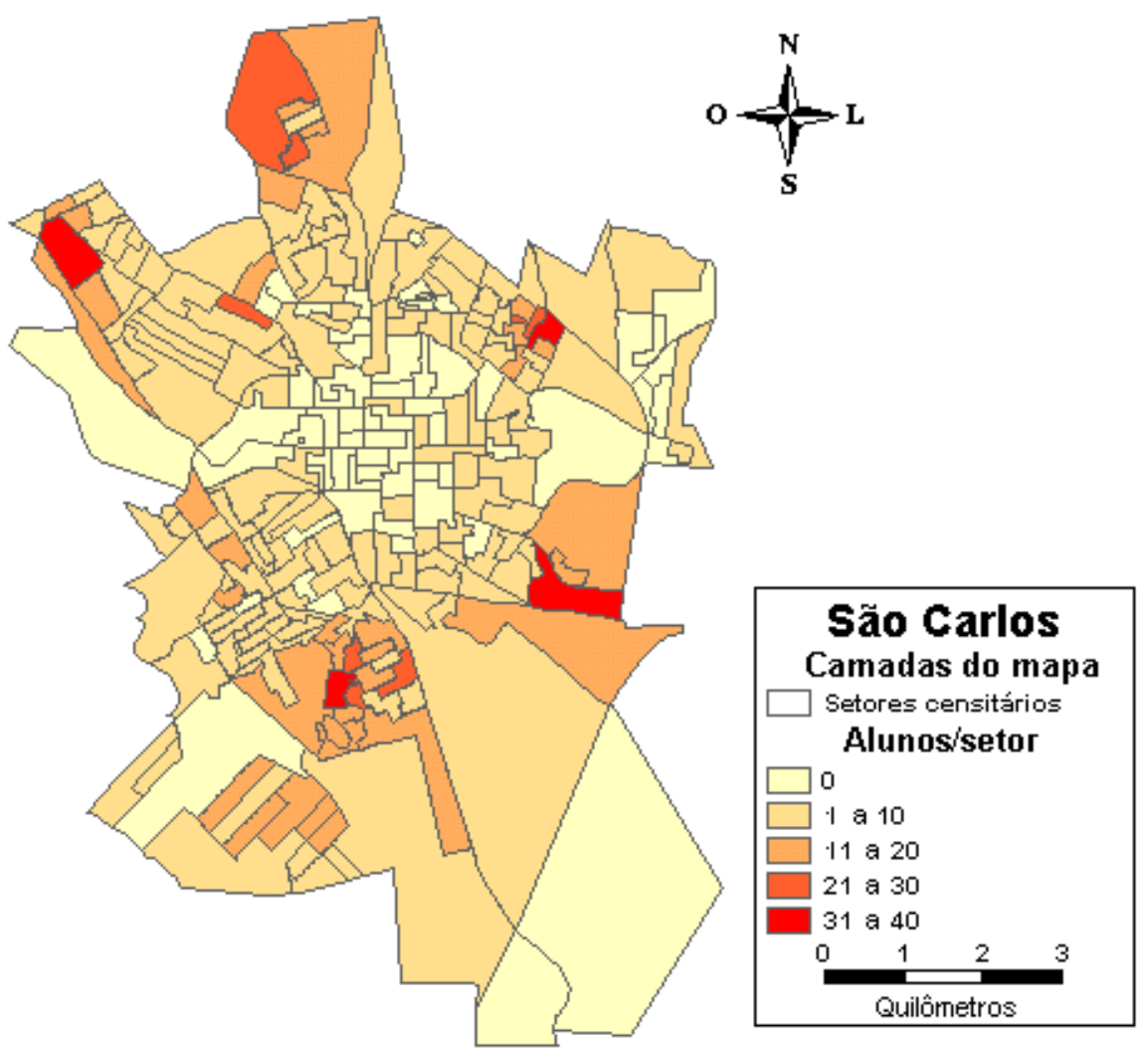

Figura 7.6 - Distribuição da demanda atendida nas Creches municipais em 2001, agregada em zonas

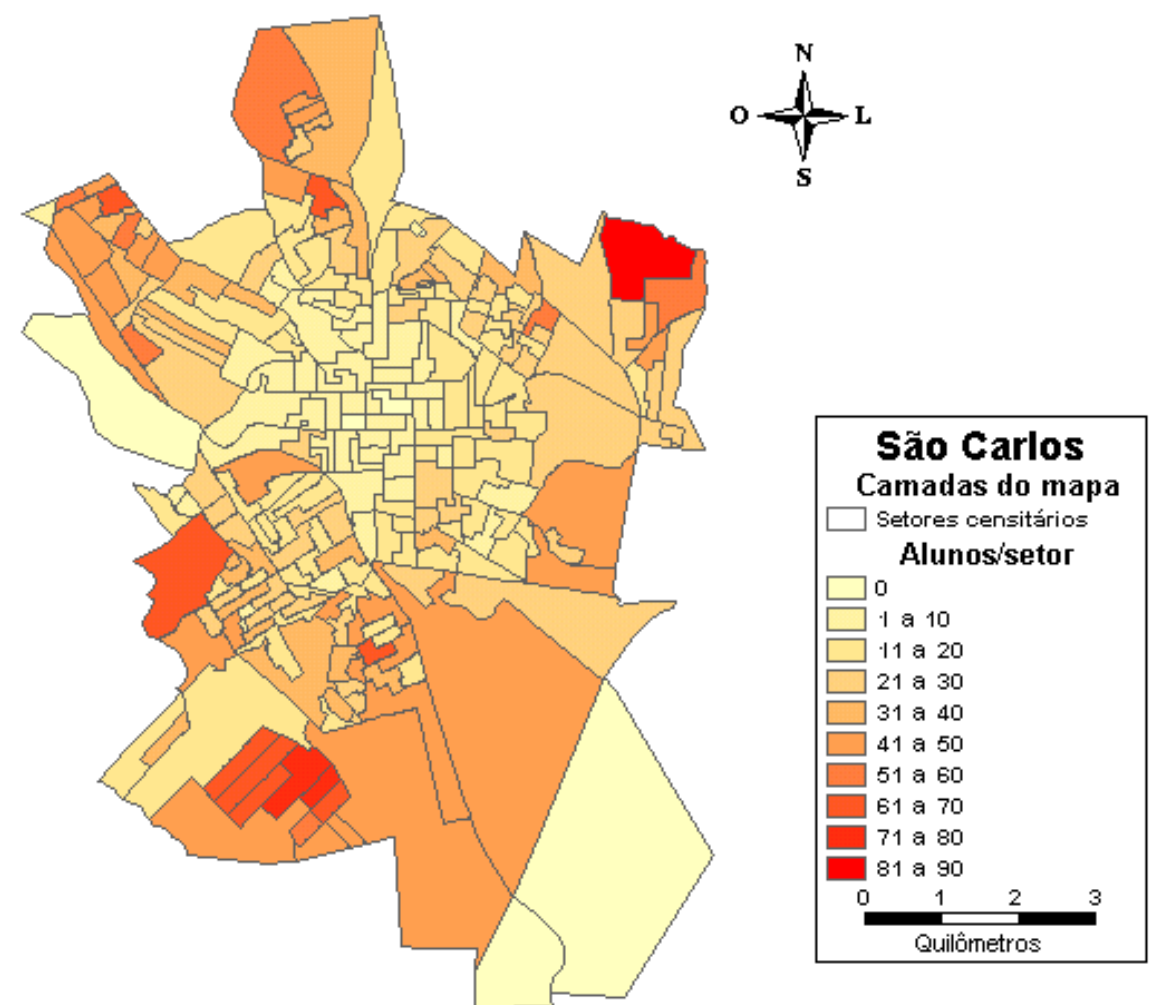

Figura 7.7 - Distribuição da demanda atendida nas EMEIs em 2000, agregada em zonas 


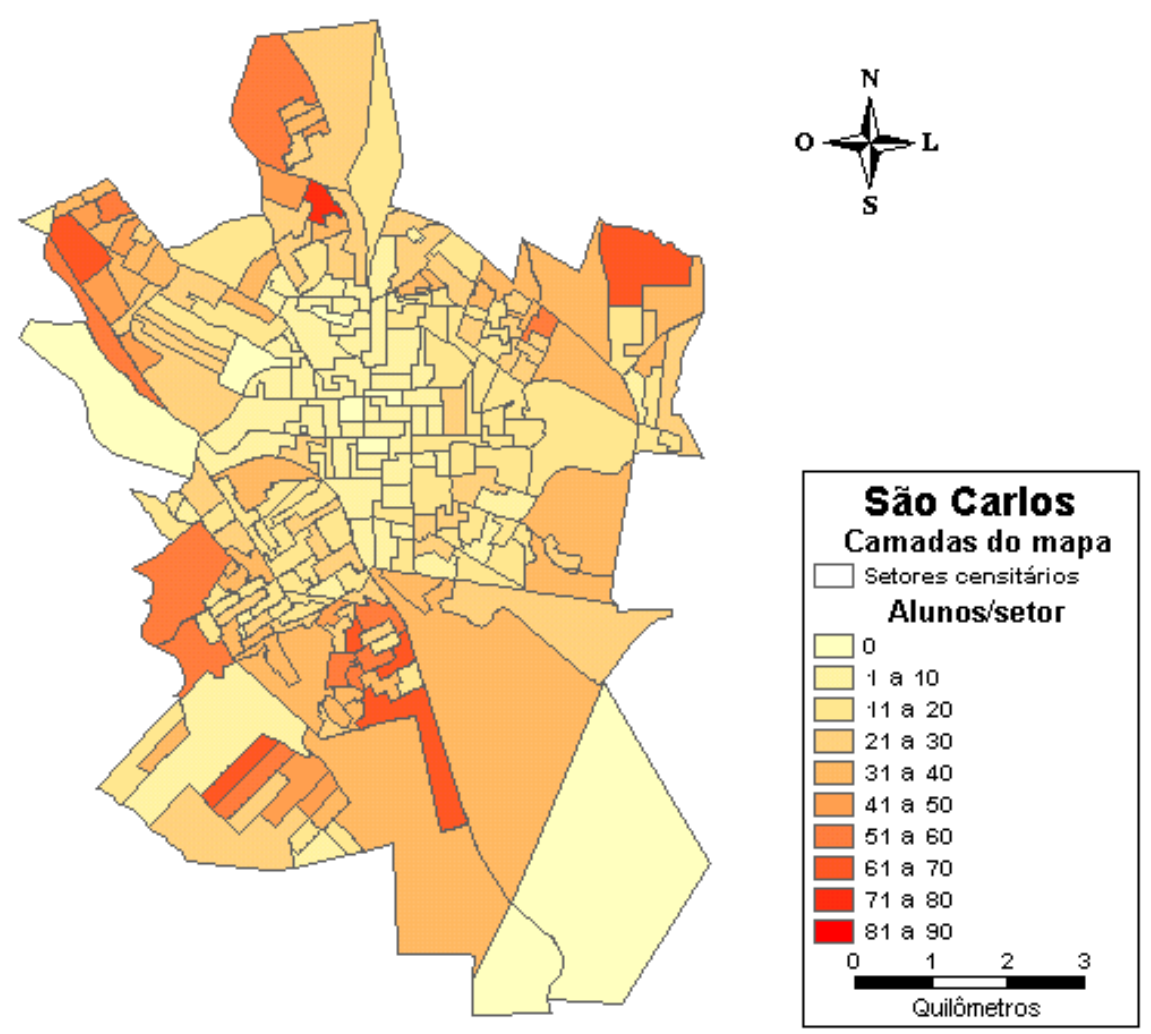

Figura 7.8 - Distribuição da demanda atendida nas EMEIs em 2001, agregada em zonas

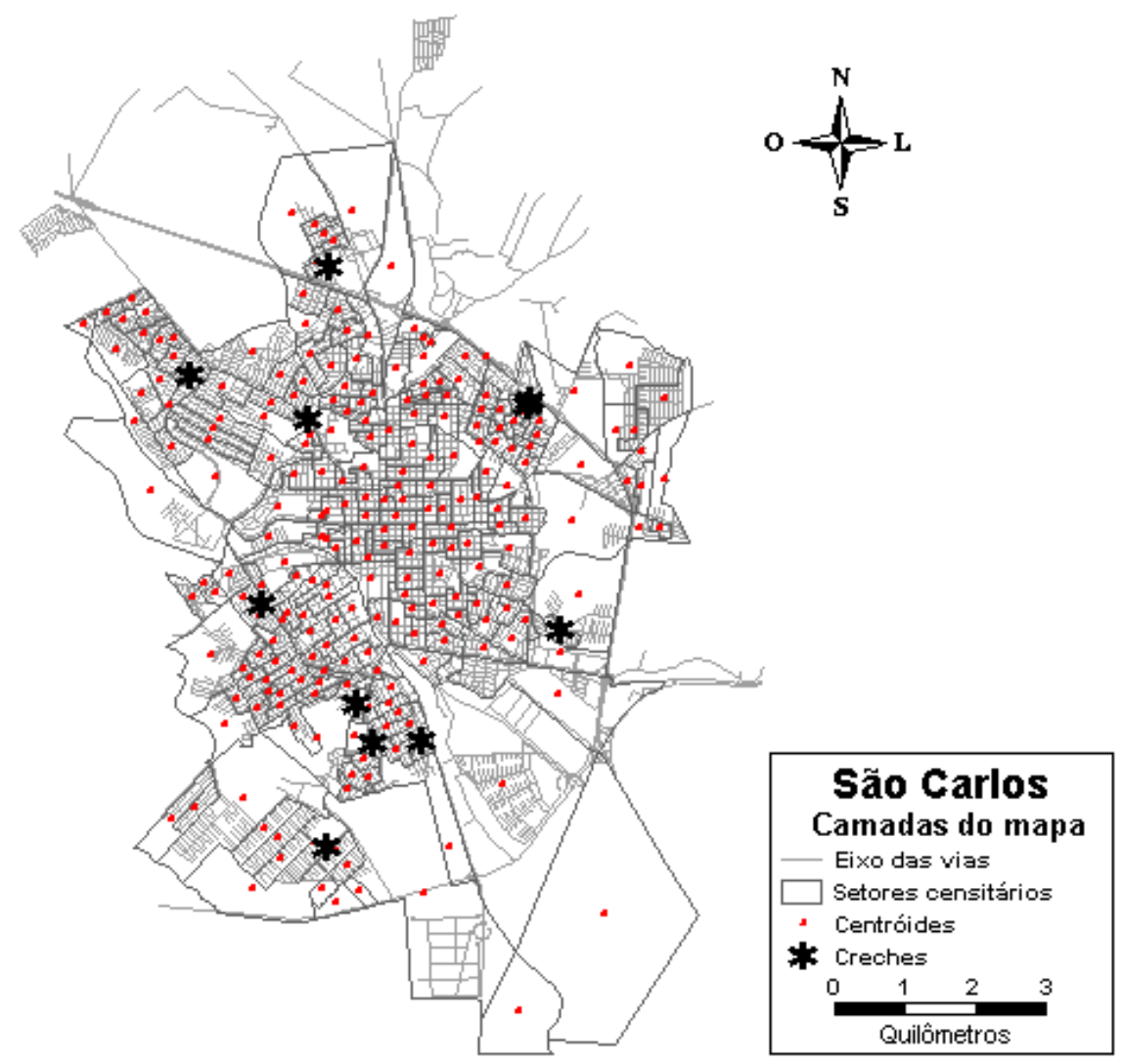

Figura 7.9 - Pontos de demanda (centróides) e oferta (Creches municipais) 


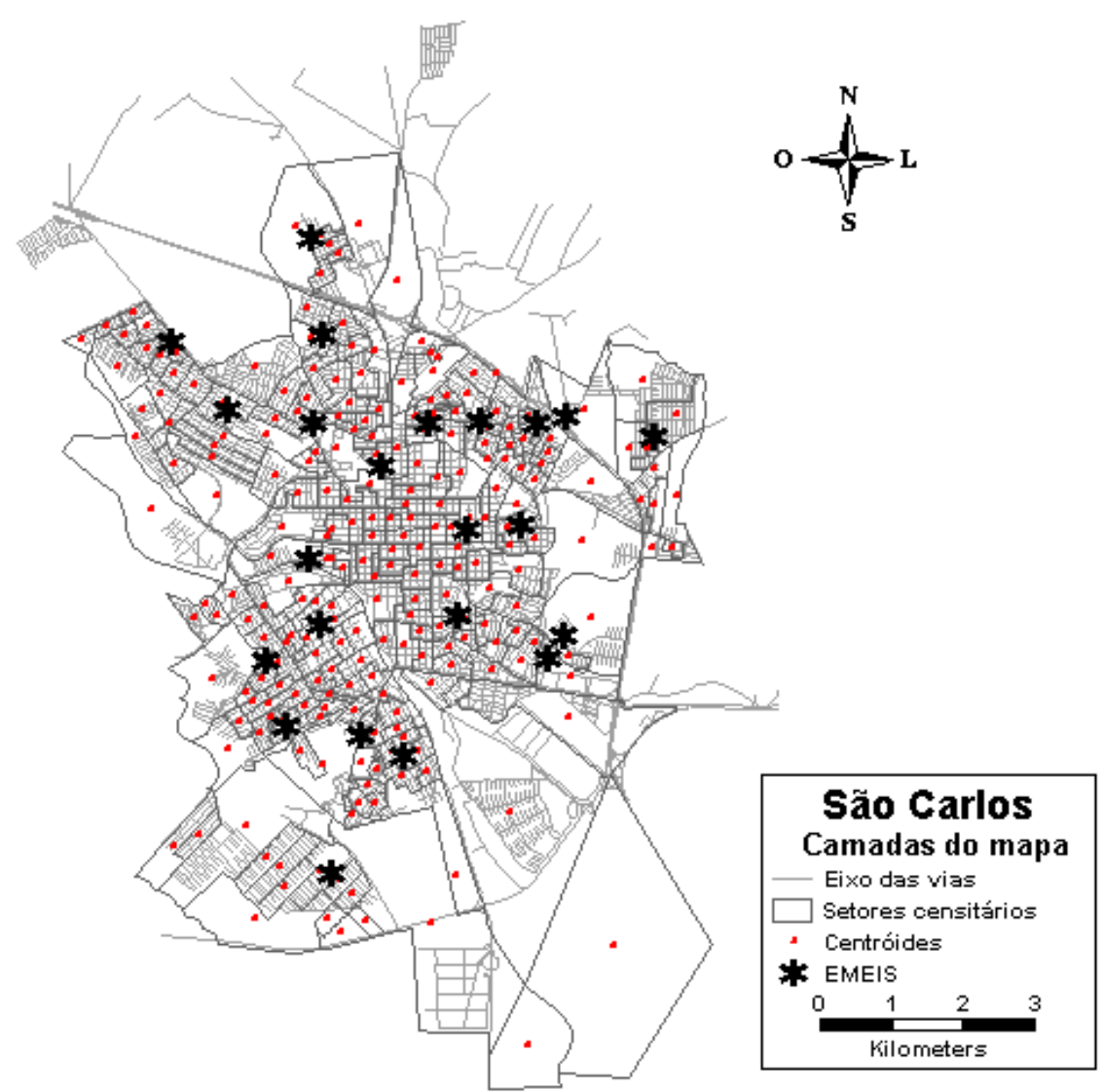

Figura 7.10 - Pontos de demanda (centróides) e oferta (EMEIs)

Após a normalização entre 0,1 e 0,9 os dados foram lançados no software EasyNN-plus. A Tabela 7.2 mostra, como exemplo, alguns valores desta etapa do projeto.

\begin{tabular}{|c|c|c|c|c|c|c|c|}
\hline \multicolumn{4}{|c|}{ dados reais } & \multicolumn{4}{|c|}{ dados normalizados } \\
\hline produção & atração & distância $(\mathrm{km})$ & fluxo & produção & atração & distância & fluxo \\
\hline 6 & 107 & 1,11 & 3 & 0,23 & 0,52 & 0,09 & 0,20 \\
\hline 2 & 106 & 4,50 & 2 & 0,14 & 0,52 & 0,38 & 0,17 \\
\hline 6 & 103 & 1,39 & 2 & 0,23 & 0,50 & 0,12 & 0,17 \\
\hline 1 & 138 & 1,90 & 1 & 0,12 & 0,72 & 0,16 & 0,13 \\
\hline 7 & 106 & 4,60 & 3 & 0,26 & 0,52 & 0,38 & 0,20 \\
\hline 15 & 138 & 0,79 & 9 & 0,43 & 0,72 & 0,07 & 0,40 \\
\hline 27 & 107 & 2,82 & 9 & 0,70 & 0,52 & 0,24 & 0,40 \\
\hline 9 & 103 & 1,09 & 3 & 0,30 & 0,50 & 0,09 & 0,20 \\
\hline 1 & 103 & 1,22 & 1 & 0,12 & 0,50 & 0,10 & 0,13 \\
\hline 2 & 138 & 2,03 & 2 & 0,14 & 0,72 & 0,17 & 0,17 \\
\hline
\end{tabular}

Tabela 7.2 - Exemplo dos dados utilizados nos modelos neurais de interação espacial 
Para a construção dos modelos de redes neurais, com três nós de entrada (total de viagens produzidas, total de viagens atraídas e distâncias) e um de saída (fluxos), os conjuntos de dados do ano 2000 (conjunto de Creches e de EMEIs) foram divididos de forma aleatória de três maneiras diferentes, em três subconjuntos: o primeiro para treinamento da rede (50\% do total de dados), o segundo para validação ( $25 \%$ do total de dados) e o terceiro para teste ( $25 \%$ do total de dados). Posteriormente, todos os dados foram utilizados para estimar os fluxos futuros a partir de pontos conhecidos de origem e destino. Estes foram, então, comparados aos fluxos reais observados no ano de 2001, através do cálculo do Erro Normalizado, segundo a Equação 3.7.

$\mathrm{Na}$ etapa de construção e teste das redes neurais artificiais foi utilizado o software EasyNN-plus v.6.0h. A estrutura de rede empregada pelo EasyNN-plus é a Multilayer Perceptron, o algoritmo utilizado no seu aprendizado, o backpropagation, e a função para se construir os modelos analisados é a sigmóide logística (WOLSTENHOLME, 2005). Para este estudo, foram consideradas apenas redes com uma camada intermediária, variando-se os valores de taxa de aprendizagem (L, de 0,3 a 0,6), momentum (M, de 0,1 a 0,4) e o número de nós da camada intermediária $(\mathrm{N}$, de 3 , 6,8 e 13). Tais valores iniciais são sugeridos pelo próprio software.

As Figuras 7.11 e 7.12 apresentam diagramas contendo as redes treinadas e os respectivos desempenhos, bem como o resultado obtido através do método gravitacional com dupla restrição, para os conjuntos de dados de Creches e EMEIs. O Erro Normalizado $(\mathrm{EN})$ corresponde à média dos erros obtidos nos três experimentos realizados, e o desvio padrão, ao desvio dos valores de EN destes três experimentos. 


\begin{tabular}{ccccc}
$\mathrm{N}$ & $\mathrm{L}$ & $\mathrm{EN}(\%)$ & desvio \\
\hline 3 & & & & \\
\hline
\end{tabular}
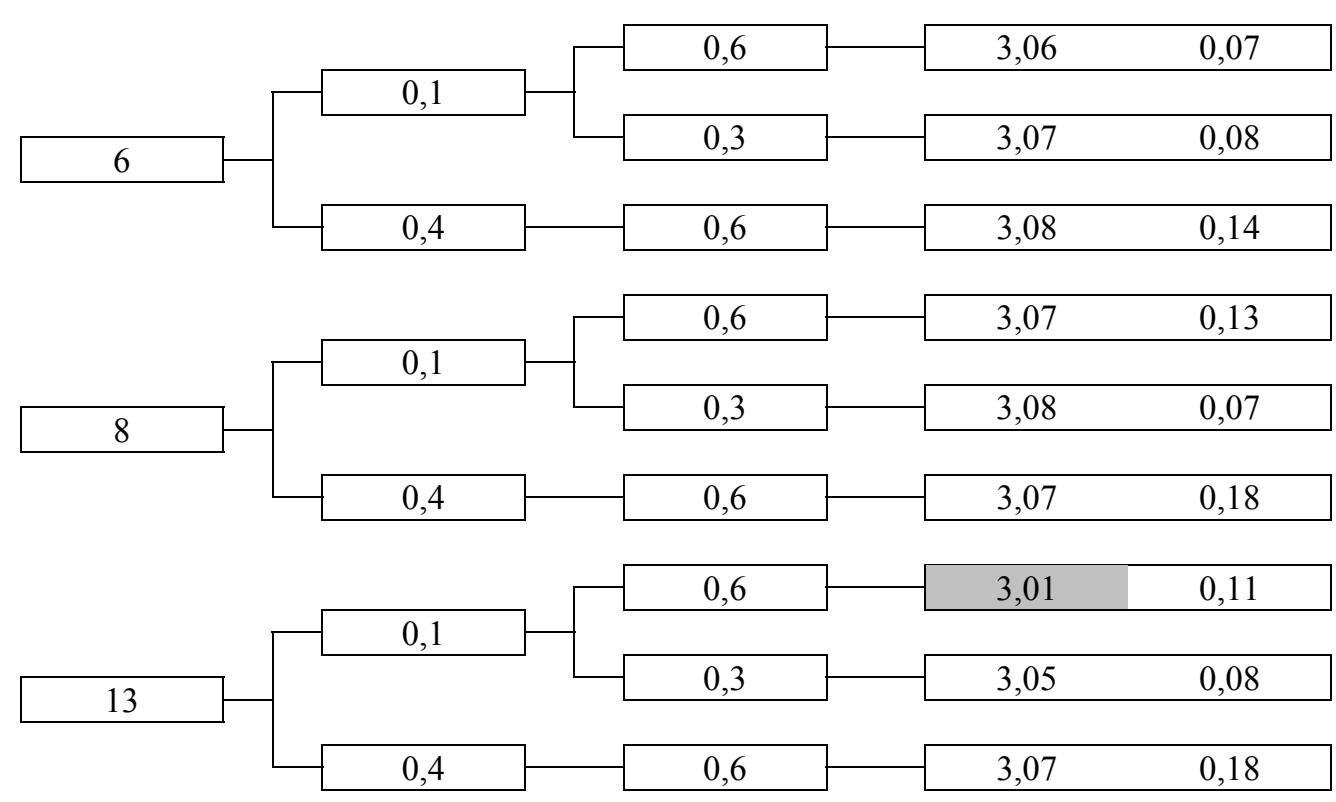

Método Gravitacional

\section{2,84}

Figura 7.11 - Desempenho das RNAs testadas com dados das Creches municipais 


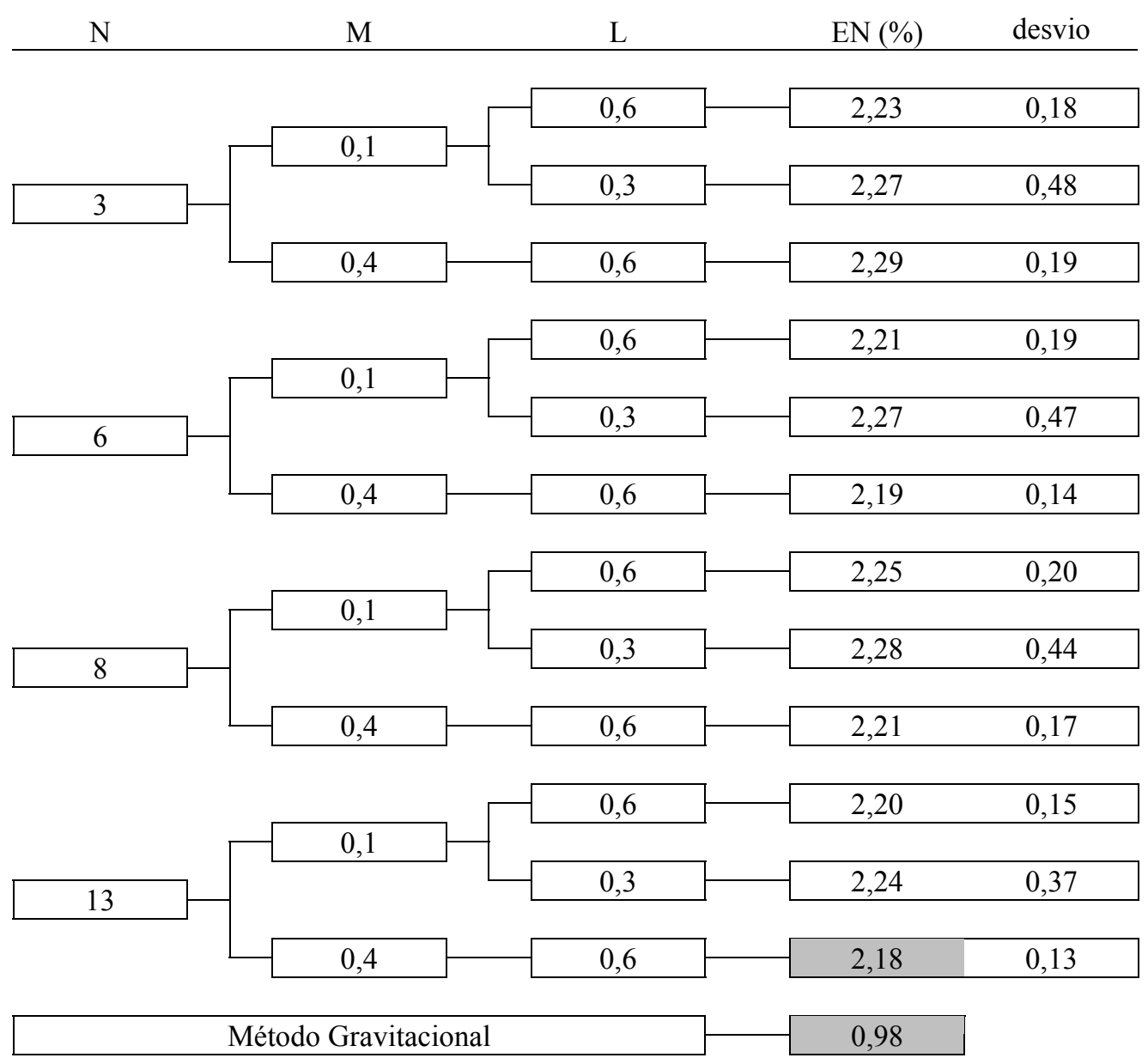

Figura 7.12 - Desempenho das RNAs testadas com dados das EMEIs

Pela análise dos diagramas pode-se perceber que, em ambos os casos, os desempenhos dos modelos neurais foram bastante próximos e que as melhores estimativas foram obtidas pelo método gravitacional com dupla restrição.

No caso dos modelos de Creches, a rede neural que apresentou melhor desempenho foi a de 13 nós na camada intermediária, $\mathrm{M}=0,1$ e $\mathrm{L}=0,6$, com Erro Normalizado igual a 3,01\%, enquanto o erro obtido pelo método gravitacional foi de 2,84\%. Para os modelos com dados de EMEIs, a rede neural de melhor desempenho foi a de 13 nós na camada intermediária, $\mathrm{M}=0,4$ e $\mathrm{L}=0,6$, com erro igual a 2,18\%, enquanto o erro obtido pelo método gravitacional foi de $0,98 \%$.

A análise do desempenho de todos os modelos estudados e a observação de que as mesmas redes treinadas com dados das EMEIs em todos os casos superaram as redes treinadas com dados das Creches, em termos de acurácia, levam à conclusão de que os dados utilizados influem diretamente nos resultados das previsões. Os dados das 
Creches não apresentam um padrão de distribuição consistente, como pode-se observar nos mapas das Figuras 7.1 e 7.2. Isto pode significar que a localização da residência dos alunos pode não estar interferindo na escolha da Creche, o que torna o modelo deficiente, já que, além do total de viagens produzidas e atraídas, apenas as distâncias entre os pontos de demanda e oferta estão sendo utilizadas como parâmetros. Até mesmo o desempenho do método gravitacional com dados das EMEIs foi superior ao obtido com dados das Creches.

\subsection{Seleção dos Modelos Neurais de Interação Espacial através de Algoritmos Genéticos}

Após a realização dos diversos testes com Redes Neurais Artificiais, foi pesquisada a técnica de otimização de Algoritmos Genéticos como alternativa para melhoria do desempenho dos modelos neurais de interação espacial. A técnica de otimização de Algoritmos Genéticos foi aplicada nas redes testadas na primeira geração de modelos (apresentada nos diagramas das Figuras 7.11 e 7.12). Adotando-se o Erro Normalizado de cada modelo neural como sendo a função a ser minimizada, ordenou-se a população de cromossomos segundo os valores de $\mathrm{EN}$, de forma decrescente e construiu-se uma coluna de aptidão, normalizando os valores da função objetivo no intervalo de 0 a 2, de forma que ao maior valor foi atribuída aptidão igual a 2 e, ao menor valor, aptidão igual a 0 . A Tabela 7.3 mostra, como exemplo, os valores desta etapa do estudo. A população deste estudo contém 12 cromossomos, como sugerido por Henderson e Fu (2004), já que cada cromossomo contém 12 genes. 


\begin{tabular}{cccccccccc}
\hline Posição & \multicolumn{3}{c}{ Rede Neural } & \multicolumn{2}{c}{ Cromossomo } & Função Objetivo & Aptidão & Aptidão Acumulada \\
\hline & $\mathrm{N}$ & $\mathrm{L}$ & $\mathrm{M}$ & $\mathrm{N}$ & $\mathrm{L}$ & $\mathrm{M}$ & $\mathrm{EN}$ & $\mathrm{f}_{\mathrm{i}}$ & \\
\hline 1 & 13 & 0,6 & 0,1 & 1101 & 0110 & 0001 & 3,0101 & 2,0000 & 2,0000 \\
\hline 2 & 13 & 0,3 & 0,1 & 1101 & 0011 & 0001 & 3,0525 & 1,8182 & 3,8182 \\
\hline 3 & 3 & 0,6 & 0,1 & 0011 & 0110 & 0001 & 3,0556 & 1,6364 & 5,4545 \\
\hline 4 & 6 & 0,6 & 0,1 & 0110 & 0110 & 0001 & 3,0636 & 1,4545 & 6,9091 \\
\hline 5 & 13 & 0,6 & 0,4 & 1101 & 0110 & 0100 & 3,0663 & 1,2727 & 8,1818 \\
\hline 6 & 8 & 0,6 & 0,4 & 1000 & 0110 & 0100 & 3,0686 & 1,0909 & 9,2727 \\
\hline 7 & 8 & 0,6 & 0,1 & 1000 & 0110 & 0001 & 3,0710 & 0,9091 & 10,1818 \\
\hline 8 & 6 & 0,3 & 0,1 & 0110 & 0011 & 0001 & 3,0749 & 0,7273 & 10,9091 \\
\hline 9 & 6 & 0,6 & 0,4 & 0110 & 0110 & 0100 & 3,0798 & 0,5455 & 11,4545 \\
\hline 10 & 8 & 0,3 & 0,1 & 1000 & 0011 & 0001 & 3,0819 & 0,3636 & 11,8182 \\
\hline 11 & 3 & 0,3 & 0,1 & 0011 & 0011 & 0001 & 3,0983 & 0,1818 & 12,0000 \\
\hline 12 & 3 & 0,6 & 0,4 & 0011 & 0110 & 0100 & 3,1012 & 0,0000 & 12,0000 \\
\hline
\end{tabular}

Tabela 7.3 - População inicial de cromossomos para seleção de modelos neurais de interação espacial

Uma vez determinado o valor da aptidão de cada cromossomo, determinou-se uma coluna de aptidão acumulada para iniciar o procedimento de seleção. Nesta fase, gerou-se um número aleatório $r$ no intervalo [0, somatotal], em que somatotal é a soma de todas as aptidões. Por fim, o cromossomo selecionado foi o primeiro (seguindo a tabela de cima para baixo) com aptidão acumulada maior que $r$ e sua cópia foi alocada na população intermediária. Os mesmos passos foram então repetidos até o preenchimento da população intermediária com, neste caso, 12 cromossomos. Observa-se neste processo de seleção, conhecido como Roda da Roleta e citado anteriormente no capítulo 4 (seção 4.3.3), que quanto maior a aptidão de um cromossomo, maior o intervalo de aptidão acumulada entre ele e o próximo cromossomo e, portanto, maior a probabilidade de passar para as etapas seguintes.

Como é interessante que o melhor indivíduo passe de uma geração a outra sem alterações, fez-se uso do elitismo, segundo o qual o cromossomo de maior aptidão é imediatamente alocado na população seguinte, sem sofrer nenhum tipo de alteração.

Após a conclusão da etapa de seleção, foram aplicados os operadores de cruzamento e de mutação. O operador de cruzamento foi aplicado aos cromossomos da população intermediária, separados aleatoriamente aos pares, gerando os cromossomos filhos. Neste trabalho, optou-se pelo cruzamento de 2 pontos. O processo de mutação consistiu na inversão dos valores de alguns bits (neste caso, $12^{-1} \%=0,083 \%$ ) do número total de bits da população. 
A técnica de otimização de Algoritmos Genéticos foi aplicada nas redes testadas na primeira geração de modelos, através da utilização do programa de computador Neural Nets Genealogy desenvolvido para esta pesquisa (AKAMINE; AKAMINE, 2005). Os resultados obtidos são apresentados abaixo, nas Tabelas 7.4 e 7.5 .

Como exposto nas Tabelas 7.4 e 7.5, os Algoritmos Genéticos foram aplicados por 20 gerações, sendo que os modelos neurais mostraram melhores desempenhos a cada iteração, embora em nenhum dos casos o resultado tenha superado o valor obtido através do método gravitacional com dupla restrição.

No caso dos modelos construídos com dados das Creches municipais, o menor valor de EN foi de 2,99\% para a rede neural de 14 nós na camada intermediária, $\mathrm{L}=0,7$ e $\mathrm{M}=0,5$. Para os modelos de dados das EMEIs, o melhor desempenho foi obtido para a mesma rede neural $(\mathrm{N}=14, \mathrm{~L}=0,7$ e $\mathrm{M}=0,5)$, com $\mathrm{EN}$ de $2,11 \%$. 


\begin{tabular}{|c|c|c|c|c|c|c|c|c|c|c|c|c|c|c|}
\hline \multirow{4}{*}{1} & \multicolumn{2}{|c|}{ 1a geração } & \multicolumn{2}{|c|}{ 2a geração } & \multicolumn{2}{|c|}{ 3a geração } & \multicolumn{2}{|c|}{ 4a geração } & \multicolumn{2}{|c|}{ 5a geração } & \multicolumn{2}{|c|}{ 6a geração } & \multicolumn{2}{|c|}{ 7a geração } \\
\hline & $\mathrm{L}=0,6$ & & $\mathrm{~L}=0,6$ & & $\mathrm{~L}=0,6$ & & $\mathrm{~L}=0,6$ & & $\mathrm{~L}=0,6$ & & $\mathrm{~L}=0,6$ & & $\mathrm{~L}=0,6$ & \\
\hline & $\mathrm{M}=0,1$ & 3,01 & $\mathrm{M}=0,1$ & 3,01 & $\mathrm{M}=0,1$ & 3,01 & $\mathrm{M}=0,1$ & 3,01 & $\mathrm{M}=0,1$ & 3,01 & $\mathrm{M}=0,1$ & 3,00 & $\mathrm{M}=0,1$ & 3,00 \\
\hline & $\mathrm{N}=13$ & & $\mathrm{~N}=13$ & & $\mathrm{~N}=13$ & & $\mathrm{~N}=13$ & & $\mathrm{~N}=13$ & & $\mathrm{~N}=15$ & & $\mathrm{~N}=15$ & \\
\hline \multirow{3}{*}{2} & $\mathrm{~L}=0,3$ & & $\mathrm{~L}=0,6$ & & $\mathrm{~L}=0,6$ & & $\mathrm{~L}=0,6$ & & $\mathrm{~L}=0,6$ & & $\mathrm{~L}=0,6$ & & $\mathrm{~L}=0,3$ & \\
\hline & $\mathrm{M}=0,1$ & 3,05 & $\mathrm{M}=0,1$ & 3,01 & $\mathrm{M}=0,1$ & 3,01 & $\mathrm{M}=0,1$ & 3,01 & $\mathrm{M}=0,1$ & 3,01 & $\mathrm{M}=0,1$ & 3,01 & $\mathrm{M}=0,5$ & 3,01 \\
\hline & $\mathrm{N}=13$ & & $\mathrm{~N}=14$ & & $\mathrm{~N}=14$ & & $\mathrm{~N}=14$ & & $\mathrm{~N}=14$ & & $\mathrm{~N}=13$ & & $\mathrm{~N}=15$ & \\
\hline \multirow{3}{*}{3} & $\mathrm{~L}=0,6$ & & $\mathrm{~L}=0,3$ & & $\mathrm{~L}=0,3$ & & $\mathrm{~L}=0,3$ & & $\mathrm{~L}=0,6$ & & $\mathrm{~L}=0,6$ & & $\mathrm{~L}=0,6$ & \\
\hline & $\mathrm{M}=0,1$ & 3,06 & $\mathrm{M}=0,1$ & 3,05 & $\mathrm{M}=0,1$ & 3,05 & $\mathrm{M}=0,1$ & 3,05 & $\mathrm{M}=0,1$ & 3,04 & $\mathrm{M}=0,1$ & 3,01 & $\mathrm{M}=0,1$ & 3,01 \\
\hline & $\mathrm{N}=3$ & & $\mathrm{~N}=13$ & & $\mathrm{~N}=13$ & & $\mathrm{~N}=13$ & & $\mathrm{~N}=12$ & & $\mathrm{~N}=14$ & & $\mathrm{~N}=13$ & \\
\hline \multirow{3}{*}{4} & $\mathrm{~L}=0,6$ & & $\mathrm{~L}=0,6$ & & $\mathrm{~L}=0,6$ & & $\mathrm{~L}=0,6$ & & $\mathrm{~L}=0,3$ & & $\mathrm{~L}=0,6$ & & $\mathrm{~L}=0,6$ & \\
\hline & $\mathrm{M}=0,1$ & 3,06 & $\mathrm{M}=0,1$ & 3,06 & $\mathrm{M}=0,1$ & 3,06 & $\mathrm{M}=0,1$ & 3,06 & $\mathrm{M}=0,1$ & 3,05 & $\mathrm{M}=0,1$ & 3,04 & $\mathrm{M}=0,1$ & 3,01 \\
\hline & $\mathrm{N}=6$ & & $\mathrm{~N}=3$ & & $\mathrm{~N}=3$ & & $\mathrm{~N}=3$ & & $\mathrm{~N}=13$ & & $\mathrm{~N}=12$ & & $\mathrm{~N}=14$ & \\
\hline \multirow{3}{*}{5} & $\mathrm{~L}=0,6$ & & $\mathrm{~L}=0,6$ & & $\mathrm{~L}=0,6$ & & $\mathrm{~L}=0,6$ & & $\mathrm{~L}=0,3$ & & $\mathrm{~L}=0,2$ & & $\mathrm{~L}=0,6$ & \\
\hline & $\mathrm{M}=0,4$ & 3,07 & $\mathrm{M}=0,1$ & 3,06 & $\mathrm{M}=0,1$ & 3,06 & $\mathrm{M}=0,1$ & 3,06 & $\mathrm{M}=0,1$ & 3,05 & $\mathrm{M}=0,1$ & 3,05 & $\mathrm{M}=0,1$ & 3,04 \\
\hline & $\mathrm{N}=13$ & & $\mathrm{~N}=6$ & & $\mathrm{~N}=6$ & & $\mathrm{~N}=6$ & & $\mathrm{~N}=15$ & & $\mathrm{~N}=15$ & & $\mathrm{~N}=12$ & \\
\hline \multirow{3}{*}{6} & $\mathrm{~L}=0,6$ & & $\mathrm{~L}=0,6$ & & $\mathrm{~L}=0,6$ & & $\mathrm{~L}=0,6$ & & $\mathrm{~L}=0,6$ & & $\mathrm{~L}=0,3$ & & $\mathrm{~L}=0,2$ & \\
\hline & $\mathrm{M}=0,4$ & 3,07 & $\mathrm{M}=0,4$ & 3,07 & $\mathrm{M}=0,4$ & $\mathbf{3 , 0 7}$ & $\mathrm{M}=0,4$ & $\mathbf{3 , 0 7}$ & $\mathrm{M}=0,1$ & 3,06 & $\mathrm{M}=0,1$ & 3,05 & $\mathrm{M}=0,1$ & 3,05 \\
\hline & $\mathrm{N}=8$ & & $\mathrm{~N}=13$ & & $\mathrm{~N}=13$ & & $\mathrm{~N}=13$ & & $\mathrm{~N}=3$ & & $\mathrm{~N}=13$ & & $\mathrm{~N}=15$ & \\
\hline \multirow{3}{*}{7} & $\mathrm{~L}=0,6$ & & $\mathrm{~L}=0,7$ & & $\mathrm{~L}=0,7$ & & $\mathrm{~L}=0,7$ & & $\mathrm{~L}=0,6$ & & $\mathrm{~L}=0,3$ & & $\mathrm{~L}=0,3$ & \\
\hline & $\mathrm{M}=0,1$ & $\mathbf{3 , 0 7}$ & $\mathrm{M}=0,1$ & $\mathbf{3 , 0 7}$ & $\mathrm{M}=0,1$ & $\mathbf{3 , 0 7}$ & $\mathrm{M}=0,1$ & $\mathbf{3 , 0 7}$ & $\mathrm{M}=0,1$ & 3,06 & $\mathrm{M}=0,1$ & 3,05 & $\mathrm{M}=0,1$ & 3,05 \\
\hline & $\mathrm{N}=8$ & & $\mathrm{~N}=8$ & & $\mathrm{~N}=8$ & & $\mathrm{~N}=8$ & & $\mathrm{~N}=6$ & & $\mathrm{~N}=15$ & & $\mathrm{~N}=15$ & \\
\hline \multirow{3}{*}{8} & $\mathrm{~L}=0,3$ & & $\mathrm{~L}=0,6$ & & $\mathrm{~L}=0,6$ & & $\mathrm{~L}=0,6$ & & $\mathrm{~L}=0,6$ & & $\mathrm{~L}=0,6$ & & $\mathrm{~L}=0,3$ & \\
\hline & $\mathrm{M}=0,1$ & $\mathbf{3 , 0 7}$ & $\mathrm{M}=0,4$ & $\mathbf{3 , 0 7}$ & $\mathrm{M}=0,4$ & $\mathbf{3 , 0 7}$ & $\mathrm{M}=0,4$ & 3,07 & $\mathrm{M}=0,4$ & 3,07 & $\mathrm{M}=0,1$ & 3,06 & $\mathrm{M}=0,1$ & 3,05 \\
\hline & $\mathrm{N}=6$ & & $\mathrm{~N}=8$ & & $\mathrm{~N}=8$ & & $\mathrm{~N}=8$ & & $\mathrm{~N}=13$ & & $\mathrm{~N}=13$ & & $\mathrm{~N}=15$ & \\
\hline \multirow{3}{*}{9} & $\mathrm{~L}=0,6$ & & $\mathrm{~L}=0,6$ & & $\mathrm{~L}=0,6$ & & $\mathrm{~L}=0,6$ & & $\mathrm{~L}=0,7$ & & $\mathrm{~L}=0,6$ & & $\mathrm{~L}=0,6$ & \\
\hline & $\mathrm{M}=0,4$ & 3,08 & $\mathrm{M}=0,1$ & $\mathbf{3 , 0 7}$ & $\mathrm{M}=0,1$ & 3,07 & $\mathrm{M}=0,1$ & $\mathbf{3 , 0 7}$ & $\mathrm{M}=0,1$ & $\mathbf{3 , 0 7}$ & $\mathrm{M}=0,1$ & 3,06 & $\mathrm{M}=0,1$ & 3,06 \\
\hline & $\mathrm{N}=6$ & & $\mathrm{~N}=8$ & & $\mathrm{~N}=7$ & & $\mathrm{~N}=7$ & & $\mathrm{~N}=8$ & & $\mathrm{~N}=6$ & & $\mathrm{~N}=3$ & \\
\hline \multirow{3}{*}{10} & $\mathrm{~L}=0,3$ & & $\mathrm{~L}=0,3$ & & $\mathrm{~L}=0,6$ & & $\mathrm{~L}=0,6$ & & $\mathrm{~L}=0,6$ & & $\mathrm{~L}=0,6$ & & $\mathrm{~L}=0,6$ & \\
\hline & $\mathrm{M}=0,1$ & 3,08 & $\mathrm{M}=0,1$ & $\mathbf{3 , 0 7}$ & $\mathrm{M}=0,1$ & 3,07 & $\mathrm{M}=0,1$ & 3,07 & $\mathrm{M}=0,4$ & $\mathbf{3 , 0 7}$ & $\mathrm{M}=0,4$ & 3,07 & $\mathrm{M}=0,1$ & 3,06 \\
\hline & $\mathrm{N}=8$ & & $\mathrm{~N}=6$ & & $\mathrm{~N}=8$ & & $\mathrm{~N}=8$ & & $\mathrm{~N}=8$ & & $\mathrm{~N}=13$ & & $\mathrm{~N}=6$ & \\
\hline \multirow{3}{*}{11} & $\mathrm{~L}=0,3$ & & $\mathrm{~L}=0,2$ & & $\mathrm{~L}=0,3$ & & $\mathrm{~L}=0,3$ & & $\mathrm{~L}=0,6$ & & $\mathrm{~L}=0,3$ & & $\mathrm{~L}=0,6$ & \\
\hline & $\mathrm{M}=0,1$ & 3,10 & $\mathrm{M}=0,1$ & 3,09 & $\mathrm{M}=0,1$ & 3,08 & $\mathrm{M}=0,1$ & 3,08 & $\mathrm{M}=0,1$ & 3,07 & $\mathrm{M}=0,1$ & 3,07 & $\mathrm{M}=0,4$ & 3,07 \\
\hline & $\mathrm{N}=3$ & & $\mathrm{~N}=13$ & & $\mathrm{~N}=6$ & & $\mathrm{~N}=5$ & & $\mathrm{~N}=7$ & & $\mathrm{~N}=6$ & & $\mathrm{~N}=13$ & \\
\hline \multirow{3}{*}{12} & $\mathrm{~L}=0,6$ & & $\mathrm{~L}=0,6$ & & $\mathrm{~L}=0,3$ & & $\mathrm{~L}=0,6$ & & $\mathrm{~L}=0,6$ & & $\mathrm{~L}=0,7$ & & $\mathrm{~L}=0,6$ & \\
\hline & $\mathrm{M}=0,4$ & 3,10 & $\mathrm{M}=0,1$ & 3,15 & $\mathrm{M}=0,1$ & 3,14 & $\mathrm{M}=0,1$ & 3,09 & $\mathrm{M}=0,1$ & $\mathbf{3 , 0 7}$ & $\mathrm{M}=0,1$ & 3,10 & $\mathrm{M}=0,0$ & $\mathbf{3 , 0 7}$ \\
\hline & $\mathrm{N}=3$ & & $\mathrm{~N}=5$ & & $\mathrm{~N}=2$ & & $\mathrm{~N}=2$ & & $\mathrm{~N}=8$ & & $\mathrm{~N}=12$ & & $\mathrm{~N}=13$ & \\
\hline
\end{tabular}

Tabela 7.4 - EN (\%) dos modelos neurais de interação espacial selecionados através de AGs, construídos com dados de Creches - continua 


\begin{tabular}{|c|c|c|c|c|c|c|c|c|c|c|c|c|c|c|}
\hline & \multicolumn{2}{|c|}{ 8a geração } & \multicolumn{2}{|c|}{ 9a geração } & \multicolumn{2}{|c|}{ 10a geração } & \multicolumn{2}{|c|}{11 geração } & \multicolumn{2}{|c|}{ 12a geração } & \multicolumn{2}{|c|}{ 13a geração } & \multicolumn{2}{|c|}{$14^{\mathrm{a}}$ geração } \\
\hline & $\mathrm{L}=0,6$ & & $\mathrm{~L}=0,6$ & & $\mathrm{~L}=0,6$ & & $\mathrm{~L}=0,6$ & & $\mathrm{~L}=0,7$ & & $\mathrm{~L}=0,7$ & & $\mathrm{~L}=0,7$ & \\
\hline \multirow[t]{3}{*}{1} & $\mathrm{M}=0,1$ & 3,00 & $\mathrm{M}=0,1$ & 3,00 & $\mathrm{M}=0,1$ & 3,00 & $\mathrm{M}=0,1$ & 3,00 & $M=0,5$ & 2,99 & $\mathrm{M}=0,5$ & 2,99 & $M=0,5$ & 2,99 \\
\hline & $\mathrm{N}=15$ & & $\mathrm{~N}=15$ & & $\mathrm{~N}=15$ & & $\mathrm{~N}=15$ & & $\mathrm{~N}=14$ & & $\mathrm{~N}=14$ & & $\mathrm{~N}=14$ & \\
\hline & $\mathrm{L}=0,3$ & & $\mathrm{~L}=0,3$ & & $\mathrm{~L}=0,3$ & & $\mathrm{~L}=0,3$ & & $\mathrm{~L}=0,6$ & & $\mathrm{~L}=0,6$ & & $\mathrm{~L}=0,6$ & \\
\hline \multirow[t]{3}{*}{2} & $\mathrm{M}=0,5$ & 3,01 & $\mathrm{M}=0,5$ & 3,01 & $\mathrm{M}=0,5$ & 3,01 & $\mathrm{M}=0,5$ & 3,01 & $\mathrm{M}=0,1$ & 3,00 & $\mathrm{M}=0,1$ & 3,00 & $\mathrm{M}=0,1$ & 3,00 \\
\hline & $\mathrm{N}=15$ & & $\mathrm{~N}=15$ & & $\mathrm{~N}=15$ & & $\mathrm{~N}=15$ & & $\mathrm{~N}=15$ & & $\mathrm{~N}=15$ & & $\mathrm{~N}=15$ & \\
\hline & $\mathrm{L}=0,6$ & & $\mathrm{~L}=0,6$ & & $\mathrm{~L}=0,6$ & & $\mathrm{~L}=0,6$ & & $\mathrm{~L}=0,3$ & & $\mathrm{~L}=0,3$ & & $\mathrm{~L}=0,3$ & \\
\hline \multirow[t]{3}{*}{3} & $\mathrm{M}=0,1$ & 3,01 & $\mathrm{M}=0,1$ & 3,01 & $\mathrm{M}=0,1$ & 3,01 & $\mathrm{M}=0,1$ & 3,01 & $\mathrm{M}=0,5$ & 3,01 & $\mathrm{M}=0,5$ & 3,01 & $\mathrm{M}=0,5$ & 3,01 \\
\hline & $\mathrm{N}=13$ & & $\mathrm{~N}=13$ & & $\mathrm{~N}=13$ & & $\mathrm{~N}=13$ & & $\mathrm{~N}=15$ & & $\mathrm{~N}=15$ & & $\mathrm{~N}=15$ & \\
\hline & $\mathrm{L}=0,6$ & & $\mathrm{~L}=0,6$ & & $\mathrm{~L}=0,6$ & & $\mathrm{~L}=0,6$ & & $\mathrm{~L}=0,6$ & & $\mathrm{~L}=0,6$ & & $\mathrm{~L}=0,6$ & \\
\hline \multirow[t]{3}{*}{4} & $\mathrm{M}=0,1$ & 3,01 & $\mathrm{M}=0,1$ & 3,01 & $\mathrm{M}=0,1$ & 3,01 & $\mathrm{M}=0,1$ & 3,01 & $\mathrm{M}=0,1$ & 3,01 & $\mathrm{M}=0,1$ & 3,01 & $\mathrm{M}=0,1$ & 3,01 \\
\hline & $\mathrm{N}=14$ & & $\mathrm{~N}=14$ & & $\mathrm{~N}=14$ & & $\mathrm{~N}=14$ & & $\mathrm{~N}=13$ & & $\mathrm{~N}=13$ & & $\mathrm{~N}=13$ & \\
\hline & $\mathrm{L}=0,6$ & & $\mathrm{~L}=0,6$ & & $\mathrm{~L}=0,6$ & & $\mathrm{~L}=0,6$ & & $\mathrm{~L}=0,6$ & & $\mathrm{~L}=0,6$ & & $\mathrm{~L}=0,6$ & \\
\hline \multirow[t]{3}{*}{5} & $\mathrm{M}=0,1$ & 3,02 & $\mathrm{M}=0,5$ & 3,02 & $\mathrm{M}=0,5$ & 3,02 & $\mathrm{M}=0,5$ & 3,02 & $\mathrm{M}=0,1$ & 3,01 & $\mathrm{M}=0,1$ & 3,01 & $\mathrm{M}=0,1$ & 3,01 \\
\hline & $\mathrm{N}=11$ & & $\mathrm{~N}=13$ & & $\mathrm{~N}=13$ & & $\mathrm{~N}=13$ & & $\mathrm{~N}=14$ & & $\mathrm{~N}=14$ & & $\mathrm{~N}=14$ & \\
\hline & $\mathrm{L}=0,6$ & & $\mathrm{~L}=0,6$ & & $\mathrm{~L}=0,6$ & & $\mathrm{~L}=0,6$ & & $\mathrm{~L}=0,6$ & & $\mathrm{~L}=0,6$ & & $\mathrm{~L}=0,6$ & \\
\hline \multirow[t]{3}{*}{6} & $\mathrm{M}=0,4$ & 3,04 & $\mathrm{M}=0,1$ & 3,02 & $\mathrm{M}=0,1$ & 3,02 & $\mathrm{M}=0,1$ & 3,02 & $\mathrm{M}=0,5$ & 3,02 & $M=0,5$ & 3,02 & $M=0,5$ & 3,02 \\
\hline & $\mathrm{N}=15$ & & $\mathrm{~N}=11$ & & $\mathrm{~N}=11$ & & $\mathrm{~N}=11$ & & $\mathrm{~N}=13$ & & $\mathrm{~N}=13$ & & $\mathrm{~N}=13$ & \\
\hline & $\mathrm{L}=0,6$ & & $\mathrm{~L}=0,6$ & & $\mathrm{~L}=0,6$ & & $\mathrm{~L}=0,6$ & & $\mathrm{~L}=0,6$ & & $\mathrm{~L}=0,6$ & & $\mathrm{~L}=0,6$ & \\
\hline \multirow[t]{3}{*}{7} & $\mathrm{M}=0,1$ & 3,05 & $\mathrm{M}=0,4$ & 3,02 & $\mathrm{M}=0,4$ & 3,02 & $\mathrm{M}=0,4$ & 3,02 & $\mathrm{M}=0,1$ & 3,02 & $\mathrm{M}=0,1$ & 3,02 & $\mathrm{M}=0,1$ & 3,02 \\
\hline & $\mathrm{N}=12$ & & $\mathrm{~N}=15$ & & $\mathrm{~N}=14$ & & $\mathrm{~N}=14$ & & $\mathrm{~N}=11$ & & $\mathrm{~N}=14$ & & $\mathrm{~N}=11$ & \\
\hline & $\mathrm{L}=0,2$ & & $\mathrm{~L}=0,6$ & & $\mathrm{~L}=0,7$ & & $\mathrm{~L}=0,7$ & & $\mathrm{~L}=0,6$ & & $\mathrm{~L}=0,6$ & & $\mathrm{~L}=0,6$ & \\
\hline \multirow[t]{3}{*}{8} & $\mathrm{M}=0,1$ & 3,05 & $\mathrm{M}=0,1$ & 3,04 & $\mathrm{M}=0,5$ & 3,03 & $\mathrm{M}=0,5$ & 3,03 & $\mathrm{M}=0,4$ & 3,02 & $M=0,4$ & 3,02 & $M=0,4$ & 3,02 \\
\hline & $\mathrm{N}=15$ & & $\mathrm{~N}=12$ & & $\mathrm{~N}=13$ & & $\mathrm{~N}=13$ & & $\mathrm{~N}=14$ & & $\mathrm{~N}=14$ & & $\mathrm{~N}=14$ & \\
\hline & $\mathrm{L}=0,6$ & & $\mathrm{~L}=0,3$ & & $\mathrm{~L}=0,6$ & & $\mathrm{~L}=0,6$ & & $\mathrm{~L}=0,6$ & & $\mathrm{~L}=0,6$ & & $\mathrm{~L}=0,6$ & \\
\hline \multirow[t]{3}{*}{9} & $\mathrm{M}=0,1$ & $\mathbf{3 , 0 7}$ & $\mathrm{M}=0,1$ & 3,05 & $\mathrm{M}=0,1$ & 3,07 & $\mathrm{M}=0,4$ & 3,04 & $\mathrm{M}=0,5$ & 3,03 & $M=0,5$ & 3,03 & $M=0,4$ & 3,04 \\
\hline & $\mathrm{N}=7$ & & $\mathrm{~N}=15$ & & $\mathrm{~N}=7$ & & $\mathrm{~N}=15$ & & $\mathrm{~N}=15$ & & $\mathrm{~N}=15$ & & $\mathrm{~N}=12$ & \\
\hline & $\mathrm{L}=0,2$ & & $\mathrm{~L}=0,6$ & & $\mathrm{~L}=0,6$ & & $\mathrm{~L}=0,6$ & & $\mathrm{~L}=0,7$ & & $\mathrm{~L}=0,7$ & & $\mathrm{~L}=0,6$ & \\
\hline \multirow[t]{3}{*}{10} & $\mathrm{M}=0,1$ & 3,09 & $\mathrm{M}=0,1$ & 3,07 & $\mathrm{M}=0,1$ & 3,09 & $\mathrm{M}=0,1$ & 3,07 & $\mathrm{M}=0,5$ & 3,03 & $M=0,5$ & 3,10 & $M=0,4$ & 3,04 \\
\hline & $\mathrm{N}=13$ & & $\mathrm{~N}=7$ & & $\mathrm{~N}=10$ & & $\mathrm{~N}=7$ & & $\mathrm{~N}=13$ & & $\mathrm{~N}=6$ & & $\mathrm{~N}=15$ & \\
\hline & $\mathrm{L}=0,6$ & & $\mathrm{~L}=0,6$ & & $\mathrm{~L}=0,2$ & & $\mathrm{~L}=0,6$ & & $\mathrm{~L}=0,3$ & & $\mathrm{~L}=0,3$ & & $\mathrm{~L}=0,7$ & \\
\hline \multirow[t]{3}{*}{11} & $\mathrm{M}=0,1$ & 3,09 & $\mathrm{M}=0,5$ & 3,13 & $\mathrm{M}=0,1$ & 3,10 & $\mathrm{M}=0,1$ & 3,09 & $M=0,5$ & 3,07 & $\mathrm{M}=0,5$ & 3,11 & $\mathrm{M}=0,4$ & 3,04 \\
\hline & $\mathrm{N}=2$ & & $\mathrm{~N}=11$ & & $\mathrm{~N}=15$ & & $\mathrm{~N}=10$ & & $\mathrm{~N}=13$ & & $\mathrm{~N}=14$ & & $\mathrm{~N}=12$ & \\
\hline & $\mathrm{L}=0,7$ & & $\mathrm{~L}=0,6$ & & $\mathrm{~L}=0,6$ & & $\mathrm{~L}=0,6$ & & $\mathrm{~L}=0,2$ & & $\mathrm{~L}=0,2$ & & $\mathrm{~L}=0,3$ & \\
\hline \multirow[t]{2}{*}{12} & $\mathrm{M}=0,1$ & 3,10 & $\mathrm{M}=0,1$ & 3,37 & $\mathrm{M}=0,1$ & 3,15 & $\mathrm{M}=0,1$ & 3,09 & $\mathrm{M}=0,4$ & 3,21 & $\mathrm{M}=0,4$ & 3,21 & $\mathrm{M}=0,4$ & 3,13 \\
\hline & $\mathrm{N}=3$ & & $\mathrm{~N}=1$ & & $\mathrm{~N}=5$ & & $\mathrm{~N}=4$ & & $\mathrm{~N}=15$ & & $\mathrm{~N}=15$ & & $\mathrm{~N}=15$ & \\
\hline
\end{tabular}

Tabela 7.4 - EN (\%) dos modelos neurais de interação espacial selecionados através de AGs, construídos com dados de Creches - continuação 


\begin{tabular}{|c|c|c|c|c|c|c|c|c|c|c|c|c|}
\hline & \multicolumn{2}{|c|}{ 15a geração } & \multicolumn{2}{|c|}{ 16a geração } & \multicolumn{2}{|c|}{ 17a geração } & \multicolumn{2}{|c|}{ 18a geração } & \multicolumn{2}{|c|}{ 19a geração } & \multicolumn{2}{|c|}{ 20a geração } \\
\hline & $\mathrm{L}=0,7$ & & $\mathrm{~L}=0,7$ & & $\mathrm{~L}=0,7$ & & $\mathrm{~L}=0,7$ & & $\mathrm{~L}=0,7$ & & $\mathrm{~L}=0,7$ & \\
\hline \multirow[t]{3}{*}{1} & $\mathrm{M}=0,5$ & 2,99 & $\mathrm{M}=0,5$ & 2,99 & $\mathrm{M}=0,5$ & 2,99 & $\mathrm{M}=0,5$ & 2,99 & $\mathrm{M}=0,5$ & 2,99 & $\mathrm{M}=0,5$ & 2,99 \\
\hline & $\mathrm{N}=14$ & & $\mathrm{~N}=14$ & & $\mathrm{~N}=14$ & & $\mathrm{~N}=14$ & & $\mathrm{~N}=14$ & & $\mathrm{~N}=14$ & \\
\hline & $\mathrm{L}=0,6$ & & $\mathrm{~L}=0,6$ & & $\mathrm{~L}=0,6$ & & $\mathrm{~L}=0,6$ & & $\mathrm{~L}=0,6$ & & $\mathrm{~L}=0,6$ & \\
\hline \multirow[t]{3}{*}{2} & $\mathrm{M}=0,5$ & 3,00 & $\mathrm{M}=0,5$ & 3,00 & $\mathrm{M}=0,5$ & 3,00 & $\mathrm{M}=0,5$ & 3,00 & $M=0,5$ & 3,00 & $\mathrm{M}=0,5$ & 3,00 \\
\hline & $\mathrm{N}=14$ & & $\mathrm{~N}=14$ & & $\mathrm{~N}=14$ & & $\mathrm{~N}=14$ & & $\mathrm{~N}=14$ & & $\mathrm{~N}=14$ & \\
\hline & $\mathrm{L}=0,6$ & & $\mathrm{~L}=0,6$ & & $\mathrm{~L}=0,6$ & & $\mathrm{~L}=0,6$ & & $\mathrm{~L}=0,6$ & & $\mathrm{~L}=0,6$ & \\
\hline \multirow[t]{3}{*}{3} & $\mathrm{M}=0,1$ & 3,00 & $\mathrm{M}=0,1$ & 3,00 & $\mathrm{M}=0,1$ & 3,00 & $\mathrm{M}=0,1$ & 3,00 & $\mathrm{M}=0,1$ & 3,00 & $\mathrm{M}=0,1$ & 3,00 \\
\hline & $\mathrm{N}=15$ & & $\mathrm{~N}=15$ & & $\mathrm{~N}=15$ & & $\mathrm{~N}=15$ & & $\mathrm{~N}=15$ & & $\mathrm{~N}=15$ & \\
\hline & $\mathrm{L}=0,3$ & & $\mathrm{~L}=0,3$ & & $\mathrm{~L}=0,3$ & & $\mathrm{~L}=0,3$ & & $\mathrm{~L}=0,3$ & & $\mathrm{~L}=0,3$ & \\
\hline \multirow[t]{3}{*}{4} & $\mathrm{M}=0,5$ & 3,01 & $\mathrm{M}=0,5$ & 3,01 & $\mathrm{M}=0,5$ & 3,01 & $\mathrm{M}=0,5$ & 3,01 & $M=0,5$ & 3,01 & $\mathrm{M}=0,5$ & 3,01 \\
\hline & $\mathrm{N}=15$ & & $\mathrm{~N}=15$ & & $\mathrm{~N}=15$ & & $\mathrm{~N}=15$ & & $\mathrm{~N}=15$ & & $\mathrm{~N}=15$ & \\
\hline & $\mathrm{L}=0,6$ & & $\mathrm{~L}=0,6$ & & $\mathrm{~L}=0,6$ & & $\mathrm{~L}=0,6$ & & $\mathrm{~L}=0,6$ & & $\mathrm{~L}=$ & \\
\hline \multirow[t]{3}{*}{5} & $\mathrm{M}=0,1$ & 3,01 & $\mathrm{M}=0,1$ & 3,01 & $\mathrm{M}=0,1$ & 3,01 & $\mathrm{M}=0,1$ & 3,01 & $\mathrm{M}=0,1$ & 3,01 & $\mathrm{M}=0,1$ & 3,01 \\
\hline & $\mathrm{N}=13$ & & $\mathrm{~N}=13$ & & $\mathrm{~N}=13$ & & $\mathrm{~N}=13$ & & $\mathrm{~N}=13$ & & $\mathrm{~N}=13$ & \\
\hline & $\mathrm{L}=0,6$ & & $\mathrm{~L}=0,6$ & & $\mathrm{~L}=0,6$ & & $\mathrm{~L}=$ & & $\mathrm{L}=0,6$ & & $\mathrm{~L}=$ & \\
\hline \multirow[t]{3}{*}{6} & $\mathrm{M}=0,1$ & 3,01 & $\mathrm{M}=0,1$ & 3,01 & $\mathrm{M}=0,1$ & 3,01 & $\mathrm{M}=0,1$ & 3,01 & $\mathrm{M}=0,1$ & 3,01 & $\mathrm{M}=0,1$ & 3,01 \\
\hline & $\mathrm{N}=14$ & & $\mathrm{~N}=14$ & & $\mathrm{~N}=14$ & & $\mathrm{~N}=14$ & & $\mathrm{~N}=14$ & & $\mathrm{~N}=14$ & \\
\hline & $\mathrm{L}=0,6$ & & $\mathrm{~L}=0$ & & $\mathrm{~L}=0,6$ & & $\mathrm{~L}=$ & & $\mathrm{L}=0,6$ & & $\mathrm{~L}=$ & \\
\hline \multirow[t]{3}{*}{7} & $\mathrm{M}=0,5$ & 3,02 & $\mathrm{M}=0,5$ & 3,02 & $\mathrm{M}=0,5$ & 3,02 & $M=0,5$ & 3,02 & $M=0,5$ & 3,02 & $M=0,5$ & 3,02 \\
\hline & $\mathrm{N}=13$ & & $\mathrm{~N}=$ & & $\mathrm{N}=13$ & & $\mathrm{~N}=$ & & $\mathrm{N}=13$ & & $\mathrm{~N}=$ & \\
\hline & $\mathrm{L}=0,6$ & & $\mathrm{~L}=0,6$ & & $\mathrm{~L}=0,6$ & & $\mathrm{~L}=0,6$ & & $\mathrm{~L}=0,6$ & & $\mathrm{~L}=0,6$ & \\
\hline \multirow[t]{3}{*}{8} & $\mathrm{M}=0,1$ & 3,02 & $\mathrm{M}=0,1$ & 3,02 & $\mathrm{M}=0,1$ & 3,02 & $\mathrm{M}=0,1$ & 3,02 & $\mathrm{M}=0,1$ & 3,02 & $\mathrm{M}=0,1$ & 3,02 \\
\hline & $\mathrm{N}=11$ & & $\mathrm{~N}=$ & & $\mathrm{N}=11$ & & $\mathrm{~N}=$ & & $\mathrm{N}=11$ & & $\mathrm{~N}=$ & \\
\hline & $\mathrm{L}=0,6$ & & $\mathrm{~L}=0,6$ & & $\mathrm{~L}=0,6$ & & $\mathrm{~L}=0,6$ & & $\mathrm{~L}=0,6$ & & $\mathrm{~L}=0,6$ & \\
\hline \multirow[t]{3}{*}{9} & $\mathrm{M}=0,4$ & 3,02 & $\mathrm{M}=0,4$ & 3,02 & $\mathrm{M}=0,4$ & 3,02 & $\mathrm{M}=0,4$ & 3,02 & $\mathrm{M}=0,4$ & 3,02 & $\mathrm{M}=0,4$ & 3,02 \\
\hline & $\mathrm{N}=14$ & & $\mathrm{~N}=14$ & & $\mathrm{~N}=14$ & & $\mathrm{~N}=14$ & & $\mathrm{~N}=14$ & & $\mathrm{~N}=14$ & \\
\hline & $\mathrm{L}=0,6$ & & $\mathrm{~L}=0,6$ & & $\mathrm{~L}=0,6$ & & $\mathrm{~L}=0,6$ & & $\mathrm{~L}=0,6$ & & $\mathrm{~L}=0,6$ & \\
\hline \multirow[t]{3}{*}{10} & $\mathrm{M}=0,4$ & 3,04 & $\mathrm{M}=0,4$ & 3,04 & $\mathrm{M}=0,4$ & 3,04 & $\mathrm{M}=0,4$ & 3,04 & $\mathrm{M}=0,4$ & 3,04 & $\mathrm{M}=0,4$ & 3,04 \\
\hline & $\mathrm{N}=12$ & & $\mathrm{~N}=12$ & & $\mathrm{~N}=12$ & & $\mathrm{~N}=12$ & & $\mathrm{~N}=12$ & & $\mathrm{~N}=12$ & \\
\hline & $\mathrm{L}=0,6$ & & $\mathrm{~L}=0,7$ & & $\mathrm{~L}=0,3$ & & $\mathrm{~L}=0,7$ & & $\mathrm{~L}=0,6$ & & $\mathrm{~L}=0,6$ & \\
\hline \multirow[t]{3}{*}{11} & $\mathrm{M}=0,4$ & 3,04 & $\mathrm{M}=0,5$ & 3,10 & $\mathrm{M}=0,5$ & 3,10 & $M=0,5$ & 3,10 & $\mathrm{M}=0,1$ & 3,07 & $\mathrm{M}=0,1$ & 3,07 \\
\hline & $\mathrm{N}=15$ & & $\mathrm{~N}=6$ & & $\mathrm{~N}=13$ & & $\mathrm{~N}=6$ & & $\mathrm{~N}=7$ & & $\mathrm{~N}=7$ & \\
\hline & $\mathrm{L}=0,6$ & & $\mathrm{~L}=0,6$ & & $\mathrm{~L}=0,6$ & & $\mathrm{~L}=0,2$ & & $\mathrm{~L}=0,7$ & & $\mathrm{~L}=0,7$ & \\
\hline \multirow[t]{2}{*}{12} & $\mathrm{M}=0,5$ & 3,04 & $M=0,5$ & 3,10 & $\mathrm{M}=0,5$ & 3,10 & $\mathrm{M}=0,1$ & 3,10 & $\mathrm{M}=0,5$ & 3,10 & $\mathrm{M}=0,5$ & 3,10 \\
\hline & $\mathrm{N}=12$ & & $\mathrm{~N}=14$ & & $\mathrm{~N}=6$ & & $\mathrm{~N}=15$ & & $N=6$ & & $N=6$ & \\
\hline
\end{tabular}

Tabela 7.4 - EN (\%) dos modelos neurais de interação espacial selecionados através de AGs, construídos com dados de Creches - conclusão 


\begin{tabular}{|c|c|c|c|c|c|c|c|c|c|c|c|c|c|c|}
\hline & \multicolumn{2}{|c|}{ 1a geração } & \multicolumn{2}{|c|}{ 2a geração } & \multicolumn{2}{|c|}{ 3a geração } & \multicolumn{2}{|c|}{ 4a geração } & \multicolumn{2}{|c|}{ 5a geração } & \multicolumn{2}{|c|}{ 6a geração } & \multicolumn{2}{|c|}{ 7a geração } \\
\hline & $\mathrm{L}=0,6$ & & $\mathrm{~L}=0,6$ & & $\mathrm{~L}=0,6$ & & $\mathrm{~L}=0,6$ & & $\mathrm{~L}=0,6$ & & $\mathrm{~L}=0,6$ & & $\mathrm{~L}=0,6$ & \\
\hline \multirow[t]{3}{*}{1} & $\mathrm{M}=0,4$ & 2,18 & $\mathrm{M}=0,1$ & 2,15 & $\mathrm{M}=0,1$ & 2,15 & $\mathrm{M}=0,1$ & 2,15 & $\mathrm{M}=0,5$ & 2,14 & $\mathrm{M}=0,5$ & 2,14 & $\mathrm{M}=0,5$ & 2,14 \\
\hline & $\mathrm{N}=13$ & & $\mathrm{~N}=14$ & & $N=14$ & & $\mathrm{~N}=14$ & & $\mathrm{~N}=14$ & & $\mathrm{~N}=14$ & & $\mathrm{~N}=14$ & \\
\hline & $\mathrm{L}=0,3$ & & $\mathrm{~L}=0,6$ & & $\mathrm{~L}=0,6$ & & $\mathrm{~L}=0,6$ & & $\mathrm{~L}=0,6$ & & $\mathrm{~L}=0,6$ & & $\mathrm{~L}=0,6$ & \\
\hline \multirow[t]{3}{*}{2} & $\mathrm{M}=0,4$ & 2,19 & $\mathrm{M}=0,4$ & 2,17 & $\mathrm{M}=0,4$ & 2,17 & $\mathrm{M}=0,4$ & 2,17 & $\mathrm{M}=0,1$ & 2,15 & $\mathrm{M}=0,1$ & 2,15 & $\mathrm{M}=0,1$ & 2,15 \\
\hline & $\mathrm{N}=6$ & & $\mathrm{~N}=14$ & & $\mathrm{~N}=14$ & & $\mathrm{~N}=14$ & & $\mathrm{~N}=14$ & & $\mathrm{~N}=14$ & & $\mathrm{~N}=14$ & \\
\hline & $\mathrm{L}=0,6$ & & $\mathrm{~L}=0,6$ & & $\mathrm{~L}=0,6$ & & $\mathrm{~L}=0,6$ & & $\mathrm{~L}=0,6$ & & $\mathrm{~L}=0,6$ & & $\mathrm{~L}=0,6$ & \\
\hline \multirow[t]{3}{*}{3} & $\mathrm{M}=0,1$ & 2,20 & $\mathrm{M}=0,4$ & 2,18 & $\mathrm{M}=0,4$ & 2,18 & $\mathrm{M}=0,1$ & 2,17 & $\mathrm{M}=0,4$ & 2,17 & $\mathrm{M}=0,4$ & 2,17 & $\mathrm{M}=0,5$ & 2,16 \\
\hline & $\mathrm{N}=13$ & & $\mathrm{~N}=13$ & & $\mathrm{~N}=13$ & & $\mathrm{~N}=15$ & & $\mathrm{~N}=14$ & & $\mathrm{~N}=14$ & & $\mathrm{~N}=15$ & \\
\hline & $\mathrm{L}=0,6$ & & $\mathrm{~L}=0,6$ & & $\mathrm{~L}=0,6$ & & $\mathrm{~L}=0,6$ & & $\mathrm{~L}=0,6$ & & $\mathrm{~L}=0,6$ & & $\mathrm{~L}=0,6$ & \\
\hline \multirow[t]{3}{*}{4} & $\mathrm{M}=0,1$ & 2,21 & $\mathrm{M}=0,4$ & 2,19 & $\mathrm{M}=0,4$ & 2,19 & $\mathrm{M}=0,4$ & 2,18 & $\mathrm{M}=0,1$ & 2,17 & $\mathrm{M}=0,1$ & 2,17 & $\mathrm{M}=0,4$ & 2,17 \\
\hline & $\mathrm{N}=6$ & & $\mathrm{~N}=6$ & & $\mathrm{~N}=6$ & & $\mathrm{~N}=13$ & & $\mathrm{~N}=15$ & & $\mathrm{~N}=15$ & & $\mathrm{~N}=14$ & \\
\hline & $\mathrm{L}=0,6$ & & $\mathrm{~L}=0,6$ & & $\mathrm{~L}=0,6$ & & $\mathrm{~L}=0,6$ & & $\mathrm{~L}=0,6$ & & $\mathrm{~L}=0,6$ & & $\mathrm{~L}=0,6$ & \\
\hline \multirow[t]{3}{*}{5} & $\mathrm{M}=0,4$ & 2,21 & $\mathrm{M}=0,1$ & 2,20 & $\mathrm{M}=0,1$ & 2,20 & $\mathrm{M}=0,4$ & 2,19 & $\mathrm{M}=0,4$ & 2,18 & $\mathrm{M}=0,4$ & 2,18 & $\mathrm{M}=0,1$ & 2,17 \\
\hline & $\mathrm{N}=8$ & & $\mathrm{~N}=13$ & & $\mathrm{~N}=13$ & & $\mathrm{~N}=6$ & & $\mathrm{~N}=13$ & & $\mathrm{~N}=13$ & & $\mathrm{~N}=15$ & \\
\hline & $\mathrm{L}=0,6$ & & $\mathrm{~L}=0,6$ & & $\mathrm{~L}=0,6$ & & $\mathrm{~L}=0,6$ & & $\mathrm{~L}=0,6$ & & $\mathrm{~L}=0,6$ & & $\mathrm{~L}=0,6$ & \\
\hline \multirow[t]{3}{*}{6} & $\mathrm{M}=0,1$ & 2,24 & $M=0,5$ & 2,20 & $\mathrm{M}=0,5$ & 2,20 & $\mathrm{M}=0,1$ & 2,20 & $\mathrm{M}=0,4$ & 2,19 & $\mathrm{M}=0,4$ & 2,19 & $\mathrm{M}=0,4$ & 2,18 \\
\hline & $\mathrm{N}=3$ & & $\mathrm{~N}=6$ & & $\mathrm{~N}=6$ & & $\mathrm{~N}=13$ & & $\mathrm{~N}=6$ & & $\mathrm{~N}=6$ & & $\mathrm{~N}=13$ & \\
\hline & $\mathrm{L}=0,3$ & & $\mathrm{~L}=0,6$ & & $\mathrm{~L}=0,6$ & & $\mathrm{~L}=0,6$ & & $\mathrm{~L}=0,6$ & & $\mathrm{~L}=0,6$ & & $\mathrm{~L}=0,6$ & \\
\hline \multirow[t]{3}{*}{7} & $\mathrm{M}=0,1$ & 2,24 & $\mathrm{M}=0,1$ & 2,21 & $\mathrm{M}=0,5$ & 2,21 & $\mathrm{M}=0,5$ & 2,20 & $\mathrm{M}=0,1$ & 2,20 & $\mathrm{M}=0,1$ & 2,20 & $\mathrm{M}=0,4$ & 2,19 \\
\hline & $\mathrm{N}=13$ & & $\mathrm{~N}=6$ & & $\mathrm{~N}=5$ & & $\mathrm{~N}=6$ & & $\mathrm{~N}=13$ & & $\mathrm{~N}=13$ & & $\mathrm{~N}=6$ & \\
\hline & $\mathrm{L}=0,6$ & & $\mathrm{~L}=0,6$ & & $\mathrm{~L}=0,6$ & & $\mathrm{~L}=0,6$ & & $\mathrm{~L}=0,6$ & & $\mathrm{~L}=0,6$ & & $\mathrm{~L}=0,6$ & \\
\hline \multirow[t]{3}{*}{8} & $\mathrm{M}=0,1$ & 2,25 & $\mathrm{M}=0,4$ & 2,21 & $\mathrm{M}=0,1$ & 2,21 & $\mathrm{M}=0,4$ & 2,20 & $M=0,5$ & 2,20 & $\mathrm{M}=0,5$ & 2,20 & $\mathrm{M}=0,0$ & 2,20 \\
\hline & $\mathrm{N}=8$ & & $\mathrm{~N}=5$ & & $\mathrm{~N}=6$ & & $\mathrm{~N}=12$ & & $\mathrm{~N}=6$ & & $\mathrm{~N}=6$ & & $\mathrm{~N}=13$ & \\
\hline & $\mathrm{L}=0,3$ & & $\mathrm{~L}=0,6$ & & $\mathrm{~L}=0,6$ & & $\mathrm{~L}=0,6$ & & $\mathrm{~L}=0,6$ & & $\mathrm{~L}=0,6$ & & $\mathrm{~L}=0,6$ & \\
\hline \multirow[t]{3}{*}{9} & $\mathrm{M}=0,1$ & 2,27 & $\mathrm{M}=0,4$ & 2,21 & $\mathrm{M}=0,4$ & 2,21 & $\mathrm{M}=0,5$ & 2,21 & $\mathrm{M}=0,4$ & 2,20 & $\mathrm{M}=0,4$ & 2,20 & $\mathrm{M}=0,1$ & 2,20 \\
\hline & $\mathrm{N}=6$ & & $\mathrm{~N}=8$ & & $\mathrm{~N}=5$ & & $\mathrm{~N}=5$ & & $\mathrm{~N}=12$ & & $\mathrm{~N}=12$ & & $\mathrm{~N}=13$ & \\
\hline & $\mathrm{L}=0,3$ & & $\mathrm{~L}=0,6$ & & $\mathrm{~L}=0,6$ & & $\mathrm{~L}=0,6$ & & $\mathrm{~L}=0,6$ & & $\mathrm{~L}=0,6$ & & $\mathrm{~L}=0,6$ & \\
\hline \multirow[t]{3}{*}{10} & $\mathrm{M}=0,1$ & 2,27 & $\mathrm{M}=0,1$ & 2,24 & $\mathrm{M}=0,4$ & 2,21 & $\mathrm{M}=0,1$ & 2,21 & $\mathrm{M}=0,5$ & 2,21 & $\mathrm{M}=0,5$ & 2,21 & $\mathrm{M}=0,5$ & 2,20 \\
\hline & $\mathrm{N}=3$ & & $\mathrm{~N}=13$ & & $\mathrm{~N}=8$ & & $\mathrm{~N}=6$ & & $\mathrm{~N}=5$ & & $\mathrm{~N}=5$ & & $\mathrm{~N}=6$ & \\
\hline & $\mathrm{L}=0,3$ & & $\mathrm{~L}=0,3$ & & $\mathrm{~L}=0,6$ & & $\mathrm{~L}=0,6$ & & $\mathrm{~L}=0,6$ & & $\mathrm{~L}=0,6$ & & $\mathrm{~L}=0,6$ & \\
\hline \multirow[t]{3}{*}{11} & $\mathrm{M}=0,1$ & 2,28 & $\mathrm{M}=0,1$ & 2,24 & $\mathrm{M}=0,1$ & 2,24 & $\mathrm{M}=0,4$ & 2,21 & $\mathrm{M}=0,1$ & 2,21 & $\mathrm{M}=0,1$ & 2,21 & $\mathrm{M}=0,4$ & 2,20 \\
\hline & $\mathrm{N}=8$ & & $\mathrm{~N}=13$ & & $\mathrm{~N}=13$ & & $\mathrm{~N}=5$ & & $\mathrm{~N}=6$ & & $\mathrm{~N}=6$ & & $\mathrm{~N}=12$ & \\
\hline & $\mathrm{L}=0,6$ & & $\mathrm{~L}=0,6$ & & $\mathrm{~L}=0,3$ & & $\mathrm{~L}=0,6$ & & $\mathrm{~L}=0,6$ & & $\mathrm{~L}=0,6$ & & $\mathrm{~L}=0,6$ & \\
\hline \multirow[t]{2}{*}{12} & $\mathrm{M}=0,4$ & 2,29 & $\mathrm{M}=0,0$ & 2,25 & $\mathrm{M}=0,1$ & 2,24 & $\mathrm{M}=0,4$ & 2,21 & $\mathrm{M}=0,0$ & 2,22 & $\mathrm{M}=0,0$ & 2,22 & $\mathrm{M}=0,5$ & 2,21 \\
\hline & $\mathrm{N}=3$ & & $\mathrm{~N}=8$ & & $\mathrm{~N}=13$ & & $\mathrm{~N}=8$ & & $\mathrm{~N}=6$ & & $N=6$ & & $\mathrm{~N}=5$ & \\
\hline
\end{tabular}

Tabela 7.5 - EN (\%) dos modelos neurais de interação espacial selecionados através de AGs, construídos com dados de EMEIs - continua 


\begin{tabular}{|c|c|c|c|c|c|c|c|c|c|c|c|c|c|c|}
\hline & \multicolumn{2}{|c|}{ 8a geração } & \multicolumn{2}{|c|}{ 9a geração } & \multicolumn{2}{|c|}{ 10a geração } & \multicolumn{2}{|c|}{11 geração } & \multicolumn{2}{|c|}{ 12a geração } & \multicolumn{2}{|c|}{ 13a geração } & \multicolumn{2}{|c|}{ 14a geração } \\
\hline & $\mathrm{L}=0,6$ & & $\mathrm{~L}=0,6$ & & $\mathrm{~L}=0,7$ & & $\mathrm{~L}=0,7$ & & $\mathrm{~L}=0,7$ & & $\mathrm{~L}=0,7$ & & $\mathrm{~L}=0,7$ & \\
\hline \multirow[t]{3}{*}{1} & $\mathrm{M}=0,5$ & 2,14 & $\mathrm{M}=0,5$ & 2,14 & $\mathrm{M}=0,5$ & 2,11 & $\mathrm{M}=0,5$ & 2,11 & $\mathrm{M}=0,5$ & 2,11 & $\mathrm{M}=0,5$ & 2,11 & $\mathrm{M}=0,5$ & 2,11 \\
\hline & $\mathrm{N}=14$ & & $\mathrm{~N}=14$ & & $\mathrm{~N}=14$ & & $\mathrm{~N}=14$ & & $\mathrm{~N}=14$ & & $\mathrm{~N}=14$ & & $\mathrm{~N}=14$ & \\
\hline & $\mathrm{L}=0,6$ & & $\mathrm{~L}=0,6$ & & $\mathrm{~L}=0,6$ & & $\mathrm{~L}=0,6$ & & $\mathrm{~L}=0,6$ & & $\mathrm{~L}=0,6$ & & $\mathrm{~L}=0,6$ & \\
\hline \multirow[t]{3}{*}{2} & $\mathrm{M}=0,1$ & 2,15 & $\mathrm{M}=0,1$ & 2,15 & $\mathrm{M}=0,5$ & 2,14 & $\mathrm{M}=0,5$ & 2,14 & $\mathrm{M}=0,5$ & 2,14 & $\mathrm{M}=0,5$ & 2,14 & $\mathrm{M}=0,5$ & 2,14 \\
\hline & $\mathrm{N}=14$ & & $\mathrm{~N}=14$ & & $\mathrm{~N}=14$ & & $\mathrm{~N}=14$ & & $\mathrm{~N}=14$ & & $\mathrm{~N}=14$ & & $\mathrm{~N}=14$ & \\
\hline & $\mathrm{L}=0,6$ & & $\mathrm{~L}=0,6$ & & $\mathrm{~L}=0,6$ & & $\mathrm{~L}=0,7$ & & $\mathrm{~L}=0,7$ & & $\mathrm{~L}=0,7$ & & $\mathrm{~L}=0,7$ & \\
\hline \multirow[t]{3}{*}{3} & $\mathrm{M}=0,0$ & 2,16 & $\mathrm{M}=0,0$ & 2,16 & $\mathrm{M}=0,1$ & 2,15 & $\mathrm{M}=0,4$ & 2,15 & $\mathrm{M}=0,4$ & 2,15 & $\mathrm{M}=0,4$ & 2,15 & $\mathrm{M}=0,4$ & 2,15 \\
\hline & $\mathrm{N}=14$ & & $\mathrm{~N}=14$ & & $\mathrm{~N}=14$ & & $\mathrm{~N}=14$ & & $\mathrm{~N}=14$ & & $\mathrm{~N}=14$ & & $\mathrm{~N}=14$ & \\
\hline & $\mathrm{L}=0,6$ & & $\mathrm{~L}=0,6$ & & $\mathrm{~L}=0,6$ & & $\mathrm{~L}=0,6$ & & $\mathrm{~L}=0,6$ & & $\mathrm{~L}=0,6$ & & $\mathrm{~L}=0,6$ & \\
\hline \multirow[t]{3}{*}{4} & $\mathrm{M}=0,5$ & 2,16 & $\mathrm{M}=0,5$ & 2,16 & $\mathrm{M}=0,0$ & 2,16 & $\mathrm{M}=0,1$ & 2,15 & $\mathrm{M}=0,1$ & 2,15 & $\mathrm{M}=0,1$ & 2,15 & $\mathrm{M}=0,1$ & 2,15 \\
\hline & $\mathrm{N}=15$ & & $\mathrm{~N}=15$ & & $\mathrm{~N}=14$ & & $\mathrm{~N}=14$ & & $\mathrm{~N}=14$ & & $\mathrm{~N}=14$ & & $\mathrm{~N}=14$ & \\
\hline & $\mathrm{L}=0,6$ & & $\mathrm{~L}=0,6$ & & $\mathrm{~L}=0,6$ & & $\mathrm{~L}=0,6$ & & $\mathrm{~L}=0,6$ & & $\mathrm{~L}=0,6$ & & $\mathrm{~L}=0,6$ & \\
\hline \multirow[t]{3}{*}{5} & $\mathrm{M}=0,4$ & 2,17 & $\mathrm{M}=0,4$ & 2,17 & $\mathrm{M}=0,5$ & 2,16 & $\mathrm{M}=0,0$ & 2,16 & $\mathrm{M}=0,0$ & 2,16 & $\mathrm{M}=0,0$ & 2,16 & $\mathrm{M}=0,0$ & 2,16 \\
\hline & $\mathrm{N}=14$ & & $\mathrm{~N}=14$ & & $N=15$ & & $\mathrm{~N}=14$ & & $\mathrm{~N}=14$ & & $\mathrm{~N}=14$ & & $\mathrm{~N}=14$ & \\
\hline & $\mathrm{L}=0,6$ & & $\mathrm{~L}=0,6$ & & $\mathrm{~L}=0,6$ & & $\mathrm{~L}=0,6$ & & $\mathrm{~L}=0,6$ & & $\mathrm{~L}=0,6$ & & $\mathrm{~L}=0,6$ & \\
\hline \multirow[t]{3}{*}{6} & $\mathrm{M}=0,1$ & 2,17 & $\mathrm{M}=0,1$ & 2,17 & $\mathrm{M}=0,4$ & 2,17 & $\mathrm{M}=0,5$ & 2,16 & $\mathrm{M}=0,5$ & 2,16 & $\mathrm{M}=0,5$ & 2,16 & $\mathrm{M}=0,5$ & 2,16 \\
\hline & $\mathrm{N}=15$ & & $\mathrm{~N}=15$ & & $\mathrm{~N}=14$ & & $\mathrm{~N}=15$ & & $\mathrm{~N}=15$ & & $\mathrm{~N}=15$ & & $\mathrm{~N}=15$ & \\
\hline & $\mathrm{L}=0,6$ & & $\mathrm{~L}=0,6$ & & $\mathrm{~L}=0,5$ & & $\mathrm{~L}=0,6$ & & $\mathrm{~L}=0,7$ & & $\mathrm{~L}=0,7$ & & $\mathrm{~L}=0,7$ & \\
\hline \multirow[t]{3}{*}{7} & $\mathrm{M}=0,4$ & 2,18 & $\mathrm{M}=0,4$ & 2,18 & $\mathrm{M}=0,5$ & 2,17 & $\mathrm{M}=0,4$ & 2,17 & $\mathrm{M}=0,1$ & 2,17 & $\mathrm{M}=0,1$ & 2,17 & $\mathrm{M}=0,1$ & 2,17 \\
\hline & $\mathrm{N}=13$ & & $\mathrm{~N}=13$ & & $\mathrm{~N}=14$ & & $\mathrm{~N}=14$ & & $\mathrm{~N}=14$ & & $\mathrm{~N}=14$ & & $\mathrm{~N}=14$ & \\
\hline & $\mathrm{L}=0,6$ & & $\mathrm{~L}=0,6$ & & $\mathrm{~L}=0,6$ & & $\mathrm{~L}=0,5$ & & $\mathrm{~L}=0,6$ & & $\mathrm{~L}=0,6$ & & $\mathrm{~L}=0,6$ & \\
\hline \multirow[t]{3}{*}{8} & $\mathrm{M}=0,4$ & 2,19 & $\mathrm{M}=0,4$ & 2,19 & $\mathrm{M}=0,1$ & 2,17 & $\mathrm{M}=0,5$ & 2,17 & $\mathrm{M}=0,4$ & 2,17 & $\mathrm{M}=0,4$ & 2,17 & $\mathrm{M}=0,4$ & 2,17 \\
\hline & $\mathrm{N}=6$ & & $\mathrm{~N}=15$ & & $\mathrm{~N}=15$ & & $\mathrm{~N}=14$ & & $\mathrm{~N}=14$ & & $\mathrm{~N}=14$ & & $\mathrm{~N}=14$ & \\
\hline & $\mathrm{L}=0,6$ & & $\mathrm{~L}=0,6$ & & $\mathrm{~L}=0,6$ & & $\mathrm{~L}=0,6$ & & $\mathrm{~L}=0,5$ & & $\mathrm{~L}=0,5$ & & $\mathrm{~L}=0,5$ & \\
\hline \multirow[t]{3}{*}{9} & $\mathrm{M}=0,0$ & 2,20 & $\mathrm{M}=0,4$ & 2,19 & $\mathrm{M}=0,4$ & 2,18 & $\mathrm{M}=0,1$ & 2,17 & $\mathrm{M}=0,5$ & 2,17 & $\mathrm{M}=0,5$ & 2,17 & $\mathrm{M}=0,5$ & 2,17 \\
\hline & $\mathrm{N}=13$ & & $\mathrm{~N}=6$ & & $\mathrm{~N}=13$ & & $\mathrm{~N}=15$ & & $\mathrm{~N}=14$ & & $\mathrm{~N}=14$ & & $\mathrm{~N}=14$ & \\
\hline & $\mathrm{L}=0,6$ & & $\mathrm{~L}=0,6$ & & $\mathrm{~L}=0,6$ & & $\mathrm{~L}=0,6$ & & $\mathrm{~L}=0,6$ & & $\mathrm{~L}=0,6$ & & $\mathrm{~L}=0,6$ & \\
\hline \multirow[t]{3}{*}{10} & $\mathrm{M}=0,1$ & 2,20 & $\mathrm{M}=0,0$ & 2,20 & $\mathrm{M}=0,4$ & 2,19 & $\mathrm{M}=0,4$ & 2,18 & $\mathrm{M}=0,1$ & 2,17 & $\mathrm{M}=0,1$ & 2,17 & $\mathrm{M}=0,1$ & 2,17 \\
\hline & $\mathrm{N}=13$ & & $\mathrm{~N}=13$ & & $\mathrm{~N}=15$ & & $\mathrm{~N}=13$ & & $\mathrm{~N}=15$ & & $\mathrm{~N}=15$ & & $\mathrm{~N}=15$ & \\
\hline & $\mathrm{L}=0,6$ & & $\mathrm{~L}=0,6$ & & $\mathrm{~L}=0,6$ & & $\mathrm{~L}=0,6$ & & $\mathrm{~L}=0,6$ & & $\mathrm{~L}=0,6$ & & $\mathrm{~L}=0,6$ & \\
\hline \multirow[t]{3}{*}{11} & $\mathrm{M}=0,5$ & 2,20 & $\mathrm{M}=0,1$ & 2,20 & $\mathrm{M}=0,4$ & 2,19 & $\mathrm{M}=0,4$ & 2,19 & $\mathrm{M}=0,4$ & 2,18 & $\mathrm{M}=0,0$ & 2,18 & $\mathrm{M}=0,0$ & 2,18 \\
\hline & $\mathrm{N}=6$ & & $\mathrm{~N}=13$ & & $\mathrm{~N}=6$ & & $\mathrm{~N}=15$ & & $\mathrm{~N}=13$ & & $\mathrm{~N}=15$ & & $\mathrm{~N}=15$ & \\
\hline & $\mathrm{L}=0,6$ & & $\mathrm{~L}=0,6$ & & $\mathrm{~L}=0,6$ & & $\mathrm{~L}=0,6$ & & $\mathrm{~L}=0,6$ & & $\mathrm{~L}=0,6$ & & $\mathrm{~L}=0,6$ & \\
\hline \multirow[t]{2}{*}{12} & $\mathrm{M}=0,4$ & 2,20 & $\mathrm{M}=0,5$ & 2,20 & $\mathrm{M}=0,0$ & 2,20 & $\mathrm{M}=0,4$ & 2,19 & $\mathrm{M}=0,4$ & 2,19 & $\mathrm{M}=0,4$ & 2,18 & $\mathrm{M}=0,4$ & 2,18 \\
\hline & $\mathrm{N}=12$ & & $N=6$ & & $\mathrm{~N}=13$ & & $N=6$ & & $\mathrm{~N}=15$ & & $\mathrm{~N}=13$ & & $\mathrm{~N}=13$ & \\
\hline
\end{tabular}

Tabela 7.5 - EN (\%) dos modelos neurais de interação espacial selecionados através de AGs, construídos com dados de EMEIs - continuação 


\begin{tabular}{|c|c|c|c|c|c|c|c|c|c|c|c|c|}
\hline & \multicolumn{2}{|c|}{ 15a geração } & \multicolumn{2}{|c|}{ 16a geração } & \multicolumn{2}{|c|}{ 17a geração } & \multicolumn{2}{|c|}{ 18a geração } & \multicolumn{2}{|c|}{ 19a geração } & \multicolumn{2}{|c|}{ 20a geração } \\
\hline & $\mathrm{L}=0,7$ & & $\mathrm{~L}=0,7$ & & $\mathrm{~L}=0,7$ & & $\mathrm{~L}=0,7$ & & $\mathrm{~L}=0,7$ & & $\mathrm{~L}=0,7$ & \\
\hline \multirow[t]{3}{*}{1} & $\mathrm{M}=0,5$ & 2,11 & $\mathrm{M}=0,5$ & 2,11 & $\mathrm{M}=0,5$ & 2,11 & $M=0,5$ & 2,11 & $\mathrm{M}=0,5$ & 2,11 & $\mathrm{M}=0,5$ & 2,11 \\
\hline & $\mathrm{N}=14$ & & $\mathrm{~N}=14$ & & $\mathrm{~N}=14$ & & $\mathrm{~N}=14$ & & $\mathrm{~N}=14$ & & $\mathrm{~N}=14$ & \\
\hline & $\mathrm{L}=0,6$ & & $\mathrm{~L}=0,7$ & & $\mathrm{~L}=0,7$ & & $\mathrm{~L}=0,7$ & & $\mathrm{~L}=0,7$ & & $\mathrm{~L}=0,7$ & \\
\hline \multirow[t]{3}{*}{2} & $\mathrm{M}=0,5$ & 2,14 & $\mathrm{M}=0,5$ & 2,13 & $\mathrm{M}=0,5$ & 2,13 & $\mathrm{M}=0,5$ & 2,13 & $\mathrm{M}=0,5$ & 2,13 & $\mathrm{M}=0,5$ & 2,13 \\
\hline & $\mathrm{N}=14$ & & $\mathrm{~N}=15$ & & $\mathrm{~N}=15$ & & $\mathrm{~N}=15$ & & $\mathrm{~N}=15$ & & $\mathrm{~N}=15$ & \\
\hline & $\mathrm{L}=0,7$ & & $\mathrm{~L}=0,6$ & & $\mathrm{~L}=0,6$ & & $\mathrm{~L}=0,6$ & & $\mathrm{~L}=0,6$ & & $\mathrm{~L}=0,6$ & \\
\hline \multirow[t]{3}{*}{3} & $\mathrm{M}=0,4$ & 2,15 & $\mathrm{M}=0,5$ & 2,14 & $\mathrm{M}=0,5$ & 2,14 & $\mathrm{M}=0,5$ & 2,14 & $\mathrm{M}=0,5$ & 2,14 & $\mathrm{M}=0,5$ & 2,14 \\
\hline & $\mathrm{N}=14$ & & $\mathrm{~N}=14$ & & $\mathrm{~N}=14$ & & $\mathrm{~N}=14$ & & $\mathrm{~N}=14$ & & $\mathrm{~N}=14$ & \\
\hline & $\mathrm{L}=0,6$ & & $\mathrm{~L}=0,7$ & & $\mathrm{~L}=0,7$ & & $\mathrm{~L}=0,7$ & & $\mathrm{~L}=0,7$ & & $\mathrm{~L}=0,7$ & \\
\hline \multirow[t]{3}{*}{4} & $\mathrm{M}=0,1$ & 2,15 & $M=0,4$ & 2,15 & $\mathrm{M}=0,4$ & 2,15 & $\mathrm{M}=0,4$ & 2,15 & $\mathrm{M}=0,4$ & 2,15 & $\mathrm{M}=0,4$ & 2,15 \\
\hline & $\mathrm{N}=14$ & & $\mathrm{~N}=14$ & & $\mathrm{~N}=14$ & & $\mathrm{~N}=14$ & & $\mathrm{~N}=14$ & & $\mathrm{~N}=14$ & \\
\hline & $\mathrm{L}=0,6$ & & $\mathrm{~L}=0,6$ & & $\mathrm{~L}=0,6$ & & $\mathrm{~L}=0,6$ & & $\mathrm{~L}=0,6$ & & $\mathrm{~L}=0,6$ & \\
\hline \multirow[t]{3}{*}{5} & $\mathrm{M}=0,0$ & 2,16 & $\mathrm{M}=0,1$ & 2,15 & $\mathrm{M}=0,1$ & 2,15 & $\mathrm{M}=0,1$ & 2,15 & $\mathrm{M}=0,1$ & 2,15 & $\mathrm{M}=0,1$ & 2,15 \\
\hline & $\mathrm{N}=14$ & & $\mathrm{~N}=14$ & & $\mathrm{~N}=14$ & & $\mathrm{~N}=14$ & & $\mathrm{~N}=14$ & & $\mathrm{~N}=14$ & \\
\hline & $\mathrm{L}=0,6$ & & $\mathrm{~L}=0,6$ & & $\mathrm{~L}=0,6$ & & $\mathrm{~L}=0,6$ & & $\mathrm{~L}=0,6$ & & $\mathrm{~L}=0,6$ & \\
\hline \multirow[t]{3}{*}{6} & $\mathrm{M}=0,5$ & 2,16 & $\mathrm{M}=0,0$ & 2,16 & $\mathrm{M}=0,0$ & 2,16 & $\mathrm{M}=0,0$ & 2,16 & $\mathrm{M}=0,0$ & 2,16 & $\mathrm{M}=0,0$ & 2,16 \\
\hline & $\mathrm{N}=15$ & & $\mathrm{~N}=14$ & & $\mathrm{~N}=14$ & & $\mathrm{~N}=14$ & & $\mathrm{~N}=14$ & & $\mathrm{~N}=14$ & \\
\hline & $\mathrm{L}=0,7$ & & $\mathrm{~L}=0,7$ & & $\mathrm{~L}=0,7$ & & $\mathrm{~L}=0,7$ & & $\mathrm{~L}=0,7$ & & $\mathrm{~L}=0,7$ & \\
\hline \multirow[t]{3}{*}{7} & $\mathrm{M}=0,1$ & 2,17 & $\mathrm{M}=0,0$ & 2,16 & $\mathrm{M}=0,0$ & 2,16 & $\mathrm{M}=0,0$ & 2,16 & $\mathrm{M}=0,0$ & 2,16 & $\mathrm{M}=0,0$ & 2,16 \\
\hline & $\mathrm{N}=14$ & & $\mathrm{~N}=14$ & & $\mathrm{~N}=14$ & & $\mathrm{~N}=14$ & & $\mathrm{~N}=14$ & & $\mathrm{~N}=14$ & \\
\hline & $\mathrm{L}=0,6$ & & $\mathrm{~L}=0,6$ & & $\mathrm{~L}=0,6$ & & $\mathrm{~L}=0,6$ & & $\mathrm{~L}=0,6$ & & $\mathrm{~L}=0,6$ & \\
\hline \multirow[t]{3}{*}{8} & $\mathrm{M}=0,4$ & 2,17 & $M=0,5$ & 2,16 & $M=0,5$ & 2,16 & $M=0,5$ & 2,16 & $\mathrm{M}=0,5$ & 2,16 & $M=0,5$ & 2,16 \\
\hline & $\mathrm{N}=14$ & & $\mathrm{~N}=15$ & & $\mathrm{~N}=15$ & & $\mathrm{~N}=15$ & & $\mathrm{~N}=15$ & & $\mathrm{~N}=15$ & \\
\hline & $\mathrm{L}=0,5$ & & $\mathrm{~L}=0,7$ & & $\mathrm{~L}=0,7$ & & $\mathrm{~L}=0,7$ & & $\mathrm{~L}=0,7$ & & $\mathrm{~L}=0,7$ & \\
\hline \multirow[t]{3}{*}{9} & $\mathrm{M}=0,5$ & 2,17 & $\mathrm{M}=0,1$ & 2,17 & $\mathrm{M}=0,1$ & 2,17 & $\mathrm{M}=0,4$ & 2,16 & $\mathrm{M}=0,4$ & 2,16 & $M=0,4$ & 2,16 \\
\hline & $\mathrm{N}=14$ & & $\mathrm{~N}=14$ & & $\mathrm{~N}=14$ & & $\mathrm{~N}=15$ & & $\mathrm{~N}=15$ & & $\mathrm{~N}=15$ & \\
\hline & $\mathrm{L}=0,6$ & & $\mathrm{~L}=0,6$ & & $\mathrm{~L}=0,6$ & & $\mathrm{~L}=0,7$ & & $\mathrm{~L}=0,7$ & & $\mathrm{~L}=0,7$ & \\
\hline \multirow[t]{3}{*}{10} & $\mathrm{M}=0,1$ & 2,17 & $\mathrm{M}=0,4$ & 2,17 & $\mathrm{M}=0,4$ & 2,17 & $\mathrm{M}=0,1$ & 2,17 & $\mathrm{M}=0,1$ & 2,17 & $\mathrm{M}=0,1$ & 2,17 \\
\hline & $\mathrm{N}=15$ & & $\mathrm{~N}=14$ & & $\mathrm{~N}=14$ & & $\mathrm{~N}=14$ & & $\mathrm{~N}=14$ & & $\mathrm{~N}=14$ & \\
\hline & $\mathrm{L}=0,6$ & & $\mathrm{~L}=0,5$ & & $\mathrm{~L}=0,5$ & & $\mathrm{~L}=0,6$ & & $\mathrm{~L}=0,6$ & & $\mathrm{~L}=0,6$ & \\
\hline \multirow[t]{3}{*}{11} & $\mathrm{M}=0,0$ & 2,18 & $\mathrm{M}=0,5$ & 2,17 & $\mathrm{M}=0,5$ & 2,17 & $\mathrm{M}=0,4$ & 2,17 & $\mathrm{M}=0,4$ & 2,17 & $\mathrm{M}=0,4$ & 2,17 \\
\hline & $\mathrm{N}=15$ & & $\mathrm{~N}=14$ & & $\mathrm{~N}=14$ & & $\mathrm{~N}=14$ & & $\mathrm{~N}=14$ & & $\mathrm{~N}=14$ & \\
\hline & $\mathrm{L}=0,3$ & & $\mathrm{~L}=0,6$ & & $\mathrm{~L}=0,6$ & & $\mathrm{~L}=0,7$ & & $\mathrm{~L}=0,7$ & & $\mathrm{~L}=0,7$ & \\
\hline \multirow[t]{2}{*}{12} & $\mathrm{M}=0,4$ & 2,29 & $\mathrm{M}=0,1$ & 2,17 & $\mathrm{M}=0,1$ & 2,17 & $\mathrm{M}=0,1$ & 2,17 & $\mathrm{M}=0,1$ & 2,17 & $\mathrm{M}=0,1$ & 2,17 \\
\hline & $\mathrm{N}=5$ & & $\mathrm{~N}=15$ & & $\mathrm{~N}=15$ & & $\mathrm{~N}=15$ & & $\mathrm{~N}=15$ & & $\mathrm{~N}=15$ & \\
\hline
\end{tabular}

Tabela 7.5 - EN (\%) dos modelos neurais de interação espacial selecionados através de AGs, construídos com dados de EMEIs - conclusão

\subsection{A Lógica Interna nos Modelos Neurais de Interação Espacial}

Com o propósito de verificar a lógica intrínseca aos modelos, a partir das redes neurais selecionadas através dos Algoritmos Genéticos, Akamine e Silva (2005) realizaram um estudo com o objetivo de explorar os modelos no desenvolvimento de ábacos que possam ser utilizados como ferramentas de planejamento mais simples e diretas, além de ajudarem aos planejadores e tomadores de decisão a entender a lógica 
dos modelos neurais de interação espacial.

Seguindo a metodologia apresentada no trabalho de Bocanegra (2002), a partir da identificação da arquitetura da rede treinada para as creches e EMEIs $(\mathrm{N}=14$, $\mathrm{L}=0,7$ e $\mathrm{M}=0,5)$ e dos valores dos pesos nas conexões entre nós e dos bias associados a cada nó, calculados pelo software EasyNN-plus, foi possível replicar o modelo em uma planilha eletrônica. Foram, então, construídos gráficos que ilustram a relação entre as três variáveis de entrada (viagens produzidas, viagens atraídas e distâncias) e a variável de saída (fluxo de viagens). Nas Figuras 7.13 a 7.22 pode-se avaliar o impacto do total de viagens produzidas e do total de viagens atraídas, no fluxo de viagens, para diferentes distâncias de deslocamento $(0,5 ; 1,0 ; 1,5 ; 2,0 ; 2,5 ; 3,0 ; 3,5 ; 4,0 ; 4,5 ; 5,0 \mathrm{~km})$, para modelos neurais de interação espacial construídos a partir de dados das Creches municipais. Nas Figuras 7.23 a 7.32 são apresentados os mesmos gráficos, porém agora construídos com dados das EMEIs. As Figuras 7.33 a 7.38 trazem, ainda, os mesmos gráficos (para as distâncias de deslocamento 0,5;2,5 e 5,0 km) representando o total de viagens produzidas, o total de viagens atraídas e os fluxos de viagens, através de uma superfície tridimensional. 


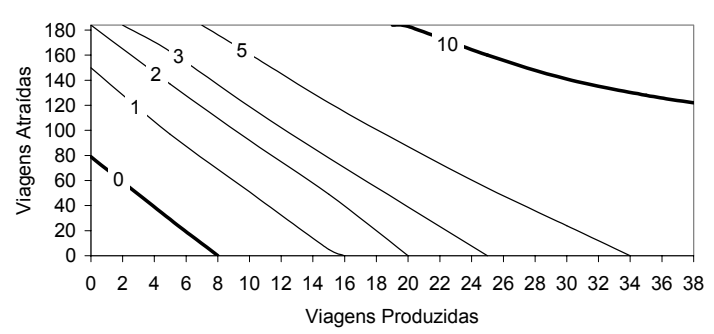

Figura 7.13 - Fluxos de viagens para Creches com distância de 0,5 quilômetro

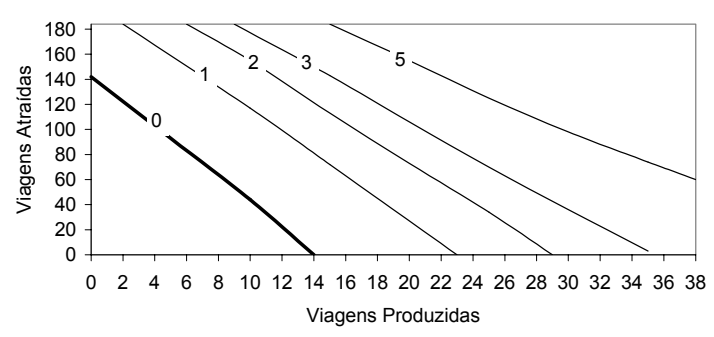

Figura 7.15 - Fluxos de viagens para Creches com distância de 1,5 quilômetro

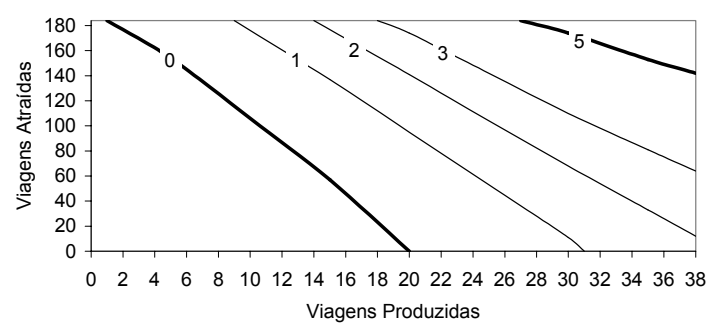

Figura 7.17 - Fluxos de viagens para Creches com distância de 2,5 quilômetros

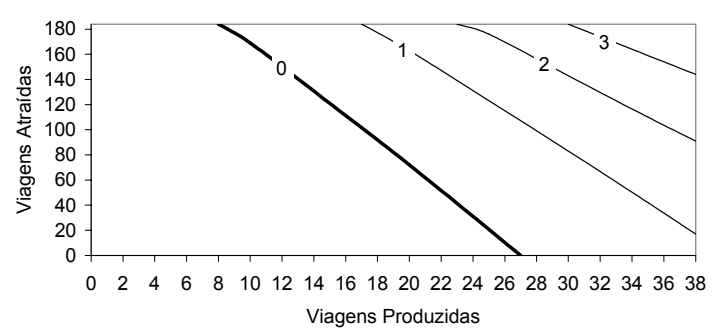

Figura 7.19 - Fluxos de viagens para Creches com distância de 3,5 quilômetros

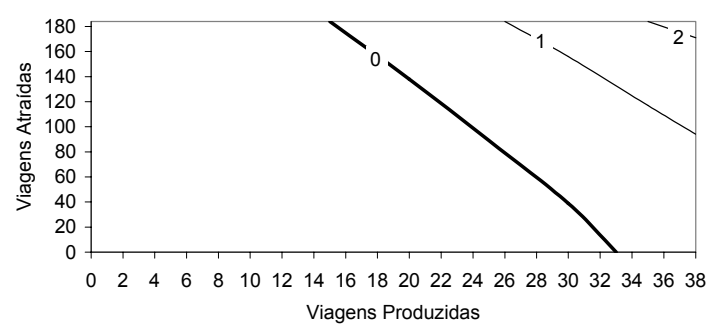

Figura 7.21 - Fluxos de viagens para Creches com distância de 4,5 quilômetros

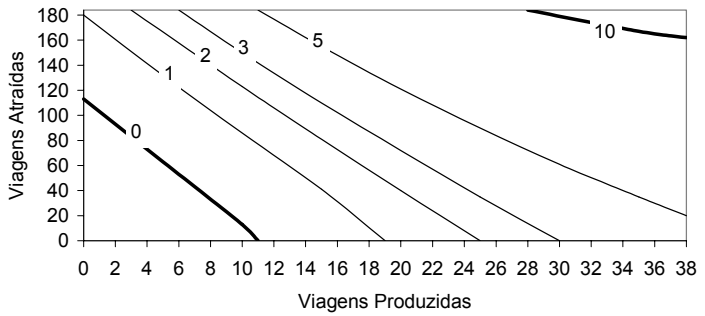

Figura 7.14 - Fluxos de viagens para Creches com distância de 1,0 quilômetro

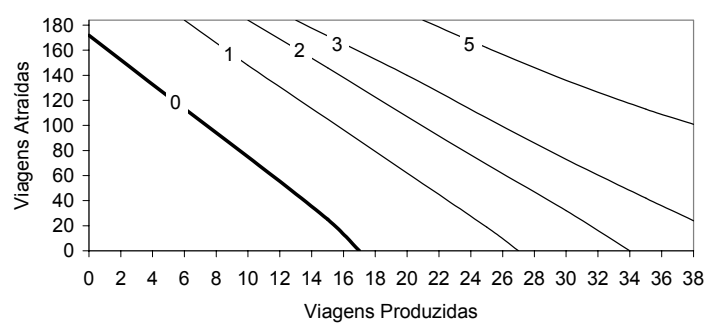

Figura 7.16 - Fluxos de viagens para Creches com distância de 2,0 quilômetros

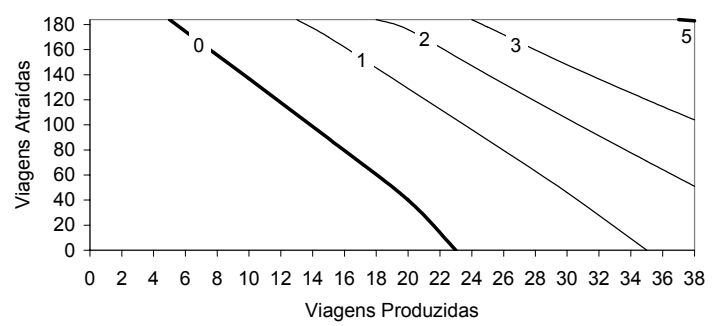

Figura 7.18 - Fluxos de viagens para Creches com distância de 3,0 quilômetros

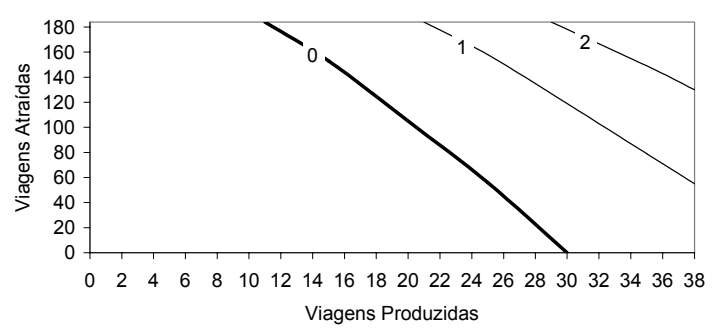

Figura 7.20 - Fluxos de viagens para Creches distância de 4,0 quilômetros

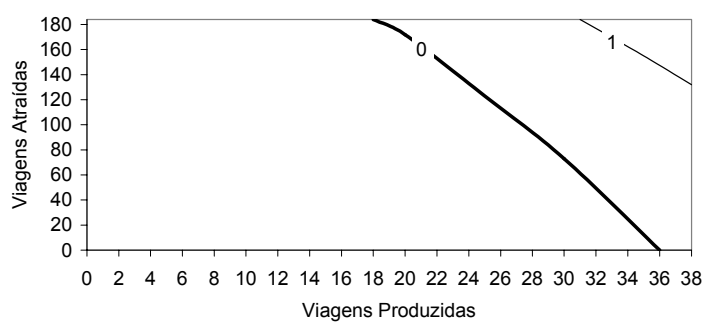

Figura 7.22 - Fluxos de viagens para Creches com distância de 5,0 quilômetros 


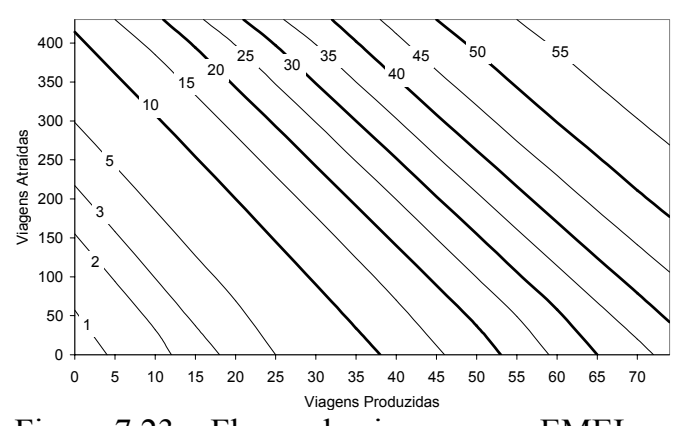

Figura 7.23 - Fluxos de viagens para EMEIs

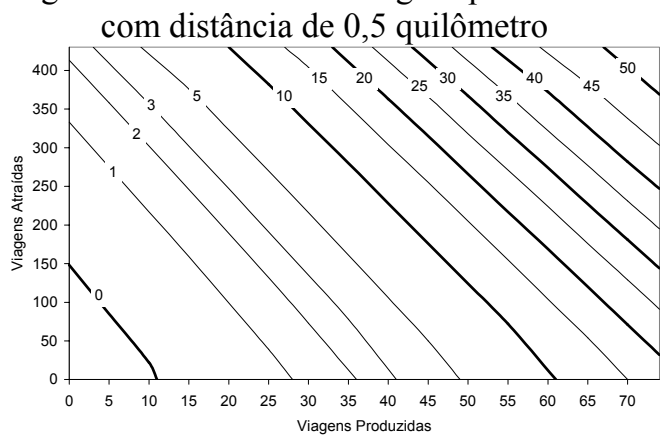

Figura 7.25 - Fluxos de viagens para EMEIs

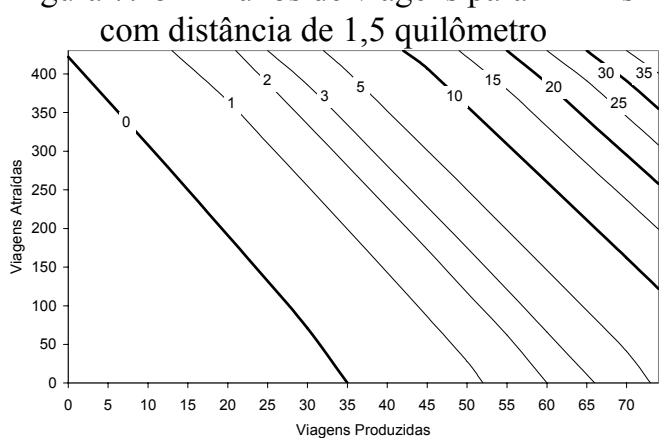

Figura 7.27 - Fluxos de viagens para EMEIs

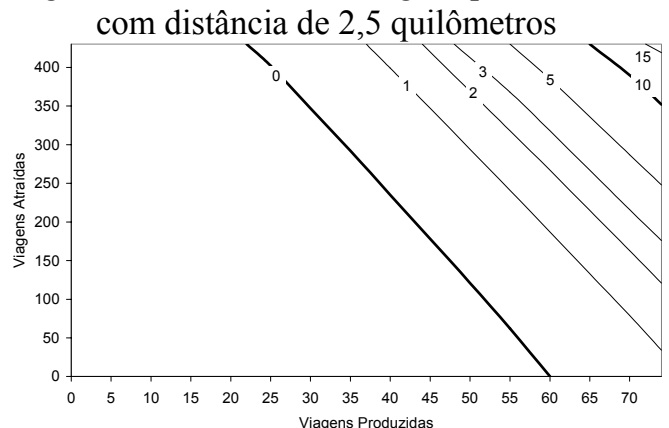

Figura 7.29 - Fluxos de viagens para EMEIs

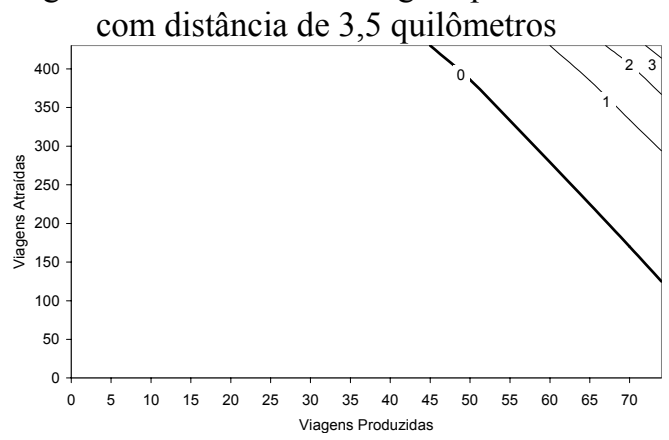

Figura 7.31 - Fluxos de viagens para EMEIs com distância de 4,5 quilômetros

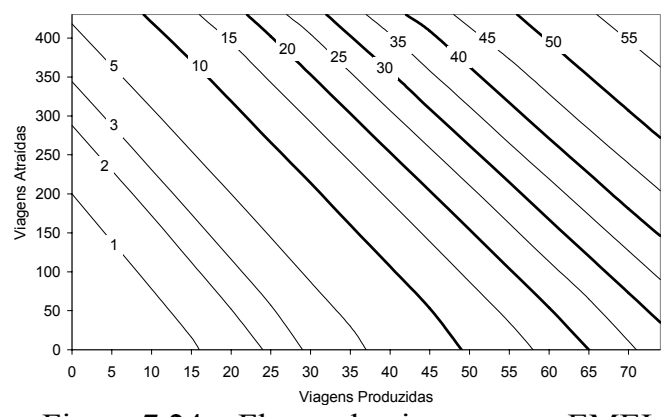

Figura 7.24 - Fluxos de viagens para EMEIs

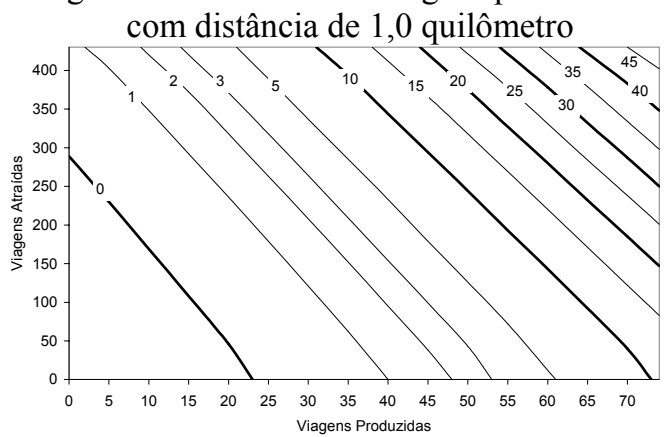

Figura 7.26 - Fluxos de viagens para EMEIs

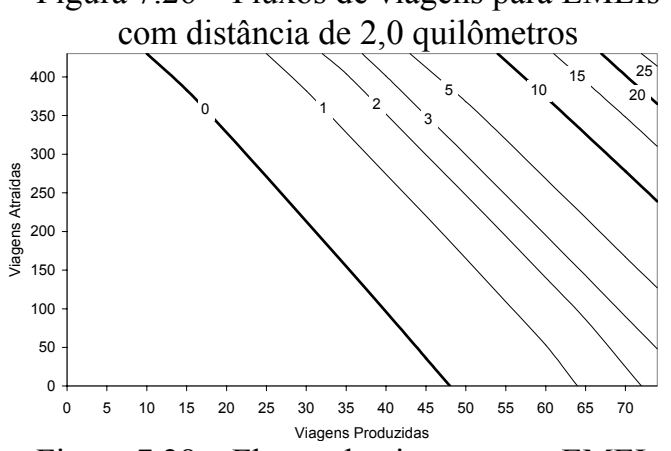

Figura 7.28 - Fluxos de viagens para EMEIs

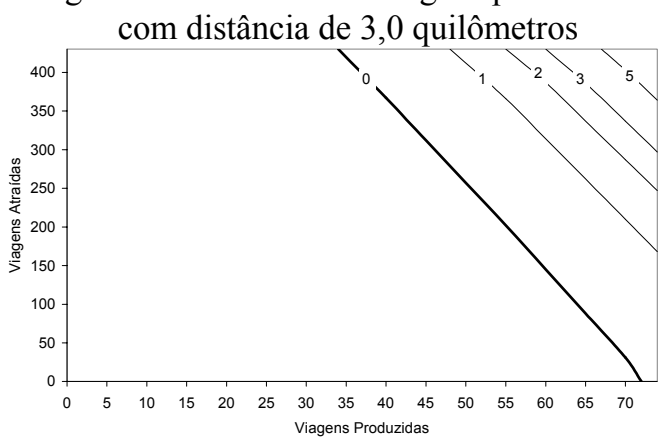

Figura 7.30 - Fluxos de viagens para EMEIs

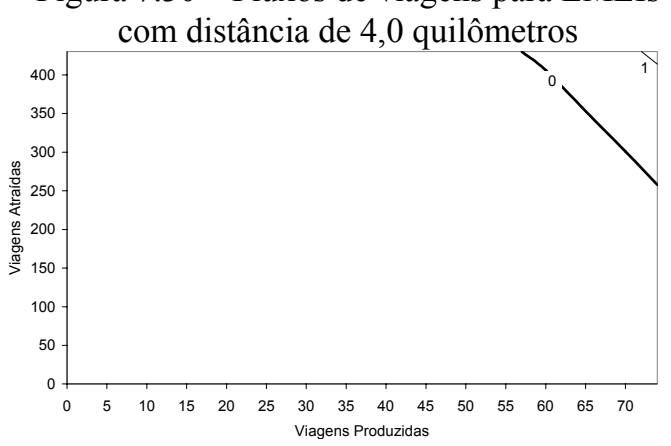

Figura 7.32 - Fluxos de viagens para EMEIs com distância de 5,0 quilômetros 


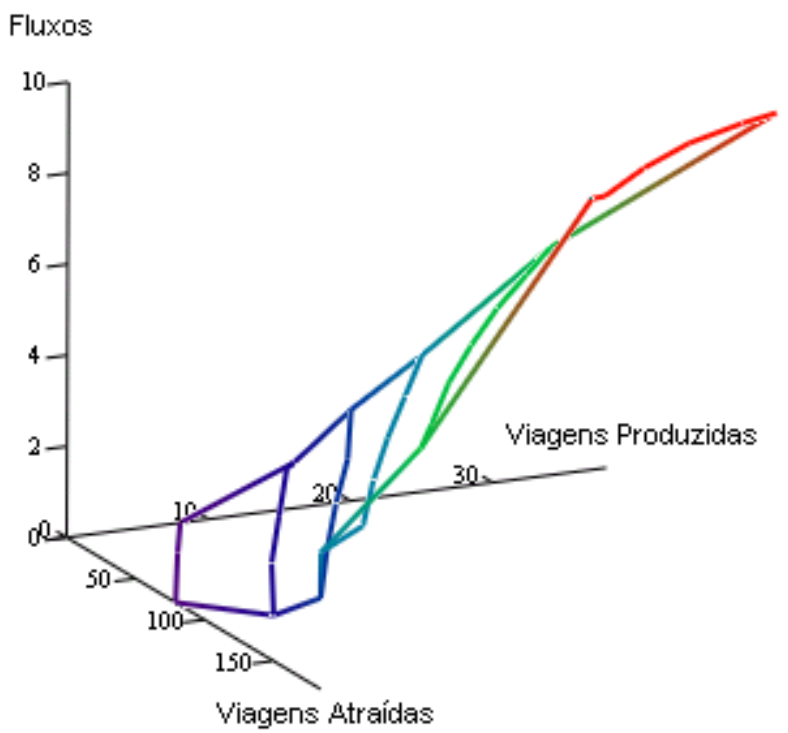

Figura 7.33 - Fluxos de viagens para Creches com distância de 0,5 quilômetro

Fluxos

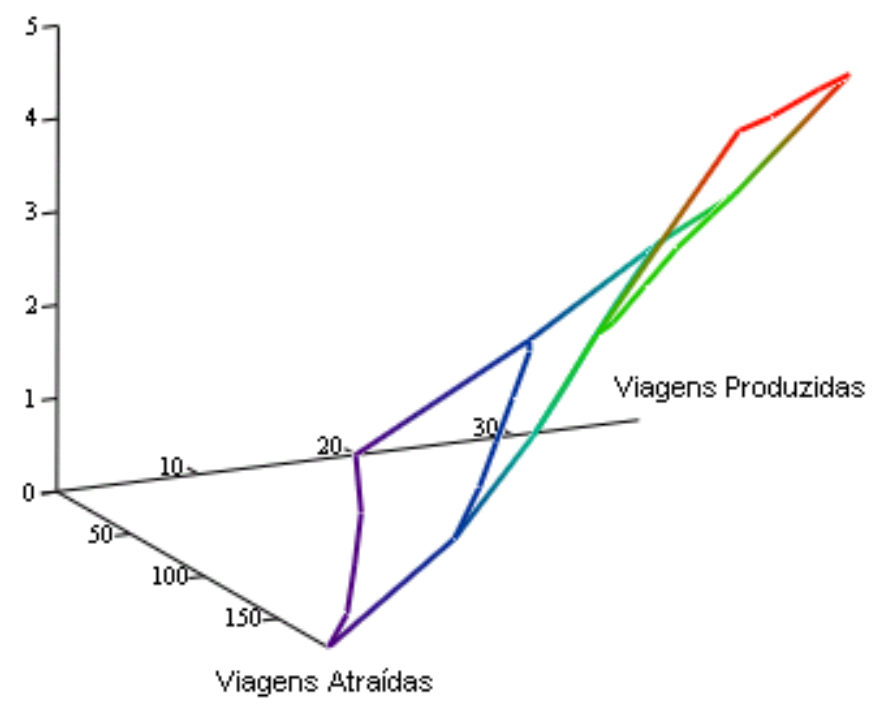

Figura 7.34 - Fluxos de viagens para Creches com distância de 2,5 quilômetros Fluxos

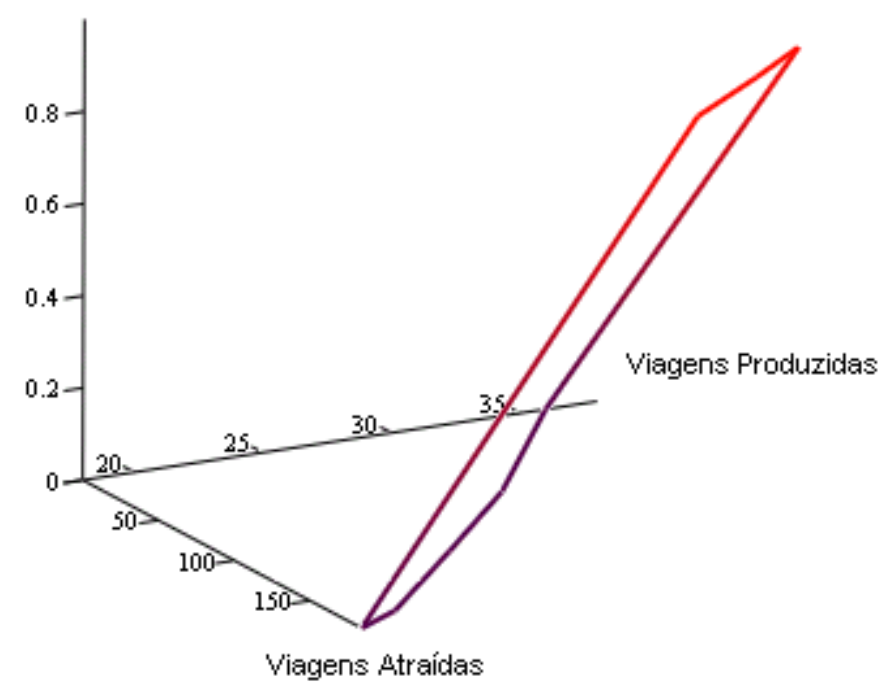

Figura 7.35 - Fluxos de viagens para Creches com distância de 5,0 quilômetros 


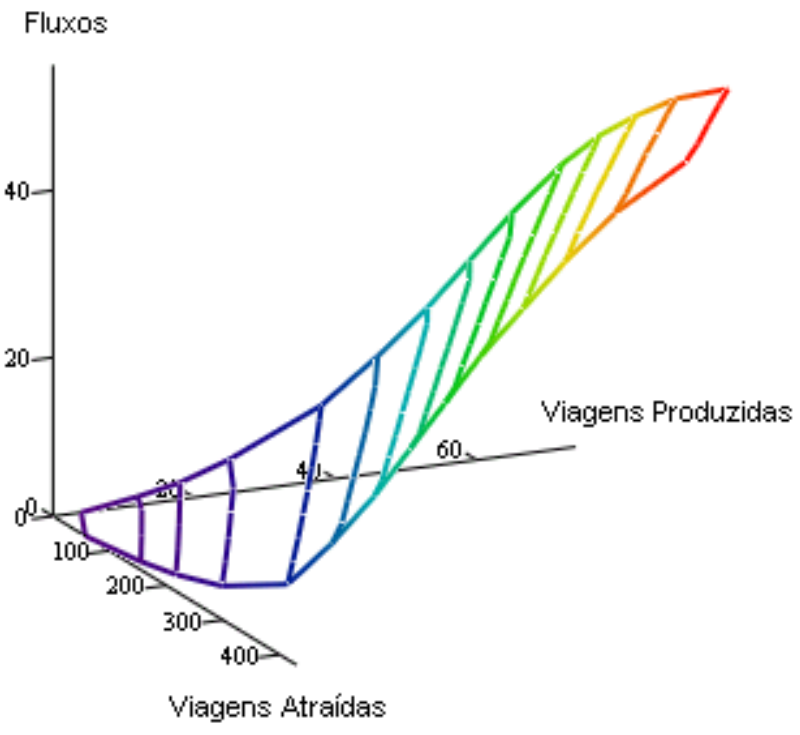

Figura 7.36 - Fluxos de viagens para EMEIs com distância de 0,5 quilômetro Fluxos

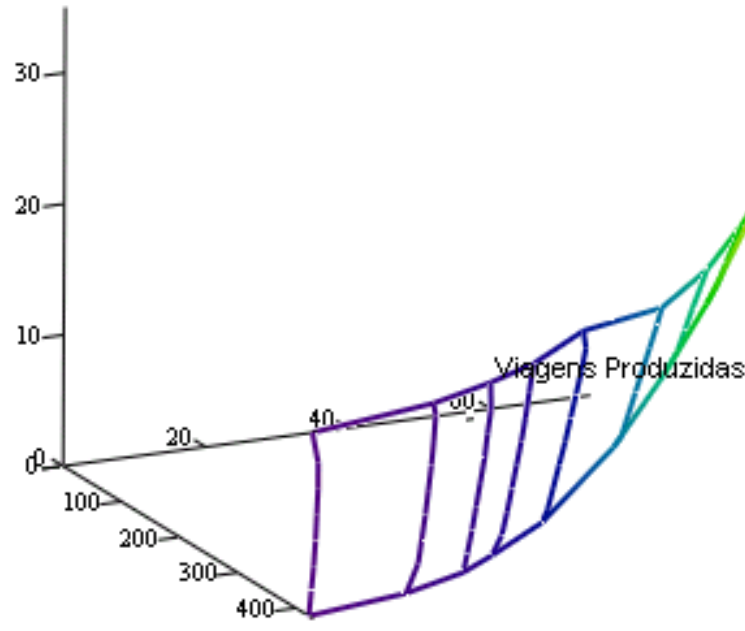

Viagens Atraídas

Figura 7.37 - Fluxos de viagens para EMEIs com distância de 2,5 quilômetros

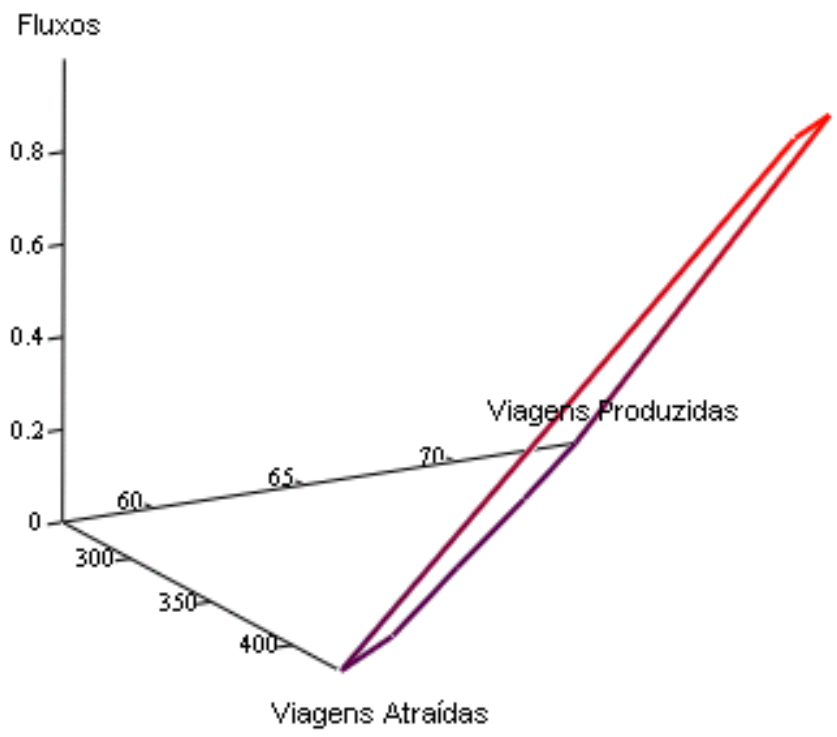

Figura 7.38 - Fluxos de viagens para EMEIs com distância de 5,0 quilômetros 
A utilização dos ábacos para a previsão do número de viagens a partir do total de viagens produzidas, total de viagens atraídas e distância é bastante simples e direta.

A análise dos gráficos mostra claramente a existência de um padrão para a distribuição das viagens calculadas, de acordo com a distância e o total de viagens produzidas. Em todos os casos, o fluxo de viagens tende a variar linearmente e é inversamente proporcional à distância de viagem, proporcional à demanda local e ao total de viagens atraídas. Esta última observação pode ser concluída pela análise dos gráficos tridimensionais ou pela análise conjunta dos demais gráficos.

Também é possível observar nos gráficos das EMEIs, principalmente na Figura 7.36, que o número de viagens varia menos nos casos extremos, isto é, nos casos em que as distâncias são grandes e a demanda é pequena ou quando a distância é pequena e a demanda é grande.

Finalmente, a análise conjunta dos gráficos, principalmente das Figuras 7.33 e 7.36, permite avaliar a diferença entre os padrões de distribuição de viagens das Creches e EMEIs.

\subsection{Utilização da Estimativa por Bootstrap}

Os conjuntos de dados do ano 2000 foram re-amostrados com reposição 50 vezes e utilizados para estimar fluxos futuros a partir de pontos conhecidos de origem e destino. Estes foram, então, comparados aos fluxos reais observados no ano de 2001, através do cálculo do Erro Normalizado, segundo a Equação 3.7. Os resultados da utilização da estimativa por bootstrap são apresentados nas Tabelas 7.6 e 7.7. 


\begin{tabular}{ccccc}
\hline \multicolumn{5}{c}{ Estimativas } \\
\hline 1 a 10 & 11 a 20 & 21 a 30 & 31 a 40 & 41 a 50 \\
\hline 3,89 & 3,06 & 4,17 & 2,79 & 3,30 \\
\hline 3,59 & 4,08 & 3,24 & 3,84 & 2,74 \\
\hline 3,38 & 2,95 & 2,67 & 3,50 & 3,53 \\
\hline 3,84 & 2,90 & 3,29 & 3,43 & 2,82 \\
\hline 3,11 & 3,28 & 2,78 & 2,99 & 3,79 \\
\hline 3,48 & 3,28 & 3,49 & 3,36 & 2,83 \\
\hline 3,31 & 3,11 & 3,29 & 3,09 & 3,71 \\
\hline 3,06 & 4,33 & 2,97 & 2,65 & 3,03 \\
\hline 3,33 & 3,10 & 2,84 & 4,00 & 3,34 \\
\hline 3,29 & 2,85 & 3,24 & 3,31 & 3,28 \\
\hline \multicolumn{5}{c}{ média } \\
\hline \multicolumn{5}{c}{3,29} \\
\hline \multicolumn{5}{c}{0,40} \\
\hline
\end{tabular}

Tabela 7.6 - EN (\%) obtidos para a estimativa bootstrap com dados de Creches municipais

\begin{tabular}{ccccc}
\hline \multicolumn{5}{c}{ Estimativas } \\
\hline 1 a 10 & 11 a 20 & 21 a 30 & 31 a 40 & 41 a 50 \\
\hline 1,83 & 1,23 & 1,84 & 2,38 & 2,41 \\
\hline 1,44 & 1,50 & 3,01 & 1,46 & 2,07 \\
\hline 1,52 & 2,61 & 1,77 & 1,64 & 1,83 \\
\hline 1,39 & 1,97 & 1,15 & 1,96 & 2,08 \\
\hline 1,22 & 2,18 & 1,73 & 2,47 & 1,22 \\
\hline 1,61 & 1,13 & 1,83 & 1,81 & 1,68 \\
\hline 1,71 & 1,51 & 4,01 & 2,73 & 2,43 \\
\hline 1,97 & 2,57 & 1,67 & 1,94 & 2,36 \\
\hline 1,93 & 2,01 & 1,41 & 1,54 & 1,78 \\
\hline 2,13 & 1,29 & 2,62 & 1,72 & 2,42 \\
\hline \multicolumn{5}{c}{ média } \\
\hline \multicolumn{5}{c}{1,91} \\
\hline \multicolumn{5}{c}{0,54} \\
\hline
\end{tabular}

Tabela 7.7 - EN (\%) obtidos para a estimativa bootstrap com dados das EMEIs

Na Tabela 7.6 pode-se verificar que a média dos erros normalizados dos 50 experimentos realizados foi de 3,29\% para os modelos das Creches, sendo que o resultado obtido sem a aplicação da técnica de bootstrap foi de 2,99\%. Para os modelos das EMEIs, como exposto na Tabela 7.7, a média dos EN dos 50 experimentos realizados foi de $1,91 \%$, valor que, ao contrário do que foi observado para os dados das Creches, supera o resultado obtido sem a aplicação da técnica de bootstrap, que foi de $2,11 \%$. 


\subsection{Análise Espacial dos Resíduos (erros) das Previsões}

Para a avaliação da distribuição espacial dos erros, foram elaborados mapas da cidade de São Carlos apresentando, através da espessura das linhas que representam os fluxos, os Erros Normalizados (Figuras 7.39 a 7.46). Estes valores foram calculados utilizando os resultados das melhores estimativas dos modelos neurais e as estimativas do Método Gravitacional para o ano 2001 e os fluxos observados neste mesmo ano, e lançados no SIG através do método de alocação Tudo ou Nada, já que não se dispõe de dados a respeito da capacidade dos arcos da rede. 

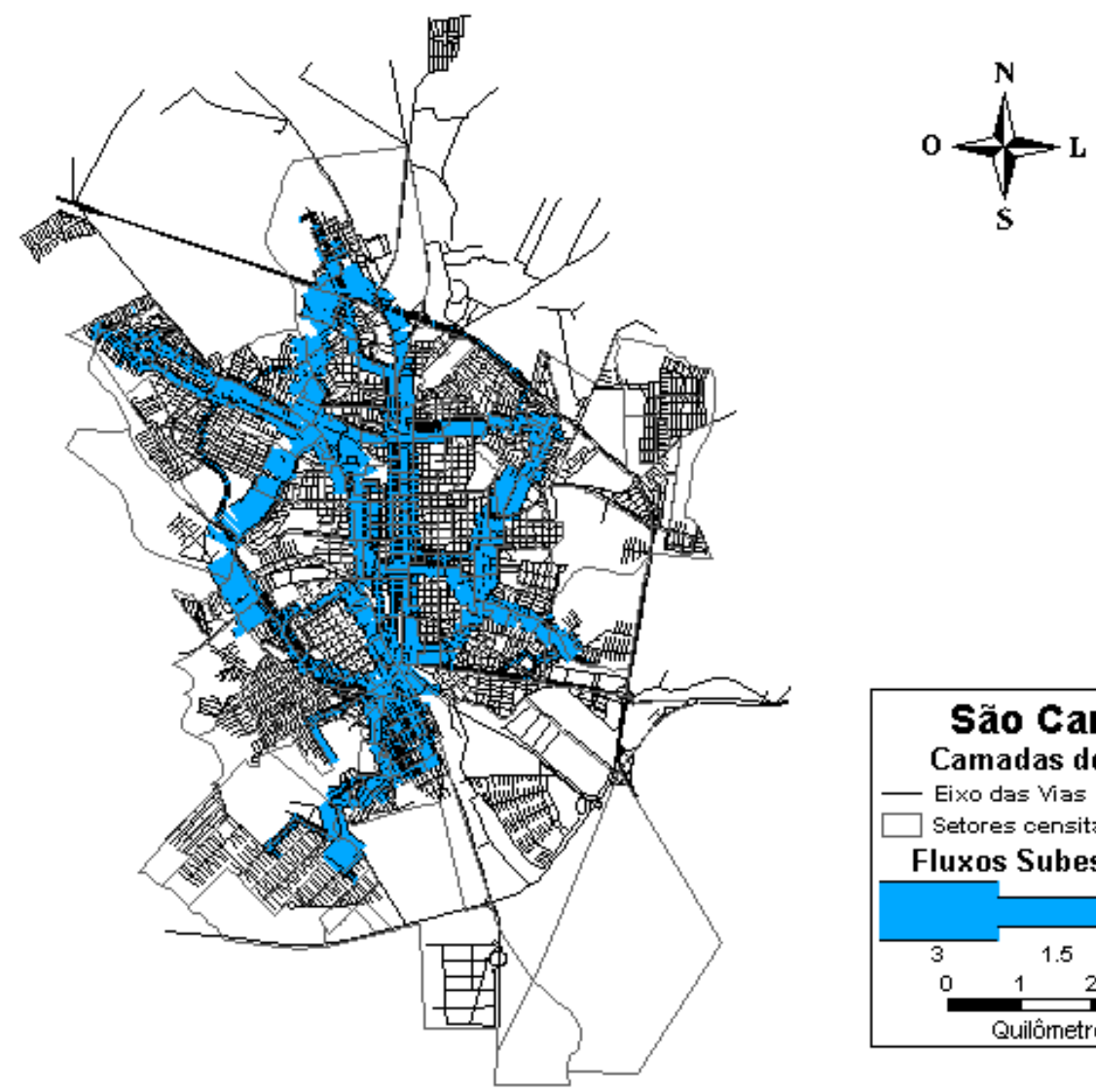

Figura 7.39 - Fluxos subestimados das Creches pelo modelo neural

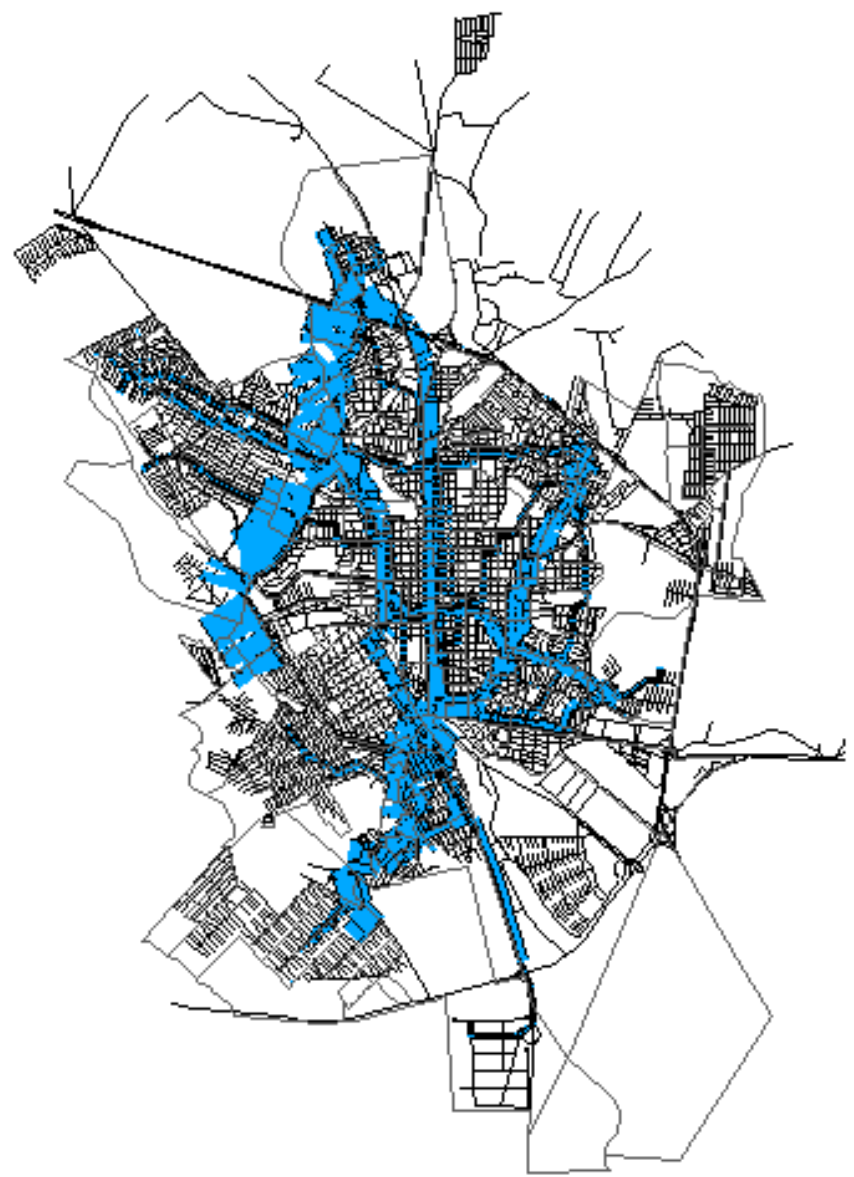

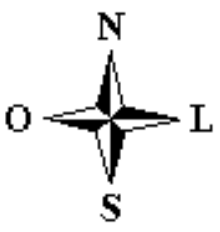

São Carlos Camadas do Mapa - Eixo das Vias

$\square$ Setores censitários

Fluxos Subestimados

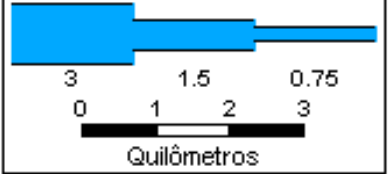

Figura 7.40 - Fluxos subestimados das Creches pelo Método Gravitacional 


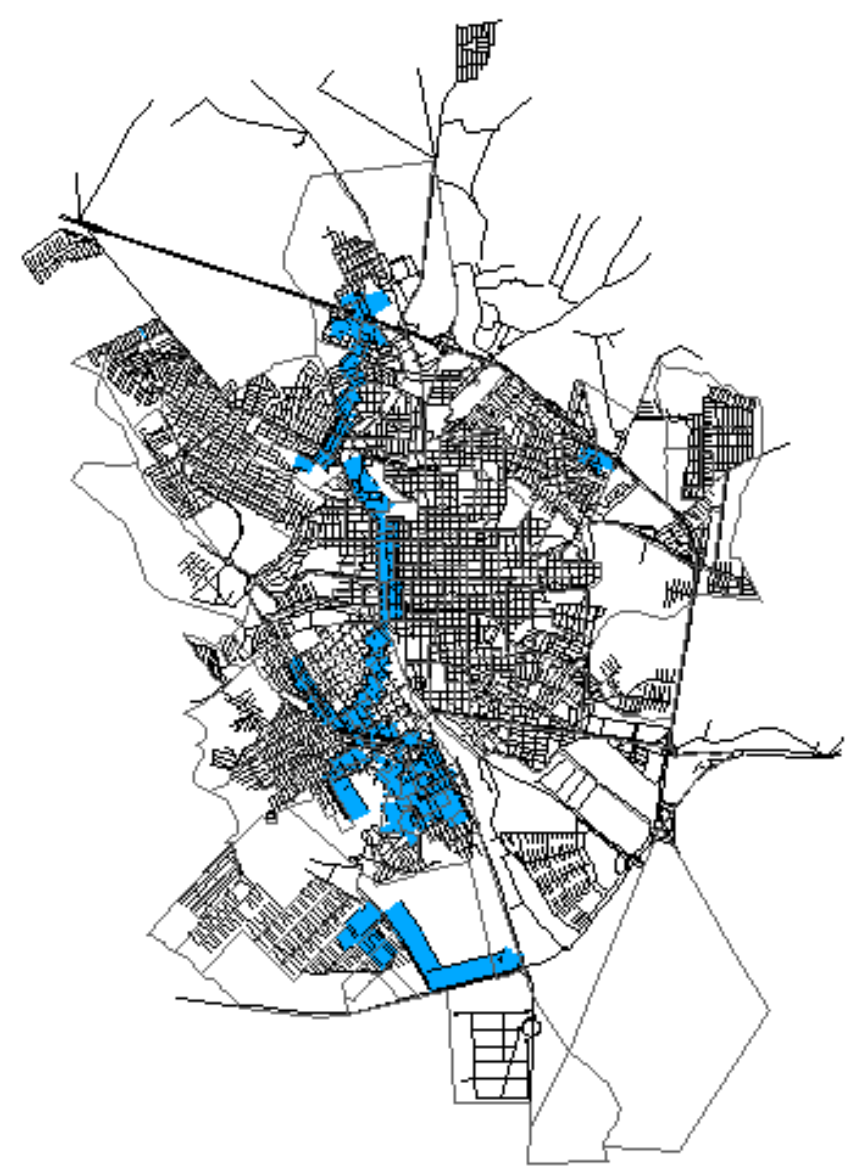<smiles>C1NC2O[IH]C1S2</smiles>

Figura 7.41 - Fluxos superestimados das Creches pelo modelo neural

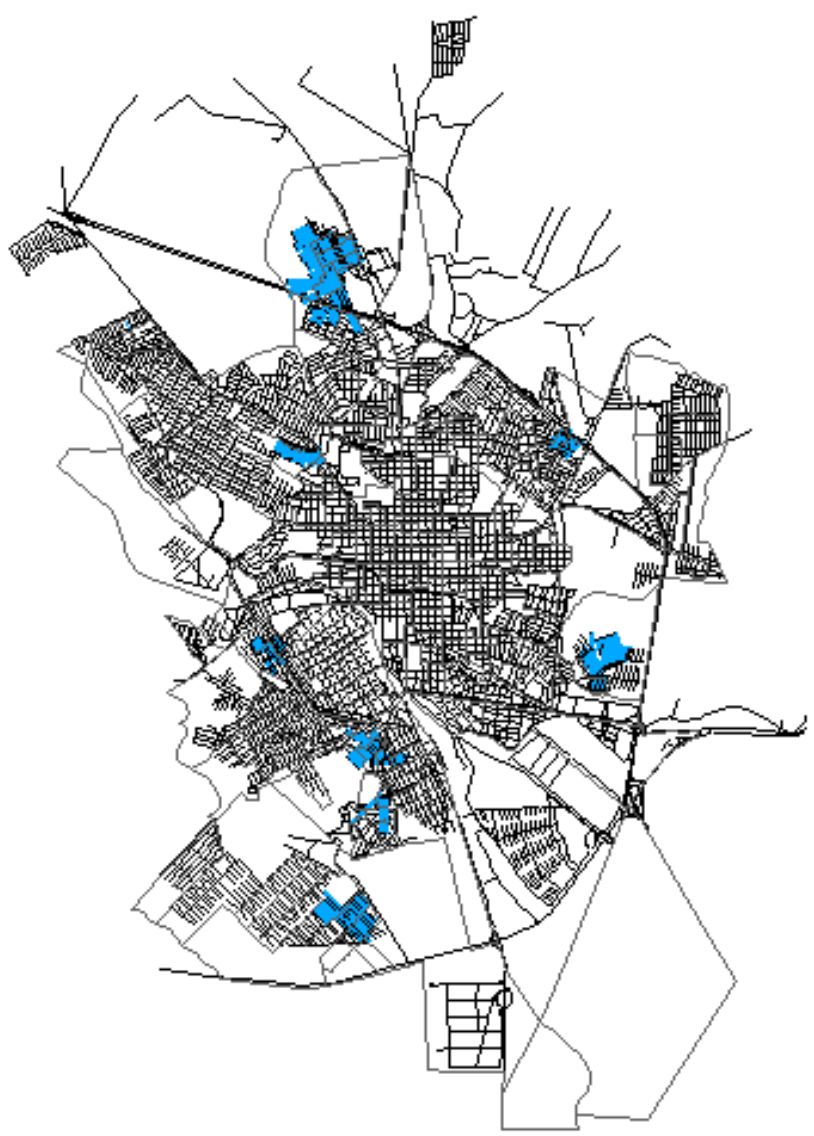

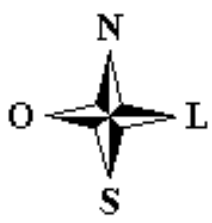

\section{São Carlos}

Camadas do Mapa

- Eixo das vias

$\square$ Setores censitários

Fluxos Superestimados

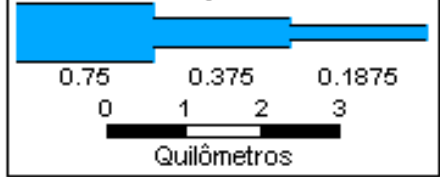

Quilômetros

Figura 7.42 - Fluxos superestimados das Creches pelo Método Gravitacional 


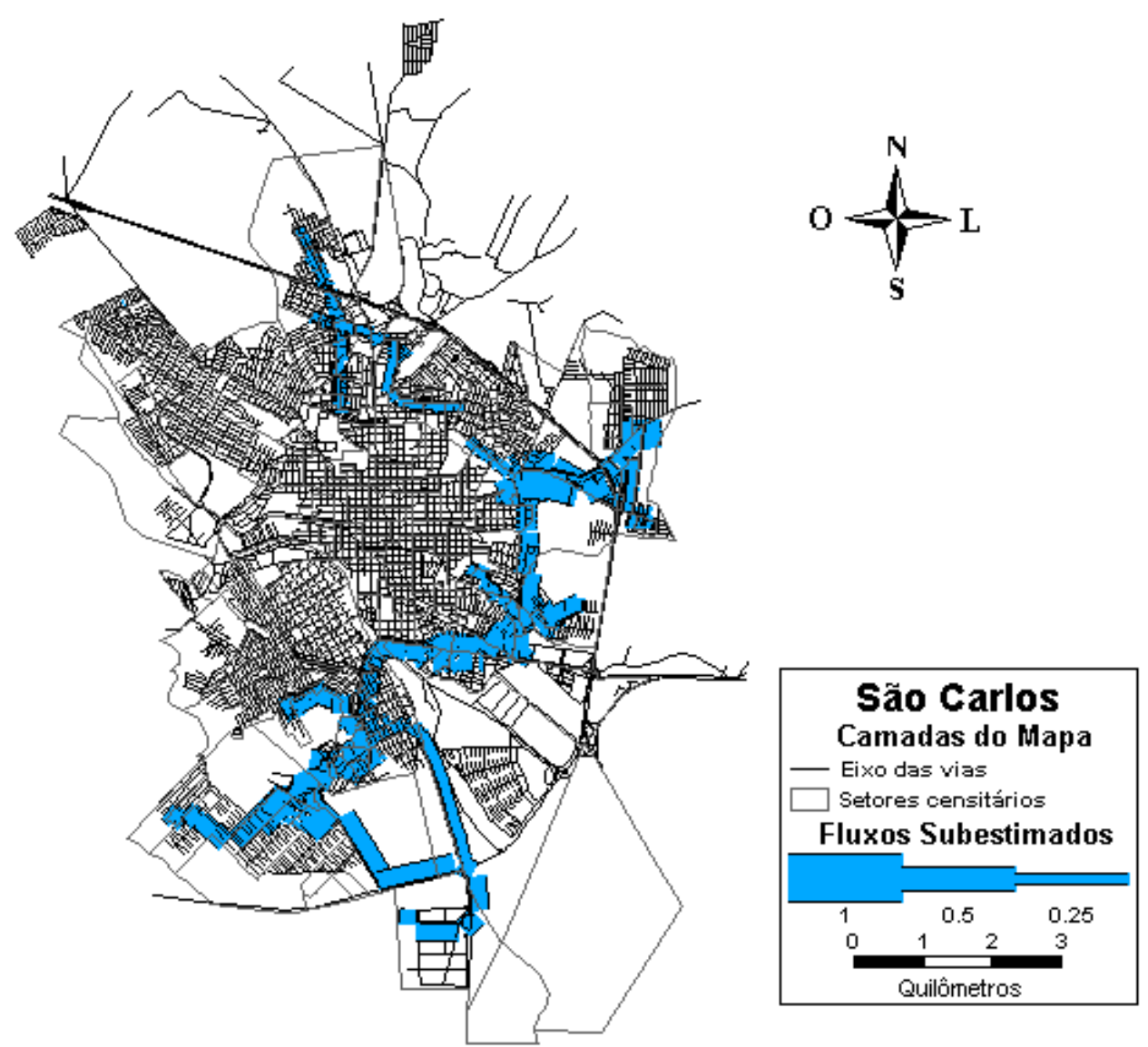

Figura 7.43 - Fluxos subestimados das EMEIs pelo modelo neural

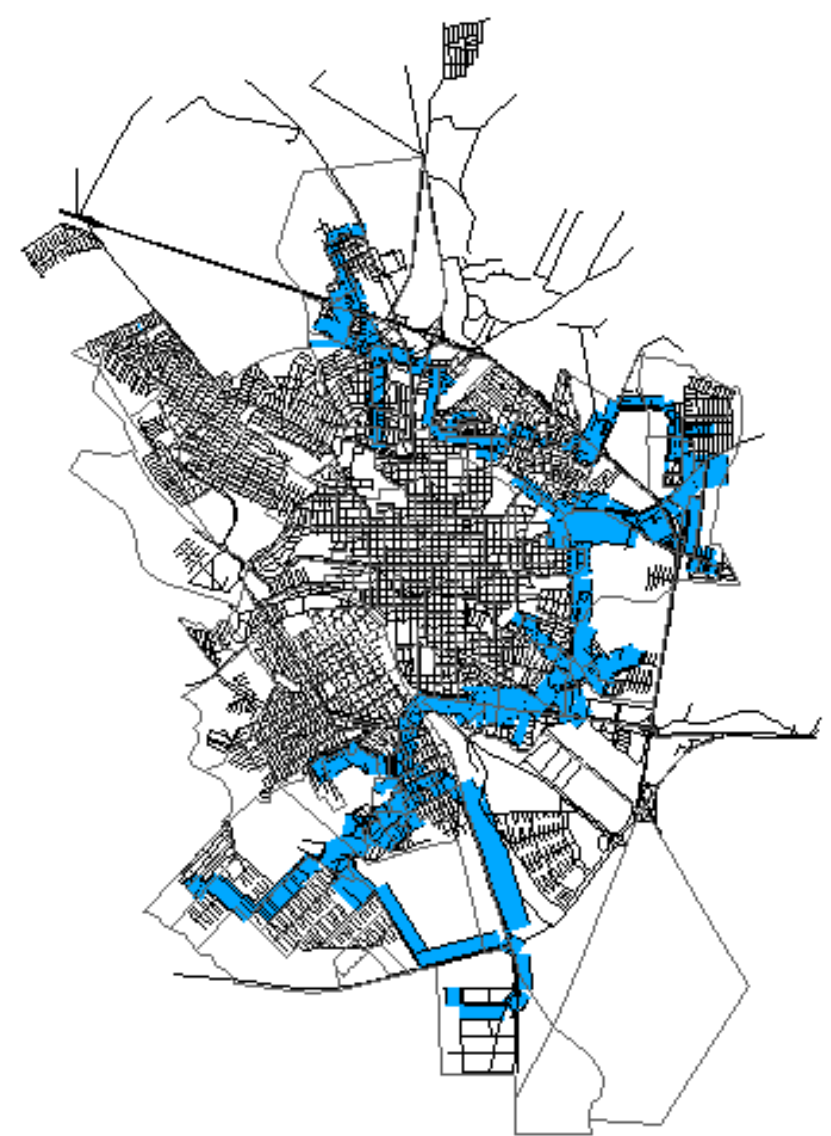<smiles>O[C@@H]1N[C@@H]2CS[C@H]1N2</smiles>

Figura 7.44 - Fluxos subestimados das EMEIs pelo Método Gravitacional 


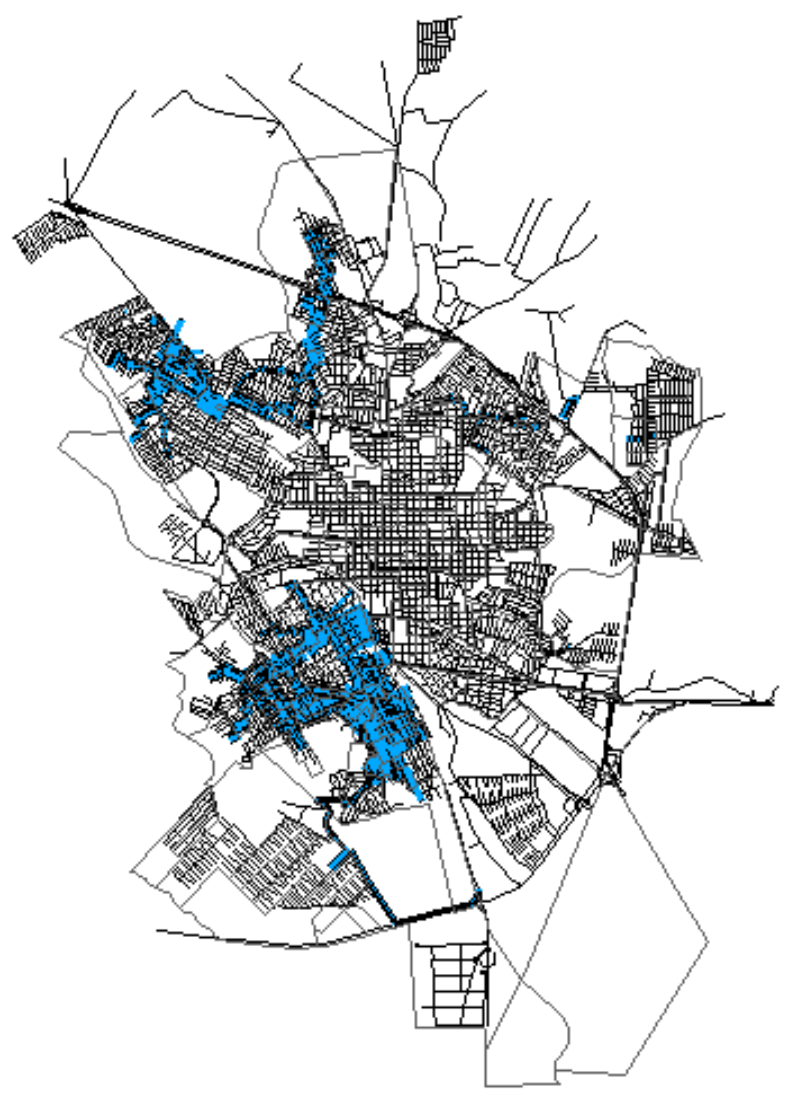<smiles>[Tl]C1COC2NC1S2</smiles>

Figura 7.45 - Fluxos superestimados das EMEIs pelo modelo neural

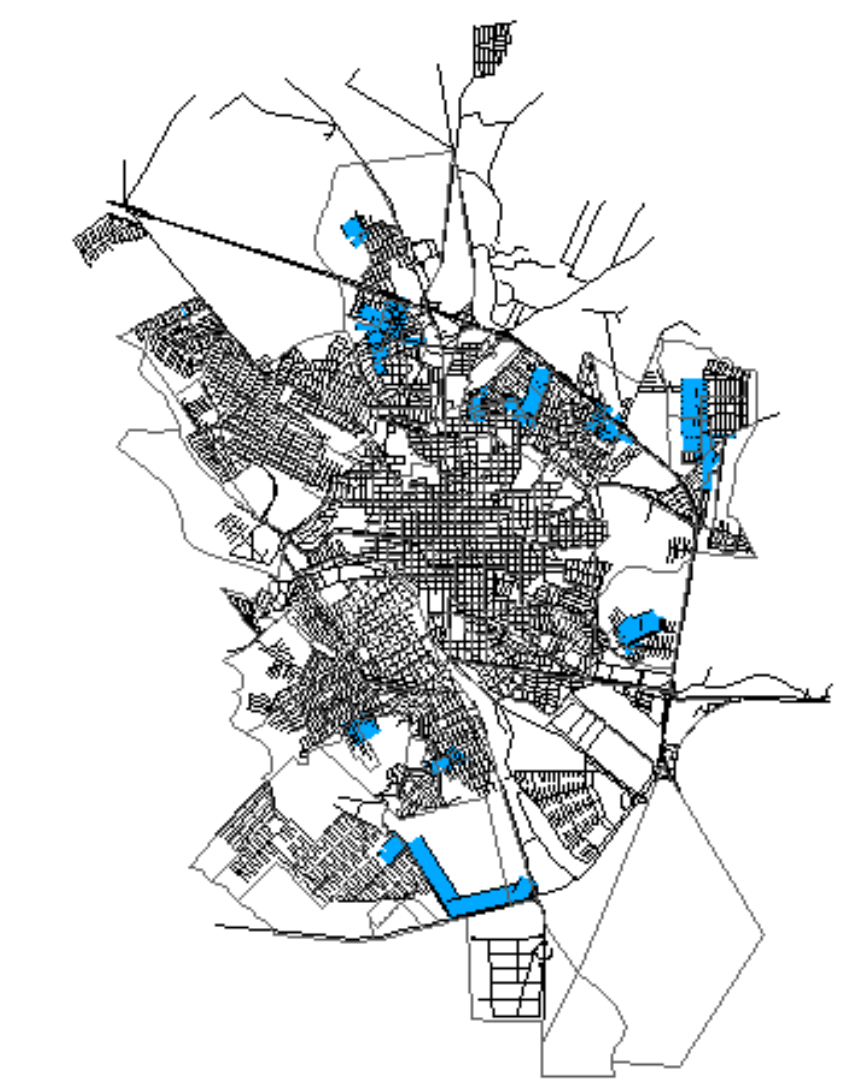<smiles>[Tl]C1OC2C[SH]1C2</smiles>

São Carlos Camadas do Mapa - Eixo das vias $\square$ Setores censitários Fluxos Superestimados

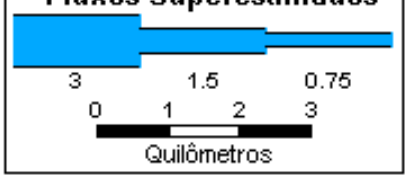

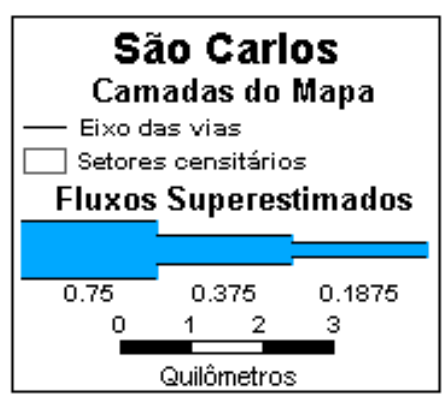

Figura 7.46 - Fluxos superestimados das EMEIs pelo Método Gravitacional 
Pelas ilustrações anteriores pode-se observar sub e superestimações em diversos fluxos alocados à rede viária de São Carlos. Isto implica na necessidade de pesquisa e de desenvolvimento de melhores modelos de interação espacial, ou mesmo da observação cuidadosa dos fluxos nestas linhas, quando utilizada a técnica no processo de planejamento.

Em todos os casos, com exceção dos erros superestimados das EMEIs (Figuras 7.45 e 7.46), os erros calculados pelo método neural e pelo método gravitacional apresentaram a mesma ordem de grandeza, como se pode verificar nas legendas dos mapas das Figuras 7.39 a 7.44 e nos próprios mapas.

Para os fluxos subestimados, tanto nas Creches quanto nas EMEIs (Figuras 7.39, 7.40, 7.43 e 7.44), é possível observar que os erros localizam-se nas mesmas vias para os dois métodos, o que pode significar a ocorrência de erros sistemáticos para tais modelos de interação espacial. Isso implica na necessidade de observação cuidadosa dos fluxos nestas linhas, quando utilizadas as técnicas no processo de planejamento.

Já pela análise das Figuras 7.41, 7.42, 7.45 e 7.46, pode-se observar que os fluxos superestimados ocorrem localmente em diferentes regiões da cidade. A ocorrência de fluxos superestimados pelo método neural (Figura 7.41) nas vias centrais da cidade denota a superioridade do método gravitacional neste caso, pois, apesar dos dois métodos apresentarem superestimativas de mesma grandeza, a ocorrência de erros nas vias centrais da cidade pode acarretar maiores transtornos se a previsão for utilizada em uma aplicação prática. Pela análise das Figuras 7.45 e 7.46 pode-se observar a superioridade do modelo gravitacional em relação ao modelo neural, em termos de desempenho, dadas as diferentes ordens de grandeza, como se pode observar principalmente nas legendas dos dois mapas. 


\section{CONCLUSÕES E SUGESTÕES PARA TRABALHOS FUTUROS}

O objetivo desta pesquisa foi avaliar o uso de diferentes alternativas, tais como a técnica de otimização de Algoritmos Genéticos na seleção de Redes Neurais Artificiais e o método de estimação por bootstrap na fase de divisão dos dados, para a construção de Modelos de Interação Espacial, e avaliar a distribuição espacial dos resíduos (erros) das previsões. Para tanto, foram utilizados dados fornecidos pela Secretaria Municipal de Educação de São Carlos que refletem a demanda por serviços municipais de educação infantil ao longo de dois anos (2000 e 2001), além do SIG TransCAD e dos aplicativos EasyNN-plus e Neural Nets Genealogy, este último desenvolvido especificamente para esta pesquisa.

Embora a utilização dos Algoritmos Genéticos tenha se mostrado eficiente para seleção de uma configuração de rede neural capaz de produzir melhores previsões, os resultados obtidos através do Método Gravitacional com dupla restrição ainda foram superiores aos dos modelos neurais de interação espacial nos dois casos estudados (Creches e EMEIs).

Tal conclusão pôde ser reforçada pela análise dos ábacos apresentados nas Figuras 7.13 a 7.38. Nestes gráficos, observou-se que os padrões extraídos da utilização das RNAs na estimativa de fluxos futuros correspondem exatamente aos que são utilizados como premissas na estimativa através do tradicional método gravitacional. Ou seja, as viagens são proporcionais aos totais produzidos e atraídos e inversamente proporcionais às distâncias. Além disso, o comportamento linear observado nos gráficos das EMEIs (Figuras 7.23 a 7.32) mostra que em casos como este, em que há um padrão de distribuição espacial consistente nos dados, o modelo 
gravitacional é capaz de produzir estimativas bastante precisas e aceitáveis para o planejamento urbano e de transportes.

Uma possível explicação para o melhor desempenho do modelo gravitacional utilizado como referência neste trabalho em relação aos modelos neurais, seria a abordagem iterativa do modelo gravitacional, que impõe que o número total de viagens seja igual ao número total de viagens produzidas e ao número total de viagens atraídas, forçando estimativas dentro de um valor limite a cada iteração. No caso dos modelos neurais, além do processo não ser iterativo, não há restrições nos totais de viagens produzidas e atraídas e, portanto, não há o ajuste das estimativas que ocorre no método gravitacional, o que pode gerar maiores erros.

Outra observação deste trabalho foi de que os modelos que utilizam dados das EMEIs mostraram desempenhos superiores aos que utilizam dados das Creches municipais em todos os casos (Método Gravitacional, Algoritmos Genéticos e Bootstrap). A explicação para este fato pode estar nos próprios dados, uma vez que, como observado nos mapas que apresentam a demanda espacial por Creches (Figuras 7.1 e 7.2), a localização da residência dos alunos pode não estar interferindo na escolha da Creche. Isto torna os modelos deficientes, pois além do total de viagens produzidas e atraídas, apenas as distâncias entre os pontos de demanda e oferta estão sendo utilizadas como parâmetros. No caso das EMEIs, a localização da instituição de ensino escolhida está diretamente relacionada à localização da residência dos alunos, como se pode verificar nos mapas que apresentam a demanda espacial por EMEIs (Figuras 7.3 e 7.4), além dos próprios resultados dos modelos.

No caso de Creches, portanto, verificou-se que, além da distância entre os pontos de demanda e oferta, são necessários outros parâmetros que influam efetivamente na escolha das instituições de ensino para se obter melhores resultados, o que geralmente é difícil de se obter (ALMEIDA; GONÇALVES, 2001).

A conclusão mais importante deste trabalho, portanto, foi a de que embora a utilização dos modelos neurais seja apropriada para a estimativa de fluxos, a partir do método gravitacional é possível mensurar de forma precisa e aceitável, o crescimento e a distribuição espacial da demanda futura por serviços de educação, permitindo-se identificar quais devem ser as melhores ações a serem tomadas pelo poder público no presente com o intuito de reduzir as distâncias de deslocamento dos alunos no futuro. A avaliação espacial dos erros das previsões permite a localização das 
sub e superestimativas, indicando os trechos da rede viária em que a utilização das técnicas de previsão de fluxos deve ser considerada com cautela. Além disso, possibilita a verificação de erros sistemáticos nos modelos de interação espacial, o que implica na necessidade de pesquisa e de desenvolvimento de melhores modelos. A comparação da distribuição espacial dos erros obtidos pelos métodos gravitacional e neural permite também observar a ordem de grandeza das sub e superestimativas e os diferentes padrões de localização dos erros, isto é, se são concentrados ou dispersos, possibilitando uma melhor avaliação dos dois métodos e uma melhor escolha de qual deve ser utilizado para o planejamento urbano.

Como recomendação para trabalhos posteriores, sugere-se o estudo dos modelos neurais de interação espacial para outros tipos de Redes Neurais, tais como as redes ART-MAP e Self-Organizing Maps; a utilização de outros dados que possam ser coletados nas escolas, além da localização dos alunos; a construção de uma aplicação computacional com recursos que permitissem a integração dos dados da Secretaria Municipal de Educação com Sistemas de Informações Geográficas e o desenvolvimento de procedimentos para que os Modelos de Interação Espacial venham a ser mais intensamente utilizados por órgãos públicos municipais e empresas de transporte. 


\section{REFERÊNCIAS BIBLIOGRÁFICAS}

Aguiar Jr., S.R. (2004) Modelo RAPIDE: uma aplicação de mineração de dados e redes neurais artificiais para a estimativa da demanda por transporte rodoviário interestadual de passageiros no Brasil. Dissertação (Mestrado). Universidade Católica de Brasília. 140p.

Akamine, A.; Silva, A.N.R (2004) An evaluation of neural spatial interaction models based on a practical application. In: Van Leeuwen, J.P.; Timmermans, H.J.P. (eds.) Recent Advances in Design and Decision Support Systems in Architecture and Urban Planning, p.19-32.

Akamine, A.; Silva, A.N.R (2005) What is Inside Neural Spatial Interaction Models? Submetido ao TRB $85^{\text {th }}$ Annual Meeting.

Akamine, A.; Silva, A.N.R.; Lima, R.S. (2004) Seleção de modelos neurais de interação espacial através de algoritmos genéticos. In: Congresso de Pesquisa e Ensino em Transportes, 18, Florianópolis, SC, 2004. Anais, v.2, p.811-820.

Akamine, T.; Akamine, A. (2005) Neural Nets Genealogy. (Disponível em https://sourceforge.net/project/showfiles.php?group_id=129267 em 17/07/2005)

Almeida, L.M.W. (1999) Desenvolvimento de uma metodologia para análise locacional de sistemas educacionais usando modelos de interação espacial e indicadores de acessibilidade. Tese (Doutorado). Departamento de Engenharia de Produção e Sistemas, Universidade Federal de Santa Catarina.

Almeida, L.M.W.; Gonçalves, M.B. (2001) A methodology to incorporate behavioral aspects in trip-distribution models with an application to estimate student flow. In: Environment and Planning A, v.33, p.1125-1138.

Antunes, R.T.; Yamashita, Y.; Aragão, J.J.G.; Dantas, A.S.; Lamar, M.V. (2001) Modelo neuro-espacial para previsão das preferências dos usuários do sistema de transporte coletivo urbano de passageiros . In: Congresso de Pesquisa e Ensino em Transportes, 15, Campinas, SP, 2001. Anais, v.2, p.309-315. 
Beale, R.; Jackson, T. (1990) Neural Computing: an introduction. York, UK. Institute of Physics Publishing.

Bielli, M.; Caramia, M.; Carotenuto, P. (2002) Genetic algorithms in bus network. In: Transportation Research Part C, v.10, p.19-34.

Black, J.; Cheung, C.; Suthanaya, P. (2003) Advances in computer software and the evaluation of spatial interaction models for urban transport sustainability anaysis. In: VIII International Conference on Computers in Urban Planning and Urban Management, Anais eletrônicos, CUPUM, Sendai-Japão.

Black, W. (1995) Spatial interection modeling using artificial neural networks. In: Journal of Transport Geography, v.3, n.3, p.159-166.

Bocanegra, C.W.R. (2002) Procedimentos para tornar mais efetivo o uso das redes neurais artificiais em planejamento de transportes. Dissertação (Mestrado). Escola de Engenharia de São Carlos, Universidade de São Paulo. 97p.

Braga, A.P.; Carvalho, A.P.L.F. e Ludemir, T.B. (1998) Fundamentos de Redes Neurais Artificiais. ed.11. Rio de Janeiro. Escola de Computação, Universidade Federal do Rio de Janeiro.

Braga, A.P.; Carvalho, A.P.L.F. e Ludemir, T.B. (2000) Redes Neurais Artificiais Teoria e Aplicações. Rio de Janeiro. LTC - Livros Técnicos e Científicos.

Brega, J.R.F (1996) Utilização de redes neurais artificiais em um sistema de gerência de pavimentos. Tese (Doutorado). Escola de Engenharia de São Carlos, Universidade de São Paulo. 234p.

Brio, B.M.; Molina, A.S. (2001) Redes neuronales y sistemas borrosos. RaMa Editorial, Madrid.

Brondino, N.C.M. (1999) Estudo da influência da acessibilidade no valor de lotes urbanos através do uso de redes neurais. Tese (Doutorado). Escola de Engenharia de São Carlos, Universidade de São Paulo. 146p.

Carvalho, A.P.L.F (2001) Projetos de Redes Neurais. Notas de aula.

Chand, M. (1991) Travel characteristics and traffic flow pattern on a district road network. In: Journal of the Institute of Engineers. India, v.72, p.118-128.

Cheu, R.L.; Jin, X.; Ng, K.C.; Ng, Y.L.; Srinivasan, D. (1998) Calibration of FRESIM for Singapore Expressway using genetic algorithm. In: Journal of Transportation Engineering. 124(6), p.526-535.

Costa, G.C.F. (2001) Uma avaliação do consumo de energia com transportes em cidades do estado de São Paulo. Dissertação (Mestrado). Escola de Engenharia de São Carlos, Universidade de São Paulo. 103p. 
Costa, G.C.F.; Silva, A.N.R.; Carvalho, A.C.P.L.F. (2001) Uma análise do consumo de energia com transportes em zonas urbanas utilizando redes neurais artificiais. In: Congresso de Pesquisa e Ensino em Transportes, 15, Campinas, SP, 2001. Anais, v.2, p.183-190.

Costa, P.T. (2003) Uma análise do consumo de energia em transportes nas cidades portuguesas utilizando redes neurais artificiais. Dissertação (Mestrado). Escola de Engenharia, Universidade do Minho. 110p.

Dantas, A; Yamamoto, K.; Lamar, M. V.; Yamashita, Y. (2001) Modelling and forecasting travel demand in an urban area: a neural geo-temporal approach. In: Journal of Eastern Asia Society for Transportation Studies, v.4, n.2, p.261-275.

Dia, H. (2001) An object oriented neural network approach to short-term traffic forecasting. In: European Journal of the Operations Research, v.132/2.

Dia, H.; Harney, D.; Boyle, A. (2001) Dynamics of drivers' route choice decisions under advanced traveler information systems. In: ARRB - Transportation Research Ltda., v.10, n.4, p.2-12.

Dia, H. e Rose, G. (1998) Development and evaluation of neural network freeway incident detection models using field data. In: Transportation Research Part C, v.5, n.5, p.313-331.

Dougherty, M. (1995) A review of neural networks applied to transport. In: Transportation Research Part C, v.3, n.4, p.247-260.

Efron, B. (1979) Bootstrap methods: another look at jacknife. Annals of Statistics, v.7, n.1, p.1-26.

Efron, B. (1987) Better bootstrap confidence intervals. In: Journal of the American Statistical Association, v.82, p.171-200.

Efron, B. e Tibshirani, R.J (1993) An Introduction to the Bootstrap. New York. Chapman and Hall.

Faghri, A. e Hua, J. (1992) Trip generation analysis by artificial neural networks. In: International Conference on Microcomputers in Transportation, 4, p.805-815.

Farias, M.M.; Dantas Neto, S.A.; Pais, J.C. (2004) Modelagem da viscosidade absoluta dos asfaltos-borracha usando redes neurais artificiais. In: Congresso de Pesquisa e Ensino em Transportes, 18, Florianópolis, SC, 2004. Anais, v.1, p.28-39.

Fischer, M.M.; Leung, Y. (1998) A Genetic-Algorithms Based Evolutionary Computational Neural Network for Modelling Spatial Interaction Data. In: The Annals of Regional Science, v.32, n.3, p.437-458.

Fischer, M.M.; Reismann, M. (2002a) Evaluating Neural Spatial Interaction Modelling by Bootstrapping. In: Networks and Spatial Economics, v.2, n.3, p.255-268. 
Fischer, M.M.; Reismann, M. (2002b) A methodology for neural spatial interaction modeling. In: Geographical Analysis, v.34, n.3, p.207-228.

Fischer, M.M.; Reismann, M.; Hlavackova-Schindler, K. (1999) Parameter estimation in neural spatial interaction modelling by a derivative free global optimization method. In: International Conference on GeoComputation, 4, Fredericksburg, Virginia, USA. Proceedings. (Disponível em http://www.geocomputation.org/1999/007/gc_007.htm em 15/08/2002).

Fred, A.L.N. (2003) Técnica de Bootstrap. Notas de aula. Instituto de Telecomunicações (Disponível em: http://www.lx.it.pt/ afred/rpist/ACETATOS/bootstrap.pdf em 13/05/03).

Furtado, A.N.D. (1998) Uma nova abordagem na avaliação de projetos de transporte: o uso das redes neurais artificiais como técnica para avaliar e ordenar alternativas. Tese (Doutorado), Escola de Engenharia de São Carlos, Universidade de São Paulo. 249p.

Goldberg, D.E., (1989) Genetic Algorithms in Search, Optimization and Machine Learning. Reading, MA. Addison-Wesley.

Guyton, A.C. (1977) Tratado de Fisiologia Médica. ed. 5. Rio de Janeiro. Ed. Interamericana.

Haupt, R.L.; Haupt, S.E. (1998) Practial Genetic Algorithms. Danvers, MA. WilleyInterscience publication.

Haykin, S. (1994) Neural networks: a comprehensive foundation. New York, Macmillan College Publishing Company.

Henderson, J.; Fu, L. (2004) Applications of genetic algorithms in Transportation Engineering. In: Transportation Research Board, 83. Washington, D.C.

Hinton, G.E.; Sejnowski, T.J. (1986) Learning and relearning in Boltzmann machines. In: Rumelhart, D.E.; McClelland, J.L. (ed.) Parallel Distributed Processing: Explorations in the Microstructure of Cognition, v.1, Cambridge, MIT Press.

Hoogendoorn, S.P. e Bovy, P.H.L. (2000) Continuum modelling of multiclass traffic flow. In: Transportation Research Part B, v.34b, n.2, p.123-134.

INSTITUTO BRASILEIRO DE GEOGRAFIA E ESTATÍSTICA (2000) Censos demográficos. (Disponível em http://www.ibge.gov.br em 11/05/2005).

Jianzhong, F; Saito, M. (1998) Application of artificial neural network for level of service analysis of signalized intersection. (Disponível em http://www.its.uci.edu/whatsnew/ sess98.html em 09/04/2003).

Kawamoto, E. (1994) Análise de sistemas de transporte. Escola de Engenharia de São Carlos, Universidade de São Paulo. Notas de aula. 
Kikushi, S.; Nanda, R.; Perincherry, V. (1993) A method to estimate trip O/D patterns using a neural network approach. In: Transportation Planning and Technology, v.17, p.51-65.

Kim, J.W.; Kim B.M. (2001) A GA-based fuzzy traffic simulation for crossroad management. In: Congress on Evolutionary Computation. v.2. Seoul, Korea.

Kim, K.O.; Rilett, L.R. (2001) Genetic-algorithm-based approach for calibrating microscopic simulation models. In: IEEE Intelligent Transportation Systems Conference, Proceedings. Oakland.

Lacerda, E.G.M.; Carvalho, A.C.P.L.F. (1999) Introdução aos algoritmos genéticos. In: Galvão, C.O. e Valença, M.J.S. (orgs) Sistemas inteligentes: aplicações a recursos hídricos e sistemas ambientais, Ed. Universidade, UFRGS, Porto Alegre.

Lavoranti, O.M. (2003) Estabilidade e adaptabilidade fenotípica através da reamostragem "bootstrap" no modelo AMMI. Tese (Doutorado). Escola Superior de Agricultura Luiz de Queiroz, Universidade de São Paulo. 166p.

Le, H.H.; Young, W. (1998a). Modelling shopping center traffic movement (1): model validation. In: Transport Planning and Technology, v.21, p.203-233.

Le, H.H.; Young, W. (1998b) Modelling shopping center traffic movement (2): model application. In: Transport Planning and Technology, v.21, p.309-321.

Ledoux, C. (1997) An urban traffic flow model integrating neural networks. In: Transportation Research Part C, v.5, n.5, p.287-300.

Lee, D.H.; Yang, X.; Chandrasekar, P. (2001) Parameter calibration for PARAMICS using genetic algorithm. In: Transportation Research Board, 80. Washington, D.C.

Lemonge, A.C.C. (1999) Aplicação de Algoritmos Genéticos em otimização estrutural. Tese (Doutorado). COPPE, Universidade Federal do Rio de Janeiro. 218p.

Lima, R.S.; Naruo, M.K.; Rorato, R.J.; Silva, A.N.R. (2001) Influência da desagragação espacial da demanda por educação no cálculo das distâncias de deslocamento em uma cidade média. In: Congresso Brasileiro de Cartografia, 20, Conferência IberoAmericana de SIG, 8, Porto Alegre, 2001. Anais em CD-ROM. Rio de Janeiro, Sociedade Brasileira de Cartografia.

Liu, Y.H.; Mahmassani, H.S. (2000) Global maximum likelihood estimation procedure for multinomial probit (MNP) model parameters. In: Transportation Research Part $B$, v.34, p.419- 449 .

Lyons, G.D; McDonald, M.; Hounsell, N.B.; Williams, B.; Cheese, J.; Radia, B. (1996) Urban traffic management: the viability of short term congestion forecasting using artificial neural networks. (Disponível em http://www.soton.ac.uk/ civileng/publications/ 1996/pub96005.pdf em 14/04/2003). 
Ma, T.; Abdulhai, B. (2002) Genetic-algorithm-based optimization approach and generic tool for calibrating traffic microscopic simulation parameters. In: Transportation Research Board, 1800. Washington, D.C., p.6-15.

Madalozo, H.C.; Dyminski, A.S.; Ribeiro, E.P. (2004) Análise de curvas horizontais de rodovias, para melhoramento de projeto e operação, utilizando redes neurais artificiais. In: Congresso de Pesquisa e Ensino em Transportes, 18, Florianópolis, SC, 2004. Anais, v.1, p.415-426.

Michalewicz, Z. (1996) Genetic algorithms + Data structures $=$ Evolution programs. ed.3 Berlim, Springer-Verlag.

Mozolin, M.; Thill, J.C.; Usery, E.L. (2000) Trip distribution forecasting with multilayer perceptron neural networks: a critical evaluation. In: Transportation Research Part B, v.34, p.53-73.

Novaes, A.G. (1978) Métodos de otimização: aplicações aos transportes. São PauloSP. Editora Edgard Blucher: transesp.

Oliva, G.M.; Cybis, H.B.B.; Pretto, C.O. (2001) Metodologia de redes neurais aplicada à previsão de produção de viagens. In: Congresso de Pesquisa e Ensino em Transportes, 15, Campinas, SP, 2001. Anais, v.2, p.283-290.

Oliveira, R.L.M.; Cury, M.V.Q. (2004) Escolha modal no transporte de cargas sob a ótica da modelagem neuro-fuzzy: um estudo de caso. In: Congresso de Pesquisa e Ensino em Transportes, 18, Florianópolis, SC, 2004. Anais, v.2, p.1122-1132.

Openshaw. S. (1993) Modeling spatial interaction using a neural net. In: Fischer M. M.; Nijkamp, P. (eds.) Geographic Information Systems, spatial modeling and policy evaluation. Springer-Verlag, Berlin, p.147-164.

Pereira, M.A.; Cárdenas, C.B.B.; Bocanegra, C.W.R.; Silva, A.N.R. (2003) La importância del conocimiento y uso de nuevas técnicas en Ingeniería Civil: una aplicación práctica con Redes Neuronales Artificiales. In: Actas del I Encuentro Internacional de Enseñanza de la Ingeniería Civil, Ciudad Real-Espanha.

Pires, A.M.; Branco, J.A. (1996) Comparação de Duas Médias: Um Velho Problema Revisitado. In: Congresso Anual da Sociedade Portuguesa de Estatística, 16, Funchal. (Disponível em: www.math.ist.utl.pt/ apires/APJB_SPE97.pdf em 11/05/2005).

Queiroz, I.N.F.; Jacques, M.A.P.; Weigang, L. (2001) Estimativa do fluxo de saturação com ausílio de redes neurais: um modelo para Brasília. In: Congresso de Pesquisa e Ensino em Transportes, 15, Campinas, SP, 2001. Anais, v.1, p.219-227.

Raia Jr., A.A. (2000) Acessibilidade e mobilidade na estimativa de um índice de potencial de viagens utilizando redes neurais artificiais e sistemas de informações geográficas. Tese (Doutorado). Escola de Engenharia de São Carlos, Universidade de São Paulo. 196p. 
Raia Jr., A.A.; Silva, A.N.R.; Bocanegra, C.W.R. (2001) Acessibilidade e mobilidade na estimativa de um índice de potencial de viagens utilizando redes neurais artificiais e SIG. In: Congresso de Pesquisa e Ensino em Transportes, 15, Campinas, SP, 2001. Anais, v.2, p.253-261

Raju, K.A.; Sikdar, P.K.; Dhingra, S.L. (1994) Mode choice model using an artificial neural network. In: International Conference on Computers in Urban Planning and Urban Management, 4. Melbourne, Austrália, v.1, p.593-602.

Rodrigues, F.A.B.R. (2000) A neural network for shortest path computation. Portugal. (Disponível em http://citesser.nj.nec.com/320677.html em 09/05/2003).

Roy, P.; Abdulhai, B. (2003) GAID: Genetic Adaptive Incident Detection for Freeways. In: Transportation Research Board, 82. Washington, D.C.

Salinas, D.T.P. (1998) Bootstrap Não-Paramétrico Aplicado a Dados Incompletos. Dissertação (Mestrado). Instituto de Matemática e Estatística, Universidade de São Paulo. 101p.

Sampaio, C.C.D.S. (2004) Determinação de uma rede ótima de transporte utilizando algoritmo genético. Dissertação (Mestrado). Faculdade de Tecnologia, Universidade de Brasília. 93p.

Silva, A.N.R.; Bocanegra, C.W.R.; Costa, G.C.F.; Pereira, M.A. (2001) Uma Introdução ao Uso de Redes Neurais Artificiais para Planejamento Urbano e de Transportes. Escola de Engenharia de São Carlos, Universidade de São Paulo. Notas de aula.

Smith, M. (1996) Neural networks for statistical modeling. Londres, UK. International Thomson Computer Press.

Srinivasan, D.; Cheu, R.L.; Poh; Y.P.; Ng, A.K.C. (2000) Development of an intelligent technique for traffic network incident detection. In: Engineering Application of Artificial Intelligence, v.13. p.311-322.

Teodorović, D.; Lučić, P.; Popović, J.; Kikuchi, S.; Stanić, B. (2001) Intelligent Isolated Intersection. In: IEEE International Fuzzy Systems Conference. Proceedings. v.1.

Torres, A.C.S.T. (2003) Determinação de rotas ótimas de ônibus urbano utilizando algoritmo genético. Dissertação (Mestrado). Faculdade de Tecnologia, Universidade de Brasília. 87p.

Trippi, R. R.; Turban, E. (1992) Neural Networks in Finance and Investing. Cambridge, UK. Probus Publishing Company.

Valente, S.A.; Lopes, H.S.; Arruda, L.V.R. (2002) Genetic algorithms for the assembly line balancing problem: a real-world automotive application. In: Roy, R.; Köppen, M.; Ovaska, S.; Fukuhashi, T.; Hoffman, F. (eds.) Soft Computing in Industry Recent Applications, Berlin: Springer-Verlag, p.319-328. 
Vidal, L.S.; Faé, M.I.; Salles, E.O.T. (2002) Utilização de redes neurais para previsão do número de acidentes e feridos em rodovias. In: Congresso de Pesquisa e Ensino em Transportes, 16, Natal, RN, 2002. Anais, Comunicações Técnicas e Relatórios de Dissertação, p.166 (publicado o resumo).

Wermersch, F.G.; Kawamoto, E. (1999) Uso de redes neurais artificiais para caracterização do comportamento de escolha do modo de viagem. In: Congresso de Pesquisa e Ensino em Transportes, 13, São Carlos, SP, 1999. Anais, v.3, p.31-34.

Wolstenholme, S. (2005) Simulador de Redes Neurais Artificiais, EasyNN-plus.

(Disponível em: http://www.easynn.com em 08/08/2005). 